\title{
Simulating the Effects of HVAC Induced Air Flow From Slot Diffusers on Detector Response
}

John H. Klote

Glenn P. Forney

William D. Davis

Richard W. Bukowski

Building and Fire Research Laboratory

National Institute of Standards and Technology

Gaithersburg, MD 20899

December 1996

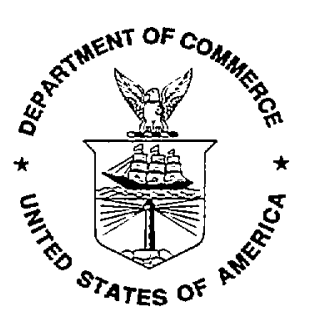

U.S. Department of Commerce Michael Kantor, Secretary

Technology Administration

Mary L. Good, Under Secretary for Technology

National Institute of Standards and Technology

Arati Prabhakar, Director 


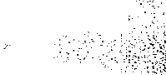

$+4$

)$_{1}+$

ntwe

sth

(3)

at

r.t.

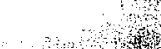

strat

a

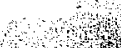

(n)

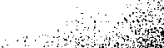

?

\&)

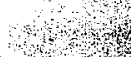

1.

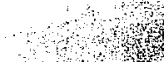

का

$\mathrm{st}^{2}$

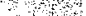

" $+3,3$

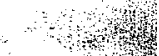

$4 \times$

$\therefore$

- Antra
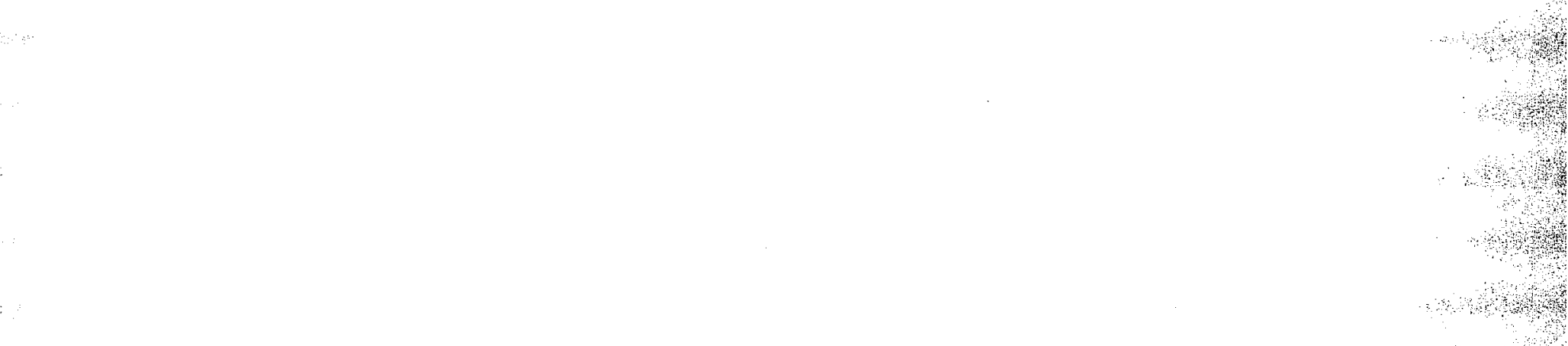


\section{Table of contents}

List of Figures $\ldots \ldots \ldots \ldots \ldots \ldots \ldots \ldots \ldots \ldots \ldots \ldots \ldots \ldots$

List of Tables $\ldots \ldots \ldots \ldots \ldots \ldots \ldots \ldots \ldots \ldots \ldots \ldots \ldots \ldots \ldots$

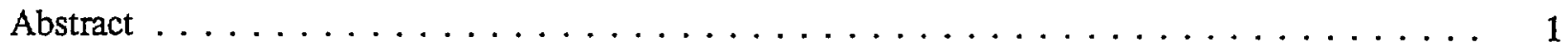

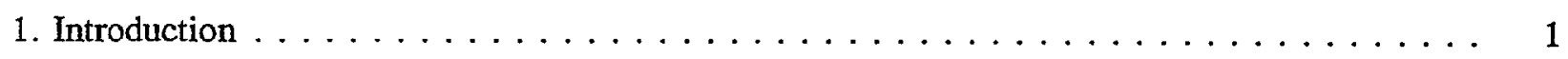

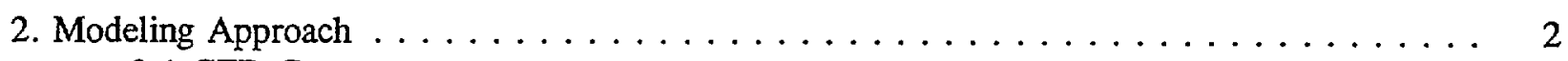

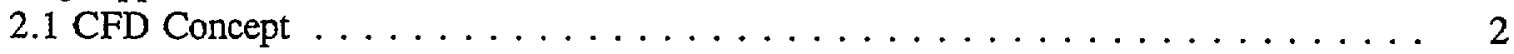

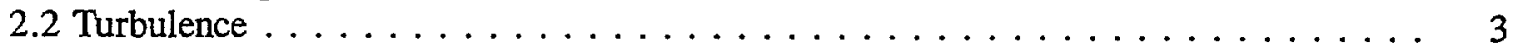

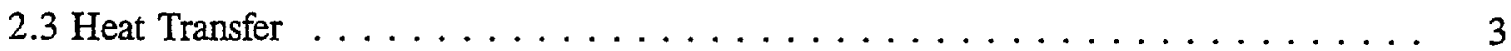

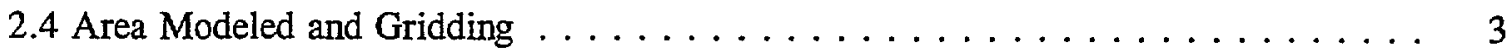

2.5 Initial Conditions . . . . . . . . . . . . . . . . . . . . 4

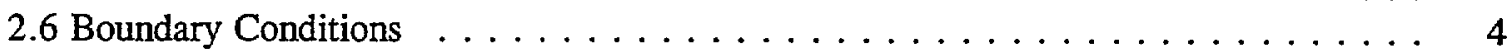

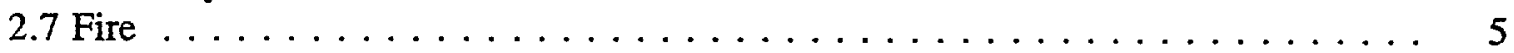

2.8 Smoke Generation and Movement $\ldots \ldots \ldots \ldots \ldots$

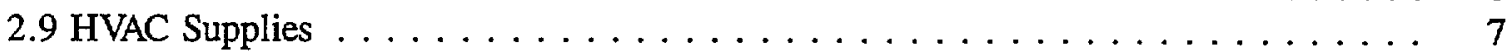

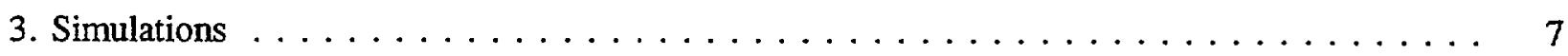

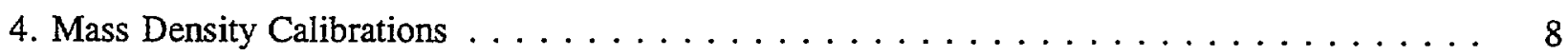

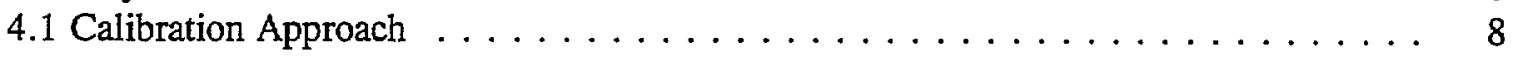

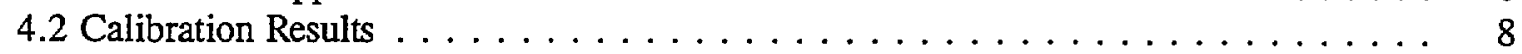

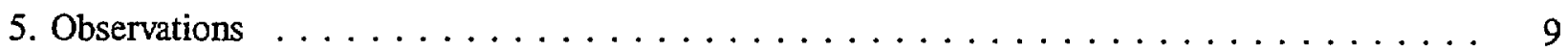

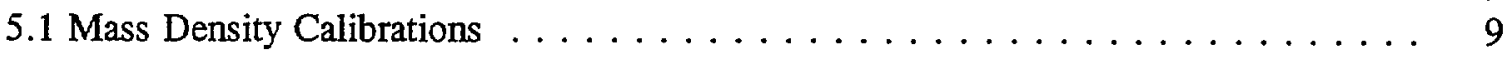

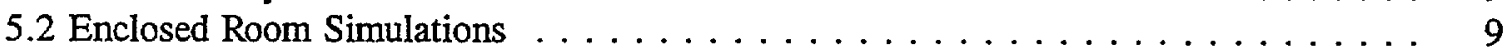

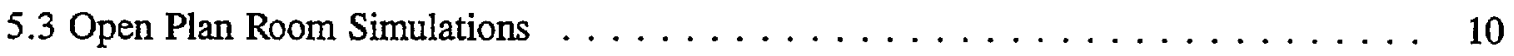

5.4 Activation Approaches $\ldots \ldots \ldots \ldots \ldots \ldots \ldots \ldots \ldots$

6. Potential For Correlations $\ldots \ldots \ldots \ldots \ldots \ldots \ldots \ldots \ldots \ldots \ldots$

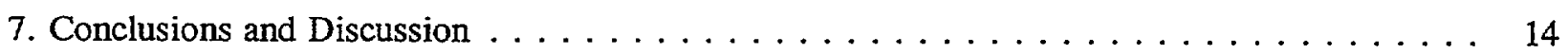

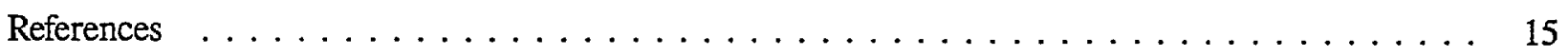

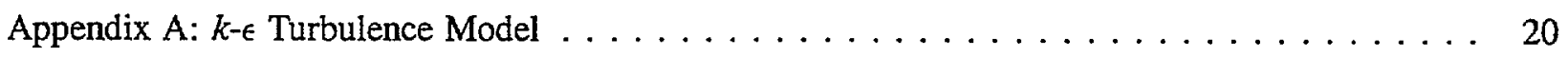

Appendix B: Smoke Generation and Mass Density of Smoke . . . . . . . . . . . . . . 24

Appendix C: Idealized Slot Diffuser Model . . . . . . . . . . . . . . . . . . . . . . . 29 


\section{List of Figures}

Figure 1: $\quad$ Layout of mass density calibration simulations $\ldots \ldots \ldots \ldots \ldots$

Figure 2: $\quad$ Plans of rooms for detector activation simulations $\ldots \ldots \ldots \ldots \ldots$

Figure 3: $\quad$ Grids typical of those used for simulations $\ldots \ldots \ldots \ldots \ldots \ldots$

Figure 4: Small room plans showing locations of fires and supply and return arrangements ............................. 39

Figure 5: Medium room plans showing locations of fires and supply and return arrangements . . . . . . . . . . . . . . . .

Figure 6: Open plan room plans (detailed area only) showing locations of fires and supply and return arrangements . . . . . . . . . . . . . . . 40

Figure 7: $\quad$ Simulated mass density at $100 \mathrm{~kW}$ from the first mass density calibration (run 1) . 41

Figure 8: $\quad$ Simulated activation time from the first mass density calibration (run 1) . . . . 42

Figure 9: $\quad$ Simulated mass density at activation time from the first mass density calibration

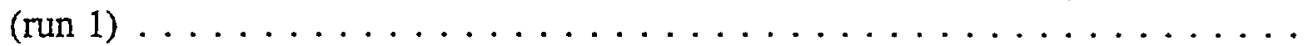

Figure 10: $\quad$ Simulated mass density at activation time from the second mass density calibration

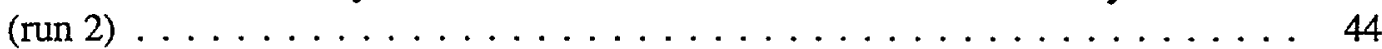

Figure 11: Simulated activation time in the small room from run $3 \ldots \ldots \ldots 45$

Figure 12: Simulated activation time in the small room from run $4 \ldots \ldots \ldots \ldots$

Figure 13: $\quad$ Simulated activation time in the small room from run $5 \ldots \ldots \ldots \ldots$. . . . . . 47

Figure 14: Simulated activation time in the small room from run $6 \ldots \ldots \ldots \ldots$

Figure 15: Simulated activation time in the small room from run $7 \ldots \ldots \ldots$. . . . . 49

Figure 16: Simulated activation time in the small room from run $8 \ldots \ldots \ldots \ldots$

Figure 17: Simulated activation time in the small room from run $9 \ldots \ldots \ldots \ldots$

Figure 18: Simulated activation time in the small room from run $10 \ldots \ldots \ldots 2$

Figure 19: $\quad$ Simulated activation time in the small room from run $11 \ldots \ldots \ldots$

Figure 20: Simulated activation time in the small room from run $12 \ldots \ldots \ldots$

Figure 21: Simulated activation time in the small room from run $13 \ldots \ldots \ldots \ldots$

Figure 22: $\quad$ Simulated activation time in the small room from run $14 \ldots \ldots \ldots \ldots$

Figure 23: $\quad$ Simulated activation time in the medium room from run $15 \ldots \ldots \ldots 7$

Figure 24: Simulated activation time in the medium room from run $16 \ldots \ldots \ldots$

Figure 25: Simulated activation time in the medium room from run $17 \ldots \ldots \ldots$

Figure 26: Simulated activation time in the medium room from run $18 \ldots \ldots \ldots$

Figure 27: Simulated activation time in the medium room from run $19 \ldots \ldots \ldots$

Figure 28: Simulated activation time in the medium room from run $20 \ldots \ldots 2$

Figure 29: Simulated activation time in the medium room from run $21 \ldots \ldots 3$

Figure 30: Simulated activation time in the medium room from run $22 \ldots \ldots \ldots$

Figure 31: Simulated activation time in the open plan room from run $23 \ldots \ldots 5$

Figure 32: $\quad$ Simulated activation time in the open plan room from run $24 \ldots \ldots 6$

Figure 33: $\quad$ Simulated activation time in the open plan room from run $25 \ldots \ldots 67$

Figure 34: Simulated activation time in the open plan room from run $26 \ldots \ldots 8$

Figure 35: $\quad$ Simulated activation time in the open plan room from run $27 \ldots \ldots$. . . . . 69

Figure 36: Simulated activation time in the open plan room from run $28 \ldots \ldots \ldots$

Figure 37: Simulated activation time in the open plan room from run $29 \ldots \ldots \ldots$

Figure 38: $\quad$ Simulated activation time in the open plan room from run $30 \ldots \ldots \ldots 72$

Figure 39: $\quad$ Simulated activation time in the open plan room from run $31 \ldots 73$

Figure 40: Comparison of simulated activation times based on temperature rise and on mass density at $0.05 \mathrm{~m}(2.0 \mathrm{in})$ below the ceiling $\ldots \ldots \ldots \ldots \ldots$ 


\section{List of Tables}

Table $1 . \quad$ Summary of smoke movement simulations $\ldots \ldots \ldots \ldots \ldots$

Table 2. Non-activation distances at $0.05 \mathrm{~m}(0.20 \mathrm{in})$ under the ceiling and horizontal separation between fire and return for enclosed room simulations . . . . . . 18

Table 3. Non-activation distances at $0.05 \mathrm{~m}(2.0 \mathrm{in})$ under the ceiling and horizontal separation between fire and return for open plan room simulations $\ldots \ldots . . .19$ 



\title{
Simulating the Effects of HVAC Induced Air Flow From Slot Diffusers on Detector Response
}

\author{
John H. Klote \\ Glenn P. Forney \\ William D. Davis \\ Richard W. Bukowski
}

\begin{abstract}
Rapid activation of fire protection systems in response to a growing fire is one of the important factors required to provide for life safety and property protection. Airflow due to the heating, ventilating and air conditioning (HVAC) system can significantly modify the flow of smoke along the ceiling and must be taken into consideration when a particular system is designed. At present, the standards used to guide the design of systems contain very little quantitative information concerning the impact of airflow produced by HVAC systems. This project is part of a multi year, International Fire Detection Research Project sponsored by the National Fire Protection Research Foundation (NFPRF), and it describes the results of a series of numerical simulations of smoke movement in response to HVAC flows resulting from slot diffusers, slot returns and rectangular returns. The computer model calculated activation times throughout the fire driven flow field.
\end{abstract}

\section{Introduction}

Rapid activation of fire protection systems in response to a growing fire is one of the important factors required to provide for life safety and property protection. Airflow due to the heating, ventilating and air conditioning (HVAC) system can significantly modify the flow of smoke along the ceiling and must be taken into consideration when a particular system is designed. At present, the standards used to guide the design of systems contain very little quantitative information concerning the impact of airflow produced by HVAC systems. 
A multi year, International Fire Detection Research Project sponsored by the National Fire Protection Research Foundation (NFPRF) was established to provide quantitative information on the impact of beamed and sloped ceilings, and HVAC flows on the distribution of heat and smoke during a fire. During the first year of the project, validation simulations were made to compare the results of numerical modeling with the experimental data of Heskestad and Delichatsios [1], and additional simulations of smoke movement under level, beamed ceilings were made [2]. During the second year, numerical simulations of smoke movement in response to sloped, beamed ceilings were made [3]. This report describes the results of the third year of the project during which numerical simulations of smoke movement in response to HVAC flows resulting from slot diffusers, slot returns and rectangular returns were studied. Mass densities of smoke were calculated, and the computer model was modified to calculate activation times throughout the flow field. Activation mass densities were selected so that they would correspond to the activation temperature rise used in prior years for fires in open plan rooms with different ceiling heights (figure 1). Simulations of smoke movement including HVAC effects were made for the small room, medium room and open plan room shown in figure 2 .

While there are many different types of HVAC diffusers and returns, resources limited the scope of this effort to slot diffusers and returns, and rectangular returns. These are the common types found in commercial properties when used in variable air volume HVAC systems. Variable air volume systems are popular for their energy efficiency and comfort features. Other types of diffuser or return may have a different impact on detector performance, but these would need to be studied. Alternatively, the techniques developed in this research could be used with commercial CFD models to design systems for specific buildings which account fully for such interactions.

\section{Modeling Approach}

The commercially available computational fluid dynamic (CFD) model CFDS-FLOW3D release 3.3 was used to perform the numerical simulations. This release is an upgrade of release 3.2.1 which was used for the simulations of the second year of this project, and the only upgraded features relevant to the simulations of this study consist of simplified data input.

A detailed description of computational fluid dynamics modeling is beyond the scope of this report. The non-mathematical descriptions in the following sections are intended to provide an explanation of the assumptions of the simulations of this paper and to provide insight for those not familiar with the field. The CFDS-FLOW3D User Manual [4] provides the exact equations and mathematical definitions that apply to these simulations. For more information about CFD modeling, readers are referred to [5][6][7][8][9]. References [10][11][12][13][14] provide genera] information about fluid dynamics.

\subsection{CFD Concept}

The CFD modeling consists of dividing the flow field into a collection of small rectangular cells, and determining the flow at each cell by solving numerically the governing conservation equations of fluid dynamics. Boundary conditions are prescribed for walls, floor, ceiling, HVAC supplies, HVAC returns, openings to the outside, and planes of symmetry. For this project, all the CFD simulations were unsteady, using the calculated properties from one time step to calculate those of the next time step. At the start of a simulation, each cell can be set to zero flow conditions or conditions read into the computer from a previous simulation. Zero flow conditions consist of zero velocity and ambient pressure and temperature. To generate fire induced flows, heat is released in several control volumes over time. 
The governing equations of fluid dynamics describe the motion of fluid throughout the flow field. These equations are: (1) conservation of mass, (2) conservation of momentum, (3) conservation of energy. The mass conservation equation depends on the concept that matter is not created or destroyed for the processes of interest in fluid dynamics. The momentum conservation or the Navier Stokes equations are equivalent to Newton's second law of motion. The energy conservation equation is equivalent to the first law of thermodynamics. In addition to these conservation equations, the ideal gas law relates density, pressure and temperature. The conservation equations are expressed mathematically as a set of simultaneous, non-linear partial differential equations. This set of equations is solved numerically for each cell to simulate the motion of fluid.

\subsection{Turbulence}

The flow equations alone can be used to simulate the effects of turbulence on a scale larger than that of the cells. However, use of the flow equations alone cannot account for turbulence on a scale smaller than the cells. Turbulence modeling was developed to account for movement and mixing effects inside the cells. In such models a number of empirically developed partial differential equations are added to the flow equations which are solved for each cell and for each time step. Because turbulence models account for turbulent effects inside the cells, the number of cells needed for a particular application can be reduced.

The turbulence model used for this work is the $k-\epsilon$ model developed by Launder and Spalding in the early seventies [15]. This is probably the most extensively used turbulence model. Additional information about this model and the specific values of empirical coefficients used for this project are provided in appendix A.

\subsection{Heat Transfer}

The solid surfaces (walls, floor and ceiling) were considered to be adiabatic. This assumption was evaluated for year 2 of the project, and it was shown that neglecting heat transfer to solid surfaces resulted in negligible variations in activation time (year 2 report figure 11). These calculations were for gypsum wall board. For wall materials that are nearly insulating, the boundary surface temperatures will rise quickly to the gas temperature, which reduces heat transfer. The time period over which a parcel of gas is in contact with a solid surface is on the order of seconds. Thus it was concluded in year 2 that the adiabatic assumption concerning fire gases and the solid surfaces is reasonable. This year 2 approach did not include HVAC jets, but the reasoning above can be extended from fire gases to HVAC jets as the jets are of lower temperature.

Radiation effects were not included explicitly in the calculation except that only a fraction of the heat release rate was assumed to contribute to convective heating of smoke and air. The rest of the heat was considered to be radiated away. The radiative fraction was taken to be 0.35 for all three years of the project.

\subsection{Area Modeled and Gridding}

A number of grids were needed to represent the three room sizes and the combinations of HVAC supplies and returns. The total number of grid cells ranged from 11,000 for the small room to 30,000 for the open plan room. Figure 3 (a), (b) and (c) show typical grids used for the simulations of the small, medium and open plan rooms. These grids have smaller spacing at locations where more flow detail is needed: the 
fire, the slot diffuser, and the slot returns. A geometric progression of grid spacing was used to make the grid cells smallest near to the ceiling where the flow effects are of greatest interest.

The selection of the area modeled for the open plan simulations was influenced by the desire to obtain realistic flow at the edge of the area of interest. In a real open plan room, the ceiling jet of combustion gases and HVAC diffuser jet continue to flow under the ceiling for a considerable distance. The common experimental approach for this type of flow is to have a much larger ceiling area than the area of specific interest, so that the edge effects are away from the area of interest. This same approach was used for the open room simulations as can be observed from figure 2 (c). Figure 3 (c) is the grid plan of the area of detailed simulations for one of the open plan simulations.

\subsection{Initial Conditions}

For any time dependent analysis, conditions at the start of the simulation must be defined. The initial velocities need to be established for each cell, and the default condition is zero velocity. This zero velocity condition was used for the mass density calibration simulations discussed later.

For the simulations that included HVAC supplies and returns, the initial conditions describing the flow resulting at every cell are so intricate that the practical way of determining them is by use of the CFD model. For these simulations an initial condition simulation was made without a fire but with the same gridding and boundary conditions. The initial condition simulations had initial zero velocity and had a duration sufficient for development of a stable supply jet up to $3 \mathrm{~m}$ (10 ft) from the supply outlet ${ }^{1}$. The velocity and other properties ${ }^{2}$ was written to a file at the end of the initial condition simulation, and the data in this file was read as the initial conditions for the start of the simulations discussed in this paper.

\subsection{Boundary Conditions}

In any fluid flow analysis, conditions at the boundaries of the flow field need be defined. For the simulations of this paper, the following boundary conditions were used (1) solid surface, (2) plane of symmetry, (3) velocity at an opening, and (4) pressure at an opening. These conditions remained constant throughout each simulation.

At the solid surfaces (walls, floors and ceilings) the velocity was assumed to be zero. This boundary condition is referred to as the no slip condition. The symmetry boundary can be compared to a mirror in that it is as if the flow in the flow field were reflected by this boundary. As with a solid surface there is no flow through a symmetry boundary, but there can be flow at a symmetry boundary provided that the direction of such flow is in the plane of the boundary.

\footnotetext{
${ }^{1}$ Test runs were made for several simulation durations. For the slot supply of this project, it was found that a duration of 30 seconds was sufficient to generate a stable supply jet.

${ }^{2}$ These other properties consist of temperature, pressure, effective viscosity, kinetic energy of turbulence, and turbulent dissipation rate. For the initial condition simulations of this project, the calculated values of temperature and pressure do not vary much from ambient. The last three properties are particular to the $k-\epsilon$ model (appendix A).
} 
Both velocity and pressure boundaries can be used where mass is to enter or leave the domain. The domain is the region of space for which the simulation is made. Velocity boundaries are used to define the velocity entering or leaving the domain.

For pressure boundaries, the pressure is defined by the user and the CFD model calculates the velocity. For the HVAC returns in the small and medium rooms, the returns were modeled as pressure boundaries at atmospheric pressure. Using pressure boundaries for returns has the advantage that the velocities at the return incorporate the effects of the room airflow due to the HVAC supply and the fire.

In order to simulate the complicated flows in and out of the large open boundaries of the open plan room [figure 2(c)], pressure boundaries were needed. However, using pressure boundaries for these large open areas resulted in difficulties concerning use of pressure boundaries for the HVAC returns. The pressures assigned to the large open areas and to the HVAC returns would need to be such that the desired flows occurred at the HVAC returns. The CFD model could be used to determine such pressures at these boundaries without a fire. However, fire induced pressure changes near the return could result in significant error in return airflow.

Velocity boundaries were used to model the flow returns for the open plan room simulations. This consisted of assigning a velocity for the return assuring realistic return flows. The return velocities were selected so that the volumetric flow of return air equaled the volumetric flow of supply air for the domain. A general HVAC design rule is that the location of a return has almost no effect on room air distribution, provided that the supply is not blowing directly into a return. In the beginning of year 3 , it was erroneously thought that this rule could be extended to indicate that returns have an insignificant effect on detector activation. Because the industry rule is so strongly and universally held, it was felt that any errors in CFD simulated velocities in the vicinity of the return would not have a significant effect on detector activation. As will be discussed later, the results of the open plan simulations cast doubt on this early position.

\subsection{Fire}

For all of the simulations discussed in this report the fire was the same as the one used for year 2 of this project. This fire was a medium growth $\mathrm{t}$-squared fire which was designed to reach $1055 \mathrm{~kW}(1000 \mathrm{Btu} / \mathrm{s})$ in 275 seconds $[16]^{3}$. A t-squared fire is one that has a heat release rate that increases with the square of time. In year 1 , it was shown that the results were not sensitive to the fire growth rate. The fires were simulated to $100 \mathrm{~kW}$ which occurs at 84.75 seconds after ignition 4 .

The fire was modeled by releasing energy over several grid cells. As in prior years, the number of cells occupied by the fire was varied during the simulation such that the heat release rate per unit volume would not exceed $2.6 \mathrm{~kW} / \mathrm{m}^{3}\left(0.070 \mathrm{Btu} / \mathrm{s} \mathrm{ft}^{3}\right)$. The fire was situated at various locations on the plane

\footnotetext{
${ }^{3}$ This $\mathrm{t}$-squared fire was used for consistency with prior years, but it could be argued that a step fire going from zero to $100 \mathrm{~kW}$ at the start of the simulation could provide the same relative information about detection with a much shorter simulation time.

${ }^{4}$ For this fire $100 \mathrm{~kW}$ is reached at $842 / 3$ seconds. Because the simulation time step was 0.25 seconds, the fire was actually simulated for 84.75 seconds at which the heat release was $100.2 \mathrm{~kW}$.
} 
of symmetry. To account for radiative losses from the fire to the walls and ceiling, the heat release prescribed for the fire was reduced by $35 \%$ [17].

As with the earlier years, the fire does not include the mass released into the flow field due to the combustion process. This is consistent with most fire models that assume that such mass release is so small in comparison to the total fire plume flow that this mass release can be neglected.

To study the impact of various fire locations relative to HVAC supplies and returns, the fire above was used for fire at all locations. The same fire was used to provide a comparable generation of fire gases for all the simulations. However, this should not be taken to indicate that materials are expected to burn the same way when they are away from walls or near a wall. Because of reradiation from hot walls, it is expected that the same fuel package would burn faster when near a wall that it would away from walls. Attempting to use a different fire growth near walls would probably not result in improved insight, and using the same fire for all simulations allows comparison of results from different simulations.

\subsection{Smoke Generation and Movement}

The movement of smoke was simulated by a species mass fraction approach by using the scalar equation feature of the CFD model. This mass concentration calculation can be explained by analogy to water flow visualization by dye injection. To prevent the dye from affecting the water flow, the flow rate of the dye is small in comparison to the water flow. The dye flows downstream and mixes with the water. Downstream of the injection point, the dye can be observed, and dye concentration can be measured. The dye injection rate can be constant or it can vary with time. If the injection rate is multiplied by a constant, the dye concentration at every point in the flow field will by multiplied by that same constant (provided that the injection flow rate is still relatively small).

In the CFD model, the species generation rate corresponds to the dye injection rate, and the mass density of species corresponds to the dye concentration. The species calculation is a perfect idealization of the dye injection experiment in the respect that the species generation rate adds no mass to the flow field. Thus a species calculation has absolutely no impact on the simulated flow field. As with the dye experiment, multiplication of the species generation rate by a constant results in multiplying the mass density at every point in the flow field by that same constant. Because this species calculation adds no mass to the flow field, this relationship between species generation and mass density is exact.

The species mass fraction approach is appropriate to simulate the flow of any species provided that the mass generation of the species and the differences in properties (specific heat, thermal conductivity and gas constant) due to the addition of species have an insignificant effect on the fluid flow. Two assumptions that are fundamental to most fire modeling are (1) that the mass released into the flow field due to the combustion process is so small in comparison to the total fire plume flow that this mass release (or mass generation) can be neglected, and (2) that the differences in properties of air and those of the mixture of air and combustion products do not have a significant effect on the flow. By these same assumptions, the species mass fraction approach is appropriate for simulation of the gases and particulates produced by the fire.

It should be noted that the particulate motion simulated does not simulate smoke particle aging (particulate agglomeration and deposition).

Another way of expressing the relationship between species generation and mass density is to state that they are normalized. The characteristics of this normalization can be summarized as: 
1. Multiplication of the species generation rate by a constant results in multiplying the mass density at every point in the flow field by that same constant.

2. The species generation and mass density are independent of units. The species generation and the mass density can be considered dimensionless, or they can be considered as being in any convenient units.

For this paper species generation and the mass density are considered dimensionless, with one unit of mass being "generated" or marked per kilowatt of convective heat released by the fire. Appendix B provides further information about smoke generation and mass density.

\subsection{HVAC Supplies}

The HVAC supplies studied were ceiling mounted slot and troffer diffusers [18]. A troffer diffuser is a type of slot diffuser located at the side of a ceiling light fixture. These diffusers were selected because they both can result in flow that is attached to the ceiling, and have the potential to affect adversely the performance of ceiling mounted detectors. The slot supplies had flow rates of $0.106 \mathrm{~m}^{3} / \mathrm{s}(225 \mathrm{cfm})$, and the troffers had flow rates of $0.0236 \mathrm{~m}^{3} / \mathrm{s}(50 \mathrm{~cm})$. It was found that supply air temperature had little effect on the HVAC jets in the region of interest for this study. Accordingly, the HVAC flow was selected to be at ambient temperature, and the results are applicable to both heating and cooling. Further information about the supplies is provided in appendix $\mathrm{C}$.

\section{Simulations}

The simulations are summarized in table 1 . These simulations consisted of mass density calibrations (runs 1 and 2) and room simulations with forced ventilation (runs 3 through 31). Figures 4, 5 and 6 show the locations of the fire and the arrangements of the HVAC supplies and returns. The results of the simulations are shown in figures 7 to 40 . Most of these figures show conditions at $0.02 \mathrm{~m}(0.79 \mathrm{in})$ and $0.05 \mathrm{~m}(2.0 \mathrm{in})$ below the ceiling with the intent of providing insight into the activation times of low profile and normal detectors. Differences between simulated results at these levels must be interpreted with caution, because the levels are only about one cell apart, and thus the difference in simulated values are highly dependant on the empirical turbulence model. All of the rooms had a height of $2.74 \mathrm{~m}(9.0$ $\mathrm{ft}$ ), and they had the following dimensions:

$\begin{array}{lcc} & \text { Width } & \text { Length } \\ \text { Small Room } & 3.42 \mathrm{~m}(11.2 \mathrm{ft}) & 4.6 \mathrm{~m}(15.1 \mathrm{ft}) \\ \text { Medium Room } & 4.6 \mathrm{~m}(15.1 \mathrm{ft}) & 5.3 \mathrm{~m}(17.4 \mathrm{ft}) \\ \begin{array}{l}\text { Open Plan Room: } \\ \text { Full Area }\end{array} & 10.5 \mathrm{~m}(34.4 \mathrm{ft}) & 18.8 \mathrm{~m}(59.6 \mathrm{ft}) \\ \begin{array}{l}\text { Open Plan Room: } \\ \text { Area of Detailed } \\ \text { Simulation }\end{array} & & \\ & 5.5 \mathrm{~m}(18.0 \mathrm{ft}) & 7.82 \mathrm{~m}(25.7 \mathrm{ft})\end{array}$




\section{Mass Density Calibrations}

\subsection{Calibration Approach}

The purpose of the mass density calibration simulations was to determine a mass density value to be used for detector activation. In the prior years, detector activation was considered to occur at a temperature rise of $13^{\circ} \mathrm{C}\left(23^{\circ} \mathrm{F}\right)$. There was a concern that HVAC induced flows could have an adverse effect on this temperature based activation. To address this concern, the species mass fraction approach was used to determine an activation mass density corresponding to the temperature rise above for an open space without heating or cooling induced flows. Because the differential equations for mass concentration are similar to those for heat diffusion with adiabatic walls, it is expected that the activation times calculated by mass density should be almost the same as those calculated by temperature rise. As will be discussed later, the simulations incorporating HVAC flows show that this expectation was correct.

These calibration simulations were for an open plan space of 12 by $24 \mathrm{~m}$ ( 39.4 by $78.7 \mathrm{ft}$ ) with a height of $2.74 \mathrm{~m}(9.0 \mathrm{ft})$ for run 1 and a height of $6.7 \mathrm{~m}(22.0 \mathrm{ft})$ for run 2 (figure 1). The initial conditions for these simulations were zero flow with ambient properties throughout the flow field. Because of symmetry, only half the volume needed to be included for all of the simulations.

FORTRAN code was added to the CFD model to calculate and store the temperature based activation time and the corresponding mass density at every cell in the flow field. This code checked the cells at the end of each 0.25 second time step, and the first time that the temperature rise exceeded $13{ }^{\circ} \mathrm{C}(23$ $\left.{ }^{\circ} \mathrm{F}\right)$, the activation time and the corresponding mass density were calculated by linear interpolation using the appropriate values at the end of this time step and the previous time step.

\subsection{Calibration Results}

Figure 7 shows the mass density at $100 \mathrm{~kW}$ from the first mass density calibration (run 1 ). As already stated, the mass density is considered dimensionless for this paper. It can be observed from figure 7 (a) and (b) that the mass density under the ceiling decreases with distance from the fire. A trend can be seen of lower mass density at $0.05 \mathrm{~m}(2.0 \mathrm{in})$ below the ceiling than at $0.02 \mathrm{~m}(0.79 \mathrm{in})$ below the ceiling.

The temperature based activation time for first density calibration (run 1) is shown in figure 8 . The conventions used in this figure are the same as for the other figures of activation time. Figure 8(a) shows the activation time at $0.02 \mathrm{~m}(0.79 \mathrm{in})$ below the ceiling. As expected, the farther from the fire the greater the activation time. Activation directly above the fire took 20 seconds or less (darkest area). The white space in figure $8(a)$ is where activation takes 80 seconds or more ${ }^{5}$. This convention is used for all of the figures of activation time, and the spaces where activation takes longer than 80 seconds will be referred to as areas of non-activation. The spaces where activation is 80 seconds or less will be referred to as the areas of activation. The range from 20 to 80 seconds was selected to simplify the scales, and these figures show the same trends as ones that go up to full 84.75 seconds of simulation.

\footnotetext{
${ }^{5}$ It should be noted that the irregular boundary on figure 9 between the white region $(>80 \mathrm{~s})$ and the next region (65 to $80 \mathrm{~s}$ ) is an artifact of graphics. Similar irregular boundaries occur on most of the other activation time plots in this paper.
} 
There is a larger area of activation at $0.02 \mathrm{~m}(0.79 \mathrm{in})$ below the ceiling than there is at $0.05 \mathrm{~m}(2.0 \mathrm{in})$ below the ceiling [figure 8(a) and 8(b)]. This is in keeping with the mass densities of figure 7 and the thin activation area at the plane of symmetry as shown on figure $8(\mathrm{c})$.

Comparison of mass densities when the fire reaches $100 \mathrm{~kW}$ to those at the time of activation leads to the selection of a value of mass density that can be used to define activation. Figures 9 and 10 show the mass density at the time of activation for the two open spaces without forced ventilation. From the calibration simulations, the range of these mass densities at activation was 13.2 to 13.8. (As already stated, this is a normalized mass density, and it can be thought of as having any arbitrary units of mass per unit volume.) The values of mass density at activation are small in comparison to the range of mass densities when the fire reaches $100 \mathrm{~kW}$. Figure 7 shows mass densities at $100 \mathrm{~kW}$ with a range of 20 to 100 , but near the fire the mass density reached about 900 . A smoke mass density of 13.4 was selected as the activation value for the rest of the simulations. For the rest of the paper, unless otherwise noted, activation time is the time required to reach this activation mass density. As previously stated, this mass density activation is equivalent to activation based on a $13{ }^{\circ} \mathrm{C}\left(23^{\circ} \mathrm{F}\right)$ rise, and it does not apply to activation which would occur at other temperature increases. For more information about this smoke mass density see appendix B.

\section{Observations}

Most of the room simulations resulted in areas of non-activation near the HVAC supplies, and tables 2 and 3 list the distances from the supplies to the area of activation at $0.05 \mathrm{~m}$ ( $2.0 \mathrm{in})$ below the ceiling. With a few exceptions addressed below, the areas of non-activation at 0.02 and $0.05 \mathrm{~m}(0.79$ and $2.0 \mathrm{in})$ below the ceiling are the same, and the selection of values $0.05 \mathrm{~m}$ ( 2.0 in) below the ceiling for the tables was to provide information for comparison among simulations.

\subsection{Mass Density Calibrations}

Observation 1 For the open plan rooms of the mass density calibrations, the activation times at $0.02 \mathrm{~m}$ $(0.79$ in) below the ceiling are noticeably smaller that those at $0.05 \mathrm{~m}(2.0 \mathrm{in})$ below the ceiling (figure 8). This is consistent with the experimental results of Marrion [19], and indicates that for open plan rooms without forced ventilation, the activation time of low profile detectors is potentially less than that of normal detectors.

\subsection{Enclosed Room Simulations}

Observation 2 For the enclosed room simulations, the activation times at $0.02 \mathrm{~m}$ ( $0.79 \mathrm{in})$ below the ceiling are very similar to those at $0.05 \mathrm{~m}$ (2.0 in) below the ceiling. This can be observed for all the enclosed room simulations (figures 11-30). The areas of non-activation are almost identical. The differences in the activation distances at these two levels below the ceiling were generally much less than $0.1 \mathrm{~m}(0.3 \mathrm{ft})$. This indicates that for the enclosed room simulations of this study with forced ventilation, that the activation time of low profile detectors is expected to be the same as that of normal detectors.

Observation 3 When a fire is located below or nearly below a return, there is a tendency toward increased non-activation distance in front of the slot diffuser. This can be illustrated by observation of the simulation results listed in table 2. Examination of runs 3 to 6 illustrates this. This group of similar simulations are separated by dotted lines on this table, because room geometry and the HVAC supply and return are the same for all of them. The only difference is the location of the fire. Run 3 has the smallest 
horizontal separation between the fire and the return of $0.3 \mathrm{~m}(1.0 \mathrm{ft})$, and this simulation has the greatest non-activation distance of $0.6 \mathrm{~m}(2.0 \mathrm{ft})$ in front of the slot diffuser. Run 4 has a little larger separation of $0.4 \mathrm{~m}(1.4 \mathrm{ft})$ and a little smaller non-activation distance of $0.5 \mathrm{~m}(1.6 \mathrm{ft})$ in front of the slot diffuser. Run 5 has a much larger separation of $2.1 \mathrm{~m}(6.9 \mathrm{ft})$ and a much smaller non-activation distance of 0.1 $\mathrm{m}(0.3 \mathrm{ft})$ in front of the slot diffuser. Examination of table 2 shows that for every group of similar simulations for enclosed rooms (runs 3 to 22), the non-activation distance in front of the supply is largest for fires nearest the return. This is probably due to hot gases from the plume entering the return and not contributing to the ceiling jet.

Observation 4 Many of the enclosed room simulations resulted in areas of non-activation to the side of the diffuser. The largest distance of non-activation on the side was $0.2 \mathrm{~m}(0.7 \mathrm{ft})$ for runs 3,15 and 16 (table 2). The reason for this maximum value is that the these areas of activation reached the wall of the room (figures 11, 23 and 24). For these three simulations the fire was also near the return, indicating that this is also a factor in the size of side non-activation area.

Observation 5 When a fire is located below or nearly below a return, there is a tendency toward decreased activation layer depth under the ceiling. The most striking example of this is run 22 , where the return is almost directly over the fire. For this simulation, the depth of activation area under the ceiling is $0.3 \mathrm{~m}$ (1.0 ft) as shown on figure 30(c). The similar simulations (runs 19,20 and 21) with fires further from the return had activation depths from 0.8 to $1.1 \mathrm{~m}(2.6$ to $3.6 \mathrm{ft})$ as shown on figures $27(\mathrm{c})$, 28(c) and 29(c).

This effect is also noticeable for runs 14 and 15 [figures 22(c) and 23(c)], which both had fires near returns and had activation layer depths of about $0.6 \mathrm{~m}(2.0 \mathrm{ft})$ while their similar simulations [figures $19(\mathrm{c}), 20(\mathrm{c}), 21(\mathrm{c}), 24(\mathrm{c}), 25(\mathrm{c})$ and $26(\mathrm{c})]$ had activation depths from 0.8 to $1.1 \mathrm{~m}$ (2.6 to $3.6 \mathrm{ft})$.

These simulations with low activation depths (runs 14, 15 and 22) are the ones that had large nonactivation distances in observation 3 . This reinforces the belief that when the fire is under the return hot gases from the plume enter the return and do not contribute to the ceiling jet.

Observation 6 In many simulations, airflow in the enclosed room caused by the HVAC system deflected the plumes during the early stages of development. This effect can be observed in the simulations where the fires that were away from walls [for example run 5; figure 13(d)] where the dark activation region (20 seconds and less) is bent over toward the supply slot.

The air flows calculated as initial conditions consist of the supply jet attached to the ceiling and a low velocity flow towards the supply from the floor and nearly up to the ceiling jet. During the early fire development, the heat generated was carried by the HVAC induced flows and resulted in this pattern of the dark activation region. This pattern also occurred in runs 9, 13, 17 and 21 [figures 13(d), 17(d), 21(d), 25(d) and 29(d)]. As this effect occurs low in the room, furniture or other objects in a room could interfere with airflow and have a different effect on early plume flow.

\subsection{Open Plan Room Simulations}

Observation 7 In some of the open plan simulations near the HVAC supplies, the areas of non-activation were larger at $0.05 \mathrm{~m}(2.0$ in) below the ceiling than at $0.02 \mathrm{~m}(0.79 \mathrm{in})$ below the ceiling. Observation of run 29 (figures 37) shows that at $0.05 \mathrm{~m} \mathrm{(2.0)}$ below the ceiling, the non-activation distances in front of the supplies and troffers were about 0.1 or $0.2 \mathrm{~m}(0.3$ or $0.7 \mathrm{ft})$ larger than they were at $0.02 \mathrm{~m}(0.79$ $\mathrm{ft}$ ) below the ceiling. Similar observations can be made for runs 23, 24 and 25 (figures 31,32 and 33 ). 
This indicates that for open plan rooms with forced ventilation, the activation time of low profile detectors can be the same or slightly faster than that of normal detectors.

Observation 8 The non-activation areas were much larger for the open floor plan simulations than they were for the enclosed room simulations. Table 3 shows that the non-activation distance in front of the slot diffuser ranged from 1.1 to $3.3 \mathrm{~m}(3.6$ to $11 \mathrm{ft})$ for the open rooms and from 0 to $1.0 \mathrm{~m}(0$ to $3.3 \mathrm{ft})$ for the enclosed rooms. Also from this table it can be seen that the non-activation distance of the side of the slot diffuser was $0.6 \mathrm{~m}(2.0 \mathrm{ft})$ for all the open rooms and ranged from 0 to $0.2 \mathrm{~m}(0$ to $0.7 \mathrm{ft})$ for the enclosed rooms. For run 31, there is very little activation area shown on figure 39, but there was considerable smoke flow and activation area outside of the area of detailed simulation (not shown).

It is well known that in room fires, a smoke layer forms under the ceiling. The enclosed room simulation generated such smoke layers as can be seen from the many of the figures [for example figure 11(c) and (d)]. In the enclosed room simulations, the HVAC jets entrained smoke from this layer, and activation within spaces of the jets resulted. In the open plan simulations, the ceiling space was so large that no smoke layer formed beyond a thin ceiling jet of fire gases. The effects of this ceiling jet can be observed from the activation time of many of the figures. For example figure 33(c) and (d) shows a thickness of activation area under the ceiling of about $0.2 \mathrm{~m}(0.7 \mathrm{ft})$. With such thin smoke layers, the amount of smoke entrained into the HVAC jets is insignificant.

Observation 9 Areas of non-activation at some of the returns in the open plan room simulations were unexpected and cause concern about the appropriateness of the simplified return model (constant upward return velocity). The rectangular returns located on the plane of symmetry were most notable (runs 26 to 30 ; figures 34 to 38 ). It may be that the simplified return model has resulted in unrealistic flows in the vicinity of the return, and further study is needed.

\subsection{Activation Approaches}

Observation 10 As expected for the conditions of this study, the activation time calculated using mass density is almost the same as that calculated using temperature. This is illustrated by comparing activation times for runs 16 and 26 (figure 40). Close examination is required to see slight differences between the temperature based activation and the mass density based activation. As previously stated, the mass density based activation was calibrated at 13.4 for the conditions of this study and this was chosen to be equivalent to a $13^{\circ} \mathrm{C}\left(23^{\circ} \mathrm{F}\right)$ rise under the ceiling of an open space without forced ventilation. The close agreement indicates that the mass density approach also is equivalent to activation based on temperature rise with forced ventilation in open spaces and in enclosed rooms. If mass density were desired to be equivalent to a different value of temperature rise, another calibration simulation would be needed.

Mass density activation was examined because of concern that the temperature based activation might be inappropriate for simulations including forced ventilation. However, agreement between the two activation approaches indicates that this issue should not be of concern provided that the walls are adiabatic and the HVAC jets are at ambient temperature as they were in this study. Further, the agreement between the two activation approaches indicates that temperature can be thought of as a good tracer of smoke mass density, provided that heat transfer in not significant as in the simulations of this project. 


\section{Potential For Correlations}

There is a desire for simple correlations that could be used in various engineering applications to relate detector performance to physical parameters that are easy to obtain. Development of such correlations is a complex process involving: (1) determination of relevant factors, (2) understanding of the relevant physical mechanisms, (3) development of theoretical model, (4) experimentation, and (5) data analysis. There is no one sequence of these efforts that will guarantee development of a useful correlation. Rather, each application requires its own combination efforts, and the results of one effort results in refinement of previously addressed efforts.

The factors involved with smoke detector activation consist of general factors applicable to all smoke detection and HVAC factors that are only applicable to some detection in the presence of forced ventilation. The general factors include heat release rate, particulate data (size, color, distribution, refractive index), room size and shape, obstructions (beams, ducts, etc.), and heat transfer. Even after many years of research into these areas, no generally accepted and widely applicable smoke detector model has been developed [20].

The HVAC factors include maximum diffuser supply flow, diffuser type, return type, and fire location (relative to diffusers and returns). In addition to these factors, all of the general factors above apply. The use of a simplified activation model like temperature rise activation or mass density activation, reduces the number of factors considerably. With such a simplified activation, the general factors are reduced to heat release rate, room size and shape, obstructions (beams, ducts, etc.), and heat transfer. By restricting application to normal building materials (no highly conductive materials like steel or aluminum ceilings) heat transfer can be eliminated. For the enclosed rooms and open plan rooms of this project, obstructions were not included.

At the beginning of year 3, an approach for a correlation of balancing an HVAC jet and the fire gases in the ceiling jet was considered. Since then, the importance of the fire location relative to the supplies and returns was learned. Fires to the side of the return deflect the HVAC jet to the side resulting in an area of non-activation on the side of the diffuser. While balancing the HVAC jet and the ceiling jet might result in useful correlation, considerable effort is needed, and the topic of non-activation on the diffuser side needs to be addressed.

There is also a desire to be able to adjust the results of the simulations for conditions different from those of the simulation. Some different conditions are: growth time, activation criteria, and building location. A simple method to adjust simulation results for fire growth time is provided in appendix $B$.

The simulations all apply to activation at a $13{ }^{\circ} \mathrm{C}\left(23^{\circ} \mathrm{F}\right)$ rise, and presently there is no way to adjust simulation results for other activation values. However, making simulations over a range of activation values could provide insight that could lead to a correlation.

The capability to adjust the simulation results for various building locations can be discussed, but development of such a capability is probably not practical. It could be considered that the simulations were intended as being for an average location in the United States in that the flow of supply air was $0.0125 \mathrm{~m}^{3} / \mathrm{s}$ per $\mathrm{m}^{2}$ of floor area $\left(2.5 \mathrm{cfm}\right.$ per $\mathrm{ft}^{2}$ of floor area) which is an average value for exterior zones of office buildings (appendix $\mathrm{C}$ ). In general an exterior zone in a hot climate like Phoenix would need more supply air for cooling than it would need in a less hot climate like Chicago. However, the opposite can be said about supply air for heating. The amount of supply air also depends on building insulation, use of insulating or reflecting glass, interior loads (heat generated by people, lights, 
computers, etc.), supply air temperature, and other specifics of the HVAC system. Some of the supply air may come from diffusers other than the ceiling slots of these simulations, and various types of slot diffusers are available. A highly energy conserving design may require less supply air than a typical design regardless of the climate. Considering the number and complexity of these variables, adjusting simulations results for building location is probably not practical.

Another approach would be to attempt a correlation based on diffuser throw. This has the advantage that manufacturers provide throw data for many diffusers. A number of simulations could be made for various throws, and these could be examined to find a pattern.

The HVAC system may not be operating at design conditions when a fire starts. In the last two decades, the vast majority of new commercial buildings have had variable air volume (VAV) systems. A VAV system is an HVAC system that controls temperature in a space by varying the quantity of supply air. When a space is not occupied, the interior loads are low, and a VAV system will supply much less air than the design value. Because the unoccupied space is of particular concern for smoke detection, the nonactivation distances in the simulations of this report may be considered conservative for spaces with VAV systems.

If some correlation could be developed to estimate the flow velocity at a specified distance from a diffuser where a detector is located, another correlation for detector response would be needed to estimate activation. For thermally activated devices, convective heat transfer theory could yield such a correlation; likely in the general form of the RTI equation used for sprinklers. For heat detectors this would require an equivalent of the plunge test -- a topic currently under discussion.

For spot-type smoke detectors it might be possible to use the aerodynamic entry model originally proposed by Heskestad [21] in combination with a means to account for the effect of air flow on the ionization chamber such as Litton's reduced source approximation [22]. The ionization detector's dependence on particle number density further means that a correlation for the dynamics of smoke agglomeration must be included. The optical detector would be simpler since the mass density correlation of Seader and Einhorn [23] provides a relationship to optical density and the indication that refractive index effects are second order.

Two alternatives to correlations should be kept in mind: (1) general guidelines and (2) computer modeling. The " 3 foot rule" discussed in the next section is a general guideline. These have the advantages that they are easy to understand and to check in the field. It is the nature of guidelines to be conservative. As already stated, the non-activation distances in the simulations of this report may be considered conservative for spaces with VAV systems. Considering this and the complexity of developing correlations, the guideline approach may be best suited for code language. However, computer modeling may have potential for a performance-based design.

As for including improved detector response algorithms into computer models, there is work ongoing. The techniques developed in this project generally can be applied to commercial CFD codes to provide design support for detection systems and their interaction with physical barriers and HVAC systems. CFD modeling should be thought of as an engineering tool for cases where a design is to be pushed beyond the guidelines. Many design engineers are using CFD for various applications. With decreasing computer costs and increasing computer power, it can only be expected that the use of CFD modeling in design will increase. Another possibility is the enhancement of zone models. The CFAST code [24] contains a ceiling jet which yields lateral temperature and velocity distributions with distance from the plume axis. If the same techniques could be used to model velocity distributions from HVAC 
diffusers, these interactions might be estimated. Unfortunately, effects from fire flows interacting with physical barriers are much more difficult.

\section{Conclusions and Discussion}

The authors suggest the following conclusions from this work. The conclusions are applicable to the interaction of detectors with slot diffusers and slot or rectangular returns as these were the only types of diffusers studied. However, since the results are consistent with industry experience over the past 20 years it is felt that these guidelines maybe more generally applicable. Further, these results were obtained with a specific CFD code under specific conditions of gridding and other assumptions. Other CFD models applied to the same cases and utilizing similar gridding and assumptions should provide similar results.

The current edition of the National Fire Alarm Code (NFPA 72) contains limited guidance on the installation of detectors relative to the components of HVAC systems. Section 5-3.6 cautions against the installation of detectors,

"... where air from supply diffusers could dilute smoke before it reaches the detectors.

Detectors shall be located to intercept the air flow toward the return air opening(s). This

may require additional detectors, since placing detectors only near return air openings

may leave the balance of the area with inadequate protection when the air handling system is shut down."

This guidance has led to a "rule of thumb" that detectors should be located no closer than 0.9 meter ( 3 $\mathrm{ft}$ ) from a supply register. This work indicates that this "3 foot rule" is appropriate for the enclosed rooms of this study. It needs to be clear that this three foot exclusion zone should include the ends of slot diffusers as this fact would not be intuitive.

For the open plan room, this 3 foot rule seems to break down as the area of non-activation reached ( 3.4 $\mathrm{m}) 11 \mathrm{ft}$ in front of the diffuser. It may be that the simplified return model (constant upward return velocity) could have an effect of the non-activation areas near the supply. Further study with a more detailed return model is needed, but it seems that the large non-activation areas in the open plan simulations were caused by the lack of a ceiling layer, depending instead solely on the ceiling jet for activation. This could occur in any space where the time for the ceiling jet to reach the far wall and reflect back to the detector exceeds the activation time for the sensor. For example, for a ceiling jet velocity of $1 \mathrm{~m} / \mathrm{s}$ and sensor activation in 30 seconds, a room with a characteristic dimension exceeding twice 30 meters should be considered an open plan room. Sensor activation time can be estimated by determining the time at which the assumed fire growth curve reaches the design fire size as defined in Appendix B of NFPA 72.

In nearly all cases, the activation areas at $0.02 \mathrm{~m}(0.79 \mathrm{in})$ and $0.05 \mathrm{~m}(2.0 \mathrm{in})$ were identical, indicating that both standard and the newer "low profile" sensors should provide similar activation performance. Even under the worst case conditions in the enclosed rooms of this study, sensors of up to $0.3 \mathrm{~m}(1 \mathrm{ft}$ ) in depth should activate.

There is insufficient information to reach conclusions about the appropriateness of the concept of locating detectors "near return air openings" mentioned in the current code. Areas of non-activation at some of the returns in the open plan room simulations were unexpected and cause concern about the appropriateness of the simplified return model (constant upward return velocity). Further study is needed 
with simulations of return flows extended to include simulation of the flow through the return and into the plenum space above the ceiling. While the unexpected non-activation areas only occurred in the open room simulations, this extended return simulation also should be used for enclosed rooms to more fully evaluate the effect of return flows on activation.

Finally, it should be kept in mind that this work involved slot diffusers only. While these are extensively used in commercial buildings, they produce a flow along the ceiling which is not found to this extent in other diffuser styles. For other diffusers, more studies need to be done to see if similar results are obtained.

\section{References}

[1] Heskestad, G. and Delichatsios, M.A. Environments of Fire Detectors - Phase I: Effect of Fire Size, Ceiling Height and Materials. Volume I - Measurements (NBS-GCR-77-86), Gaithersburg, MD, National Bureau of Standards, 1977.

[2] Forney, G.P., Bukowski, R.W., Davis, W.D. Simulating the effect of flat beamed ceilings on detector and sprinkler response, 1993. Available from the National Fire Protection Association, Batterymarch Park, Quincy, MA.

[3] Davis, W.D., Forney, G.P., Bukowski, R.W. Simulating the effect of sloped beamed ceilings on detector and sprinkler response, 1994. Available from the National Fire Protection Association, Batterymarch Park, Quincy, MA.

[4] CFC Department, AEA Industrial Technology, Harwell Laboratory, Oxfordshire, United Kingdom, CFDS-FLOW3D Release 3.3: User Manual, June 1994.

[5] Abbott, M.B. and Basco, D.R. Computational Fluid Dynamics: An Introduction for Engineers, Wiley, New York, NY, 1989.

[6] Anderson, D.A., Tannehill J.C. and Pletcher, R.H. Computational Fluid Mechanics and Heat Transfer, Hemisphere, New York, NY, 1984.

[7] Hirsch, C. Numerical Computation of Internal and External Flows, Vol 2: Computational Methods for Inviscid and Viscous Flows, Wiley, New York, NY, 1990.

[8] Hoffmann, K.A. Computational Fluid Dynamics for Engineers, Engineering Education System, Austin, TX, 1989.

[9] Kumar, S. Mathematical Modelling of Natural Convection in Fire - A State of the Art Review of the Field Modelling of Variable Density Turbulent Flow, Fire and Materials, Vol 7, No 1, pp 1-24, 1983.

[10] Schetz, J.A. Boundary Layer Analysis, Prentice Hall, Englewood Cliffs, NJ, 1993.

[11] Schlichting, H. Boundary Layer Theory, 4th ed., Kestin, J. Translator, McGraw, New York, NY, 1960.

[12] Sherman, F.S. Viscous Flow, McGraw, New York, NY, 1990. 
[13] White, F.M. Viscous Fluid Flow, McGraw, New York, NY, 1974.

[14] Yuan, S.W. Foundations of Fluid Dynamics, Prentice Hall, Englewood Cliffs, NJ, 1967.

[15] Launder, B.E. and Spalding, D.B. The numerical computation of turbulent flows, Computer Methods in Applied Mechanics and Engineering, 3:269-289, 1974.

[16] NFPA 72, National Fire Alarm Code, National Fire Protection Association, 1993.

[17] Drysdale, D. An Introduction to Fire Dynamics, Wiley, New York, 1985, p 281.

[18] Straub, H. Engineering Data: Grills, Registers, Diffusers, Terminals, Catalog T49, TITUS, Richardson TX, 1994.

[19] Marrion, C.E. Lag Time Modeling and Effects of Ceiling Jet Velocity on the Placement of Optical Smoke Detectors, Masters Thesis, Worcester Polytechnic Institute, Worcester MA, 1989.

[20] Schifiliti, R.P. and Pucci, W.E., Fire Detection Modeling, State of the Art, Fire Detection Institute, 1996 (in press).

[21] Heskestad, G, Generalized Characteristics of Smoke Entry and Response for Products of Combustion Detectors, Proceedings, 7th International Conference on Problems of Automatic Fire Detection, Rheinish-Westfalischen Technischen Hochschule Aachen, 1975.

[22] Litton, C.D., A Mathematical Model for Ionization Type Smoke Detectors and the Reduced Source Approximation, Fire Technology, 13, 4, NFPA, 1974.

[23] Seader, J. and Einhorn, I., Some Physical, Chemical, Toxicological, and Physiological Aspects of Fire Smokes, Sixteenth Symposium on Combustion, The Combustion Institute, Pittsburgh, PA, 1423-1445, 1976.

[24] Peacock, R.D., Forney, G.P., Reneke, P., Portier, R., and Jones, W.W., CFAST, the Consolidated Model of Fire Growth and Smoke Transport, NIST TN 1299, Nat. Inst. Stand. Tech., 1993. 
Table 1. Summary of smoke movement simulations

\begin{tabular}{|c|c|c|c|c|c|}
\hline Run & $\begin{array}{c}\text { ID } \\
\text { Number }\end{array}$ & $\begin{array}{c}\text { Fire } \\
\text { Location }\end{array}$ & Room & Supply & Return \\
\hline 1 & $\mathrm{~m} 35.9420$ & 1 & open plan & none & none \\
\hline 2 & $\mathrm{~m} 36.25035$ & 1 & open plan & none & none \\
\hline 3 & $\mathrm{~m} 15.4031$ & 1 & small & slot & 1 \\
\hline 4 & $\mathrm{~m} 17.5257$ & 2 & small & slot & 1 \\
\hline 5 & $\mathrm{~m} 22.18499$ & 3 & small & slot & 1 \\
\hline 6 & $\mathrm{~m} 23.392$ & 4 & small & slot & 1 \\
\hline 7 & $\mathrm{~m} 24.10420$ & 1 & small & slot & 2 \\
\hline 8 & $\mathrm{~m} 25.12804$ & 2 & small & slot & 2 \\
\hline 9 & $\mathrm{~m} 26.14811$ & 3 & small & slot & 2 \\
\hline 10 & $\mathrm{~m} 27.17238$ & 4 & small & slot & 2 \\
\hline 11 & m30.19435 & 1 & small & slot & 3 \\
\hline 12 & $\mathrm{~m} 31.23467$ & 2 & small & slot & 3 \\
\hline 13 & $\mathrm{~m} 32.2844$ & 3 & small & slot & 3 \\
\hline 14 & $\mathrm{~m} 33.7374$ & 4 & small & slot & 3 \\
\hline 15 & $\mathrm{~m} 37.744$ & 1 & medium & slot & 1 \\
\hline 16 & $\mathrm{~m} 38.2297$ & 2 & medium & slot & 1 \\
\hline 17 & $\mathrm{~m} 41.9616$ & 3 & medium & slot & 1 \\
\hline 18 & m39.1395 & 4 & medium & slot & 1 \\
\hline 19 & $\mathrm{~m} 44.12465$ & 1 & medium & slot & 2 \\
\hline 20 & $\mathrm{~m} 45.17524$ & 2 & medium & slot & 2 \\
\hline 21 & $\mathrm{~m} 46.1637$ & 3 & medium & slot & 2 \\
\hline 22 & $\mathrm{~m} 47.7006$ & 4 & medium & slot & 2 \\
\hline 23 & $\mathrm{~m} 56.20302$ & 1 & open plan & slot \& troffer & 1 \\
\hline 24 & $\mathrm{~m} 57.28839$ & 2 & open plan & slot \& troffer & 1 \\
\hline 25 & $\mathrm{~m} 58.1020$ & 3 & open plan & slot \& troffer & 1 \\
\hline 26 & m61.16895 & 1 & open plan & slot \& troffer & 2 \\
\hline 27 & $\mathrm{~m} 62.7907$ & 2 & open plan & slot \& troffer & 2 \\
\hline 28 & $\mathrm{~m} 63.13997$ & 3 & open plan & slot \& troffer & 2 \\
\hline 29 & $\mathrm{~m} 64.1034$ & 1 & open plan & slot \& troffer & 3 \\
\hline 30 & $\mathrm{~m} 65.6572$ & 2 & open plan & slot \& troffer & 3 \\
\hline 31 & m66.10699 & 3 & open plan & slot \& troffer & 3 \\
\hline
\end{tabular}


Table 2. Non-activation distances at $0.05 \mathrm{~m}(0.20$ in) under the ceiling and horizontal separation between fire and return for enclosed room simulations

\begin{tabular}{|c|c|c|c|c|c|c|}
\hline \multirow[b]{3}{*}{ Run } & \multirow{2}{*}{\multicolumn{2}{|c|}{$\begin{array}{l}\text { Fire to } \\
\text { Return } \\
\text { Separation }\end{array}$}} & \multicolumn{4}{|c|}{ Distances of Non-Activation } \\
\hline & & & \multicolumn{2}{|c|}{ Slot Front ${ }^{*}$} & \multicolumn{2}{|c|}{ Slot Side } \\
\hline & $\mathrm{m}$ & $\mathrm{ft}$ & $\mathrm{m}$ & $\mathrm{ft}$ & $\mathbf{m}$ & $\mathrm{ft}$ \\
\hline 3 & 0.3 & 1.0 & 0.6 & 2.0 & 0.2 & 0.7 \\
\hline 4 & 0.4 & 1.3 & 0.5 & 1.6 & 0.1 & 0.3 \\
\hline 5 & 2.1 & 6.9 & 0.1 & 0.3 & 0.1 & 0.3 \\
\hline 6 & 4.3 & 14.1 & 0.1 & 0.3 & 0.1 & 0.3 \\
\hline 7 & 4.3 & 14.1 & 0.0 & 0.0 & 0.0 & 0.0 \\
\hline 8 & 4.0 & 13.1 & 0.2 & 0.7 & 0.1 & 0.3 \\
\hline 9 & 2.2 & 7.2 & 0.4 & 1.3 & 0.1 & 0.3 \\
\hline 10 & 0.3 & 1.0 & 0.5 & 1.6 & 0.1 & 0.3 \\
\hline 11 & 4.2 & 13.8 & 0.0 & 0.0 & 0.0 & 0.0 \\
\hline 12 & 4.0 & 13.1 & 0.2 & 0.7 & 0.1 & 0.3 \\
\hline 13 & 2.0 & 6.7 & 0.4 & 1.3 & 0.1 & 0.3 \\
\hline 14 & 0.0 & 0.0 & 0.7 & 2.3 & 0.1 & 0.3 \\
\hline 15 & 0.0 & 0.0 & 1.0 & 3.3 & 0.2 & 0.7 \\
\hline 16 & 0.2 & 0.7 & 0.7 & 2.3 & 0.2 & 0.7 \\
\hline 17 & 2.1 & 6.9 & 0.2 & 0.7 & 0.1 & 0.3 \\
\hline 18 & 4.3 & 14.1 & 0.2 & 0.7 & 0.1 & 0.3 \\
\hline 19 & 4.4 & 14.4 & 0.6 & 2.0 & 0.1 & 0.3 \\
\hline 20 & 4.1 & 13.5 & 0.7 & 2.3 & 0.1 & 0.3 \\
\hline 21 & 2.1 & 6.9 & 0.6 & 2.0 & 0.1 & 0.3 \\
\hline 22 & 0.0 & 0.0 & 0.9 & 3.0 & 0.1 & 0.3 \\
\hline
\end{tabular}

"Values listed are the greatest distance of non-activation in front of the diffuser and perpendicular to the diffuser length. The front of the slot (or troffer) is taken to be the direction of flow.

FValues listed are largest distance of non-activation on either side of the slot diffuser (or troffer).

$\S$ The fire is at the edge of the area of detailed simulation, and there is only small areas of activation. 
Table 3. Non-activation distances at $0.05 \mathrm{~m}(2.0 \mathrm{in})$ under the ceiling and horizontal separation between fire and return for open plan room simulations

\begin{tabular}{|c|c|c|c|c|c|c|c|c|c|c|}
\hline \multirow[b]{3}{*}{ Run } & \multirow{2}{*}{\multicolumn{2}{|c|}{$\begin{array}{c}\text { Fire to } \\
\text { Return } \\
\text { Separation }\end{array}$}} & \multicolumn{8}{|c|}{ Distances of Non-Activation } \\
\hline & & & \multicolumn{2}{|c|}{ Slot Front ${ }^{*}$} & \multicolumn{2}{|c|}{ Slot Side } & \multicolumn{2}{|c|}{ Troffer Front ${ }^{*}$} & \multicolumn{2}{|c|}{ Troffer Side ${ }^{\ddagger}$} \\
\hline & m & $\mathrm{ft}$ & $\mathrm{m}$ & $\mathrm{ft}$ & $\mathrm{m}$ & $\mathrm{ft}$ & $\mathrm{m}$ & $\mathrm{ft}$ & $\mathrm{m}$ & $\mathrm{ft}$ \\
\hline 23 & 0.0 & 0.0 & 2.2 & 7.2 & 0.6 & 2.0 & 0.5 & 1.6 & 0.6 & 2.0 \\
\hline 24 & 0.4 & 1.3 & 1.9 & 6.2 & 0.6 & 2.0 & 0.7 & 2.3 & 0.6 & 2.0 \\
\hline 25 & 5.2 & 17.1 & 1.1 & 3.6 & 0.6 & 2.0 & 0.9 & 3.0 & 0.6 & 2.0 \\
\hline 26 & 2.5 & 8.2 & 1.6 & 5.2 & 0.6 & 2.0 & 0.6 & 2.0 & 0.2 & 0.7 \\
\hline 27 & 2.3 & 7.5 & 1.4 & 4.6 & 0.6 & 2.0 & 1.0 & 3.3 & 0.3 & 1.0 \\
\hline 28 & 2.2 & 7.2 & $3.3^{\dagger}$ & $10.8^{\dagger}$ & 0.6 & 2.0 & 1.0 & 3.3 & 0.6 & 2.0 \\
\hline 29 & 4.7 & 15.4 & 1.7 & 5.6 & 0.6 & 2.0 & 0.5 & 1.6 & 0.2 & 0.7 \\
\hline 30 & 4.5 & 14.8 & 1.4 & 4.6 & 0.6 & 2.0 & 0.6 & 2.0 & 0.2 & 0.7 \\
\hline 31 & 0.1 & 0.3 & $N A^{\S}$ & $\mathrm{NA}^{\S}$ & $\mathrm{NA}^{\S}$ & $\mathrm{NA}^{\S}$ & $\mathrm{NA}^{\S}$ & $\mathrm{NA}^{\S}$ & $N A^{\S}$ & $N A^{\S}$ \\
\hline
\end{tabular}

*Values listed are the greatest distance of non-activation in front of the diffuser and perpendicular to the diffuser length. The front of the slot (or troffer) is taken to be the direction of flow.

FValues listed are largest distance of non-activation on either side of the slot diffuser (or troffer).

tThis area of non-activation joins with another around the return.

${ }^{\S}$ The fire is at the edge of the area of detailed simulation, and there is only small areas of activation. 


\section{Appendix A: $k-\epsilon$ Turbulence Model}

In computational fluid dynamic (CFD) modeling, the space where flow is to be simulated is divided into a number of cells (or finite volumes), and the governing equations of fluid flow are solved numerically for each cell and for each time step of the simulation. The governing equations alone can be used to simulate the effects of turbulence on a scale larger than that of the cells. However, use of these flow equations alone cannot account for turbulence on a scale smaller than the cells. Turbulence modeling was developed to account for turbulence effects inside the cells. In such models a number of empirically developed partial differential equations are added to the flow equations which are solved for each cell and for each time step. Because turbulence models account for turbulent effects inside the cells, the number of cells needed for a particular application can be reduced.

The turbulence model used for this work is the $k-\epsilon$ model developed by Launder and Spalding [1] in the early seventies. This is probably the most extensively used turbulence model. The $k-\epsilon$ model is referred to as a two equation model, because it amounts to increasing the number of partial differential equations for the simulation by two. The purpose of this appendix is to provide introductory information about the $k-\epsilon$ model and provide the constants used in the simulations for this report.

The reader should be aware that a thorough knowledge of the $k-\epsilon$ model requires extensive understanding of graduate level fluid dynamics. For more information about CFD modeling and the $k-\epsilon$ model, readers are referred to Launder and Spalding and [2][3][4][5][6].

The effective viscosity, $\mu_{\mathrm{eff}}$, used in the governing equations is the sum of the kinematic viscosity, $\mu$, and the turbulent viscosity, $\mu_{\mathrm{T}}$.

$$
\mu_{\text {eff }}=\mu+\mu_{T}
$$

It is assumed that

$$
\mu_{T}=C_{\mu} \rho \frac{k^{2}}{\epsilon}
$$

The transport equations for the turbulent kinetic energy, $k$, and the turbulent dissipation rate, $\epsilon$, are

$$
\frac{\partial \rho k}{\partial t}+\nabla \cdot(\rho U k)-\nabla \cdot\left(\left(\mu+\frac{\mu_{T}}{\sigma_{k}}\right) \nabla k\right)=P+G+\rho \epsilon
$$

and

$$
\frac{\partial \rho \epsilon}{\partial t}+\nabla \cdot\left(\rho U_{\epsilon}\right)-\nabla \cdot\left(\left(\mu+\frac{\mu_{T}}{\sigma_{\epsilon}}\right) \nabla \epsilon\right)=C_{1} \frac{\epsilon}{k}\left(P+C_{3} \max (G, 0)\right)-C_{2} \rho \frac{\epsilon^{2}}{k} .
$$

In addition to defining $k$ and $\epsilon$, the above equations are the two added partial differential equations of the $k$ - $\varepsilon$ model.

The symbol $\nabla$ is called the gradient, and it is written as

$$
\nabla=i \frac{\partial}{\partial x}+j \frac{\partial}{\partial y}+k \frac{\partial}{\partial z}
$$

and the velocity vector is 


$$
U=u \dot{i}+v j+w k
$$

where $i, j$ and $k$ are unit vectors in the $x, y$ and $z$ direction, and where $u, v$ and $w$ are the velocity components in the $x, y$ and $z$ direction. The operation $\max (a, b)$ has the greater value of $a$ or $b$.

The shear production, $P$, is defined as

$$
P=\mu_{e f f} \nabla U \cdot\left(\nabla U+(\nabla U)^{T}\right)-\frac{2}{3} \nabla \cdot U\left(\mu_{e f f} \nabla \cdot U+\rho k\right),
$$

where $(\nabla U)^{T}$ is the transpose of the tensor $\nabla U$. For information about tensors readers are referred to $[7][8][9][10]$.

The production, $G$, due to body force is defined as

$$
G=-\frac{\mu_{e f f}}{\rho \sigma_{T}} g \nabla \rho
$$

The turbulent Prandtl number, $\sigma_{\epsilon}$, is

$$
\sigma_{\epsilon}=\frac{\kappa^{2}}{\left(C_{2}-C_{1}\right) \sqrt{C_{\mu}}}
$$

Table A1 lists default values of the empirical coefficients and the values used in this study. The values used in this study are the same as the default values except for $C_{\mu}$ and $C_{3}$, which were shown by Nam and Bill [11] to result in somewhat improved plume simulation in comparison to simulations using the default coefficients.

Table A1. Values of constants used in turbulence equations

\begin{tabular}{||ccc||}
\hline & FLOW3D Default & Used In This Paper \\
\hline \hline$C_{\mu}$ & 0.09 & 0.18 \\
$C_{1}$ & 1.44 & 1.44 \\
$C_{2}$ & 1.92 & 1.92 \\
$C_{3}$ & 0.0 & 1.0 \\
$K$ & 0.4187 & 0.4187 \\
$\sigma_{k}$ & 1.0 & 1.0 \\
\hline
\end{tabular}




\section{Nomenclature}

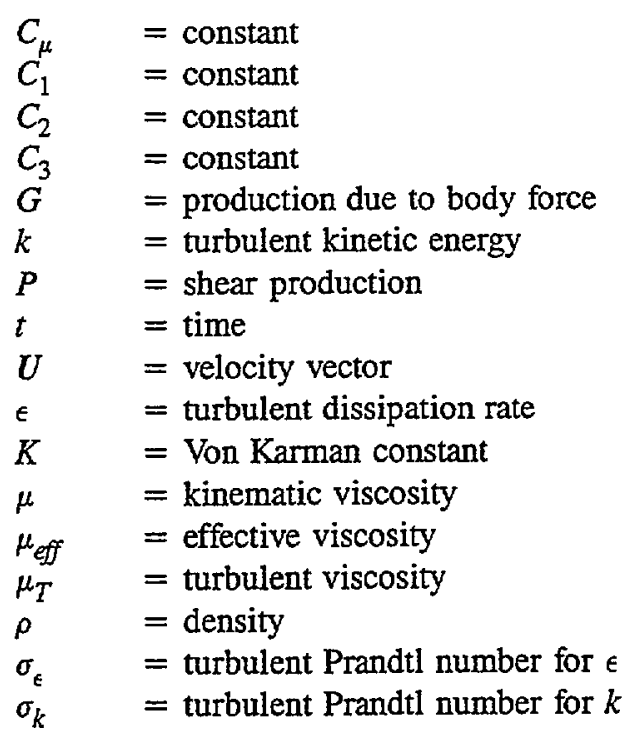

\section{References}

[1] Launder, B.E. and Spalding, D.B. The numerical computation of turbulent flows, Computer Methods in Applied Mechanics and Engineering, 3:269-289, 1974.

[2] Abbott, M.B. and Basco, D.R. Computational Fluid Dynamics: An Introduction for Engineers, Wiley, New York, NY, 1989.

[3] Anderson, D.A., Tannehill J.C. and Pletcher, R.H. Computational Fluid Mechanics and Heat Transfer, Hemisphere, New York, NY, 1984.

[4] Hirsch, C. Numerical Computation of Internal and External Flows, Vol 2: Computational Methods for Inviscid and Viscous Flows, Wiley, New York, NY, 1990.

[5] Hoffmann, K.A. Computational Fluid Dynamics for Engineers, Engineering Education System, Austin, TX, 1989.

[6] Kumar, S. Mathematical Modelling of Natural Convection in Fire - A State of the Art Review of the Field Modelling of Variable Density Turbulent Flow, Fire and Materials, Vol 7, No 1, pp 1-24, 1983.

[7] Aris, R. Vectors, Tensors, and the Basic Equations of Fluid Mechanics, Dover, NY, 1962.

[8] Kay, D.C. Theory and Problems of Tensor Calculus, McGraw, New York, 1988.

[9] Borisenko, A.I. and Tarapov, I.E. Vector and Tensor Analysis with Applications, Translated by R.A. Silverman, Dover, New York, 1968.

[10] Hay, G.E. Vector and Tensor Analysis, Dover, New York, 1953. 
[11] Nam, S. and Bill, R.G. Jr. Numerical simulation of thermal plumes, Life Safety Journal, 21:231256, 1993. 


\section{Appendix B: Smoke Generation and Mass Density of Smoke}

For this project, the mass density activation criteria was calibrated to be equivalent to activation based temperature rise. This appendix gives an approach that can be used to the relate optical density needed to put a detector into alarm to the mass generation rate of smoke. However, the approach is only appropriate for medium growth rate t-squared fires with combinations of detectors and smoke that would result in activation if subjected to a $13{ }^{\circ} \mathrm{C}\left(23^{\circ} \mathrm{F}\right)$ temperature rise under the ceiling of a large open space without forced ventilation.

For the analysis of this appendix, smoke was generated at a rate of one non-dimensional unit of mass per second per $\mathrm{kW}$ of convective heat released. The convective heat released by the fire was

$$
Q_{c}=C_{s} C_{c} 1055\left(\frac{t}{t_{g}}\right)^{2}
$$

where

$Q_{c} \quad=$ convective heat release rate, $\mathrm{kW}$,

$C_{s} \quad=$ symmetry factor,

$C_{c}=$ convective fraction of heat release,

$t=$ time from ignition, $\mathrm{s}$,

$t_{g} \quad=$ growth time, $\mathrm{s}$.

Because all the fires were on the plane of symmetry, a symmetry factor of $1 / 2$ was used. A convective factor of 0.65 was used, and a growth time of $275 \mathrm{~s}$ was used. The fire was modeled by releasing energy over several grid cells. The number of cells occupied by the fire was varied during the simulation such that the heat release rate per unit volume would not exceed $2.6 \mathrm{~kW} / \mathrm{m}^{3}$.

Optical density per unit distance is

$$
D=-\frac{\log _{10}\left(I_{x} / I_{o}\right)}{x}
$$

where

$D=$ optical density per unit distance, $\mathrm{m}^{-1}$,

$I_{o} \quad=$ intensity of light at the beginning of the path length,

$I_{x} \quad=$ intensity of light remaining after it has passed through the path length,

$x=$ path length the light travels, $\mathrm{m}$.

The units of light intensity are arbitrary, and such units are unnecessary for the discussion that follows. The extinction coefficient per unit length is

$$
K=-\frac{\log _{e}\left(I_{x} / I_{o}\right)}{x}
$$

where $K$ is the extinction coefficient with units of $\mathrm{m}^{-1}$. The two coefficients are related as 


$$
D=\frac{K}{2.3}
$$

The extinction coefficient can also be expressed as

$$
K=K_{m} m
$$

where

$K_{m} \quad=$ specific extinction coefficient, $\mathrm{m}^{2} / \mathrm{g}$,

$m \quad=$ mass concentration of smoke, $\mathrm{g} / \mathrm{m}^{3}$.

Small scale experiments on wood, cellulose and plastics by Seader and Einhorn [1] resulted in average values of $K_{m}$ of $7.6 \mathrm{~m}^{2} / \mathrm{g}$ for smoke produced by flaming combustion and of $4.4 \mathrm{~m}^{2} / \mathrm{g}$ for smoke produced by non-flaming combustion. However, only the value for flaming combustion is relevant to this project.

For the simulations of this report, the mass generation of smoke can be expressed as

$$
m_{g}=\frac{m_{n g} m}{0.65 m_{n a}}
$$

where

$m_{g} \quad=$ mass generation rate of smoke per unit of heat released, $\mathrm{g} \mathrm{s}^{-1} \mathrm{~kW}^{-1}$,

$m_{n g} \quad=$ normalized smoke generation per unit of convective heat released, $\mathrm{s}^{-1} \mathrm{~kW}^{-1}$,

$m$ = mass concentration of smoke at activation, $\mathrm{g} / \mathrm{m}^{3}$,

$m_{n a}=$ normalized mass concentration of smoke at activation, $\mathrm{m}^{-3}$.

For this project, the value of $m_{n g}$ was $1 \mathrm{~s}^{-1} \mathrm{~kW}^{-1}$, and the value of $m_{n a}$ was $13.4 \mathrm{~m}^{-3}$. Using these values, $K_{m}=7.6 \mathrm{~m}^{2} / \mathrm{g}$ and combining equations (4), (5) and (6) results in

$$
m_{g}=\frac{D}{28.8}
$$

where

$m_{g} \quad=$ mass generation rate of smoke per unit of heat released, $\mathrm{g} \mathrm{s}^{-1} \mathrm{~kW}^{-1}$,

$D \quad=$ optical density per unit distance at which a detector goes into alarm, $\mathrm{m}^{-1}$.

Equation (7) describes combinations of detectors and smoke that would result in activation if subjected to a $13^{\circ} \mathrm{C}\left(23^{\circ} \mathrm{F}\right)$ temperature rise under the ceiling of a large open space without forced ventilation with a t-squared fire that had a growth time of $275 \mathrm{~s}$. Because these are the conditions of the simulations of this paper, equation (7) is applicable to the results of these simulations.

The above approach can be extended for different $t$-squared fires, considering that the dominate consideration in activation time is the convective heat release rate. Consider a second fire described as 


$$
Q_{c 2}=C_{s 2} C_{c 2} 1055\left(\frac{t_{2}}{t_{g 2}}\right)^{2}
$$

where

$Q_{c 2}=$ convective heat release rate of the second fire, $\mathrm{kW}$,

$C_{s 2}=$ symmetry factor of the second fire,

$C_{c 2} \quad=$ convective fraction of heat release of the second fire,

$t_{2} \quad=$ time from ignition of the second fire, $\mathrm{s}$,

$t_{g 2}=$ growth time of the second fire, $\mathrm{s}$.

In adjusting simulation time, the simulation geometry remains unchanged as does the symmetry factors $\left(C_{s 2}=C_{s}\right)$. Corresponding time is when the convective heat release rates are the same for both fires $\left(Q_{c}=Q_{c 2}\right)$. Equating equations (1) and (8) and canceling like terms results in

$$
t_{2}=t \frac{t_{g 2}}{t_{g}} \sqrt{\frac{C_{c}}{C_{c 2}}}
$$

In the absence of well defined application criteria for this equation, it is suggested use of it be restricted to $\left(t_{g 2} / t_{g}\right)$ from 0.5 to 2 .

\section{Example 1:}

Calculate the generation rate of smoke needed to activate a detector in the simulations of this paper for a smoke detector that goes into alarm when smoke reaches an optical density of $0.07 \mathrm{~m}^{-1}$.

\section{Approach a:}

From equation (4), the extinction coefficient is

$$
K=2.3 D=2.3(0.07)=0.161 \mathrm{~m}^{-1} \text {. }
$$

From equation (5), the mass concentration of smoke can be estimated as

$$
m=\frac{K}{K_{m}}=\frac{0.161 \mathrm{~m}^{-1}}{7.6 \mathrm{~m}^{2} / \mathrm{g}}=0.021 \mathrm{~g} / \mathrm{m}^{3}
$$

From equation (6), the smoke generation rate per $\mathrm{kW}$ of heat released is

$$
m_{g}=\frac{m_{n g} m}{0.65 m_{n a}}=\frac{1}{.65}\left(\frac{1}{\mathrm{~s} \mathrm{~kW}}\right) \frac{0.021 \mathrm{~g} / \mathrm{m}^{3}}{13.4 / \mathrm{m}^{3}}=0.0024 \frac{\mathrm{g}}{\mathrm{s} \mathrm{kW}} \text {. }
$$

Approach b:

From equation $(7)$, the smoke generation rate per $\mathrm{kW}$ of heat released is 


$$
m_{g}=\frac{D}{28.8}=\frac{0.07}{28.8}=0.0024 \frac{\mathrm{g}}{\mathrm{s} \mathrm{kW}}
$$

\section{Example 2:}

Assuming the convective fraction is unchanged, how does a faster fire growth time of $t_{g}=190 \mathrm{~s}$ affect the simulated activation time?

From equation (9), the times are related as

$$
t_{2}=t \frac{190}{275}=0.69 t
$$

Where 80 seconds is shown on one of the activation time figures in the paper, the adjusted time would be $(80)(.69)=55$ seconds.

This is used to adjust the time scale on the activation time figures as follows:

$\begin{array}{cc}\text { Existing Scale } & \text { Adjusted Scale } \\ >80 & 55 \\ 80 & 55 \\ 65 & 45 \\ 50 & 35 \\ 35 & 24 \\ 20 & 14 \\ <20 & <14\end{array}$

The adjusted scale above can be used with any of the activation time figures in the report to see the pattern of activation resulting from a fire with a growth time of 190 seconds.

\section{Fundamental Equations}

Two of the fundamental equations are examined below with the intent of providing insight into the relationship between smoke generation and mass density of smoke. For the simulations of this study, the energy equation was that for weakly compressible flow

$$
\frac{\partial \rho H}{\partial t}+\nabla \cdot(\rho U H)-\nabla \cdot(\lambda \nabla T)=E,
$$

and the scalar equation was used for simulation of the mass density of smoke

$$
\frac{\partial \rho \phi}{\partial t}+\nabla \cdot(\rho U \phi)-\nabla \cdot\left(\rho D_{\phi} \nabla \phi\right)=S,
$$

where 


$$
\begin{array}{ll}
\rho & =\text { fluid density, } \mathrm{kg} / \mathrm{m}^{3}, \\
H & =\text { total enthalpy of fluid, } \mathrm{J} / \mathrm{kg}, \\
U & =\text { fluid velocity vector, } \mathrm{m} / \mathrm{s}, \\
\lambda & =\text { fluid thermal conductivity, } \mathrm{W} /(\mathrm{m} \mathrm{K}) \\
T & =\text { fluid temperature, } \mathrm{K}, \\
t & =\text { time, } \\
E & =\text { energy source term, } \mathrm{W} \\
\Phi & =\text { species mass fraction, dimensionless, } \\
D_{\Phi} & =\text { mass diffusivity of } \mathrm{species}, \mathrm{m}^{2 /} \mathrm{s}, \text { and } \\
S & =\text { species source term, } \mathrm{kg} /\left(\mathrm{s} \mathrm{m}^{3}\right) .
\end{array}
$$

The total enthalpy is

$$
H=C_{p} T+\frac{1}{2} U^{2}
$$

where $C_{p}$ is the specific heat of fluid, $J /(\mathrm{kg} \mathrm{K})$.

Equations (10) and (11) are similar. The third term on the left of equation (10) is the thermal diffusion term, and the third term on the left of equation (11) is the species diffusion term. The Lewis number is the ratio of thermal diffusion to species diffusion. If the Lewis number is one, equations (10) and (11) would be the same.

\section{Reference}

[1] Seader, J. and Einhorn, I., Some physical, chemical, toxicological, and physiological aspects of fire smoke, National Science Foundation Report PB83-2502, July 1976. 


\section{Appendix C: Idealized Slot Diffuser Model}

If computer memory and running time were not concerns, the best way to simulate a slot diffuser would be model the flow inside the diffuser along with the rest of the room simulation. Because this approach would approximately double the number of cells in the simulation, another method was needed. Most computer simulations of room airflow have used constant velocity at the supply outlet to model HVAC supply (for example $[1][2][3][4][5][6]$ ). While these references have some information about CFD simulation of the effects of wall diffusers, there is no corresponding information about ceiling mounted slot diffusers. This appendix describes the idealized slot diffuser model that was used for this project. Because troffer diffusers are similar to slot diffusers, this model was also used for the troffers.

The intent of ceiling mounted slot diffusers is to discharge the air in a direction such that the flow attaches itself to the ceiling. This attached flow is referred to as Coanda effect [7], and this effect is often desired in HVAC applications to prevent supply jets from blowing on occupants. The mass flow rate of supply air is

$$
\dot{m}=\rho h L V_{z}
$$

where

$\dot{m} \quad=$ mass flow rate,

$\rho \quad=$ supply air density,

$h \quad=$ slot width,

$L \quad=$ slot length,

$V_{z} \quad=$ downward component of outlet velocity.

The component of outlet velocity in the ceiling direction is

$$
V_{x}=\frac{V_{z}}{\tan \theta}
$$

where

$V_{x} \quad=$ component of outlet velocity in the direction of the ceiling,

$\theta=$ discharge angle between inlet velocity and the ceiling.

This idealized model is intended to result in computer simulated flows near the ceiling that are representative of those produced by slot diffusers. However, this model does not simulate flow details within the diffuser. Accordingly, values $h$ and $\theta$ should not be considered the values of an actual diffuser. The values of $h$ and $\theta$ should be thought of as parameters of the idealized model that can be adjusted to yield HVAC jet flows that are desired for the simulations. The idealized model is illustrated in figure $\mathrm{C} 1$. CFD simulations showed that for discharge angles of about $45^{\circ}$ or less, the jet was attached to the ceiling.

The throw of a jet is the distance that the jet travels for it to slow down to a particular speed. Manufacturers supply throw data for many diffusers, and common values are for velocities of $0.25,0.5$ and $0.75 \mathrm{~m} / \mathrm{s}(50,100$ and $150 \mathrm{fpm})$. The throw is represented by $L_{v}$, where $v$ is the value of the velocity. Accordingly, $L_{.25}, L_{.5}$ and $L_{.75}$ are the throws to $0.25,0.5$ and $0.75 \mathrm{~m} / \mathrm{s}(50,100$ and $150 \mathrm{fpm})$. For this application, $L_{.75}$ is of most interest because the velocity $0.75 \mathrm{~m}(150 \mathrm{fpm})$ is more likely to 
adversely affect detector performance than the lower velocities. Thus in selection of the idealized slot diffuser for this project, particular emphasis was places on $L_{.75}$.

In the diffuser industry, it is generally accepted that $L_{75}$ is nearly the same for isothermal jets, cooling jets and heating jets [8]. Figure C2 demonstrates the this industry rule for a few CFD simulations. The level of agreement among the throws of this figure provides added confidence in the industry rule. The simulations of this study (runs 3-31) were made for isothermal jets. For the reasons above, it can be concluded that the results of these simulations can be applied to both cooling and heating jets.

Throw recommendations for various applications are provided by ASHRAE [9] and Straub [10]. Based on ASHRAE recommendations, an $L .5$ of $1.5 \mathrm{~m}(5 \mathrm{ft})$ would be used to achieve a high level of comfort in the enclosed rooms of this study. However, HVAC designers have indicated that the ASHRAE recommendations concerning throws for ceiling mounted slot diffusers have often been exceeded in practice. For the enclosed rooms of this study, Straub's suggestions amount to selecting a diffuser with an $L_{.25}$ of 7 to $15 \mathrm{~m} \mathrm{(23} \mathrm{to} 50 \mathrm{ft}$ ). This can result in an $L_{.5}$ much greater than the ASHRAE recommendations. For this study an $L_{.75}$ of $1.5 \mathrm{~m}(4.9 \mathrm{ft})$ was selected as a value which might be considered an upper limit for such an application.

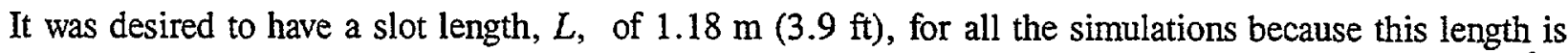
common in the industry. For a perimeter office, supply air is usually in the range of 0.01 to $0.015 \mathrm{~m}^{3} / \mathrm{s}$ per $\mathrm{m}^{2}$ of floor area ( 2 to $3 \mathrm{cfm}$ per $\mathrm{ft}^{2}$ of floor area). The value of $0.0125 \mathrm{~m}^{3} / \mathrm{s} \mathrm{per} \mathrm{m}^{2}$ of floor area $(2.5$ $\mathrm{cfm}$ per $\mathrm{ft}^{2}$ of floor area) was selected. For the slot diffuser in small room of this project this amounted to supply air $0.106 \mathrm{~m}^{3} / \mathrm{s}(225 \mathrm{cfm})$. This slot was also used for the medium and the open plan rooms at the same flow rate per unit of floor area.

In summary, the desired values for the slot diffuser were:

$\begin{array}{lll}\text { Throw to } 0.75 \mathrm{~m} / \mathrm{s} & L_{.75} & 1.5 \mathrm{~m}(5 \mathrm{ft}) \\ \text { Slot Length } & L & 1.18 \mathrm{~m}(3.9 \mathrm{ft}) \\ \text { Volumetric Flow } & G & 0.106 \mathrm{~m}^{3} / \mathrm{s}(225 \mathrm{cfm})\end{array}$

The CFD model was used to find the other values of the supply slot as described below. It is the nature of a CFD model that geometry and boundary conditions are specified, and the model calculates the flows at each cell. For the small room of this project, simulations were made with values of $L, h, V_{x}$ and $V_{z}$ specified, and the output was examined to determine $L_{.5}$ and $L_{.75}$ resulting from the specified values. Slot widths, $h$, were considered from 0.06 to $0.10 \mathrm{~m}$ (2.36 to $3.94 \mathrm{in}$ ). For each slot width, $V_{z}$ was calculated as $V_{z}=G /(L h)$, and simulations were made for values of $V_{x}$ representing discharge angles, $\theta$, from $30^{\circ}$ to $45^{\circ}$ using equation (2).

A number of CFD simulations were required to determine that values of $\theta=39^{\circ}$ and $h=0.08 \mathrm{~m}$ (3.1 in) resulted in the desired $L_{.75}$. These simulations were in the small room with return arrangement 1 . Table $\mathrm{Cl}$ compares the throw from this idealized slot diffuser with two commercial diffusers all with the same values of $L$ and $G$. The differences between the throws of the commercial and idealized diffusers is $-7 \%$ and $6 \%$ for $L_{.5}$ and $-27 \%$ and $-5 \%$ for $L_{.75}$. This level of agreement indicates that the throws of the idealized diffuser can be considered in the range of throws that could occur from commercial slot diffusers. 
Lack of data for slot diffusers prevented detailed comparison of the CFD simulated jet with experimental data. However, the general trends of the CFD simulated jet from the above slot diffuser agrees with observed trends of jets from other types of diffusers based on experimental data. The experimental data shown in figure $\mathrm{C} 3(\mathrm{a})$ and (b) shows that for HVAC jets adjacent to surfaces (walls or ceilings) [11]:

(a) the maximum velocity, $V_{\max }$, decreases with distance, $x$, from the diffuser,

(b) at any distance, $x$, from the diffuser, the maximum velocity, $V_{\max }$, is near the surface, and

(c) the thickness of the jet [dashed lines in figure C3 (a) and (b)] increases with distance, $x$, from the diffuser.

The CFD simulated jet from the idealized slot diffuser of this project shows that same trends, as shown in figure $\mathrm{C} 3(\mathrm{c})$.

The light troffers were modeled in the same way as the slot diffuser. The troffers were also $1.18 \mathrm{~m}$ (3.9 $\mathrm{ft}$ ) long, and they had a flow rate of $0.0236 \mathrm{~m}^{3} / \mathrm{s}(50 \mathrm{cfm})$. A value of $0.4 \mathrm{~m}(1.3 \mathrm{ft})$ was selected as a conservative value of the $0.75 \mathrm{~m} / \mathrm{s}(150 \mathrm{fpm})$ throw for this troffer. In the same manner as the slot diffusers, a number of CFD simulations were made to find that values of $\theta=21^{\circ}$ and $h=0.03 \mathrm{~m} \mathrm{(1.1}$ in) resulted in the desired throw. Comparison with the throws of a commercial troffer shows much larger differences than those of the slot diffusers (table C1). The difficulty in getting better agreement could be a basic limitation of the idealized diffuser model presented in this appendix. However, the idealized troffer jet is a longer jet than that of the commercial troffer. Considering that flow of the troffers was $22 \%$ of that from the slot diffusers, it seems that the main detection challenge was due to the slots, and that the troffers were included in the simulations to account for the relatively small level detection interference they would produce. Further, it should be noted that the trends of jet flows attached to surfaces discussed above also occurred for the idealized troffer jet. 


\section{References}

[1] Horace, H. and Nakamura, Y. Room Airflow Analysis by Means of Differential Stress Model, International Symposium on Room Air Convection and Ventilation Effectiveness, ASHRAE, Atlanta, GA, pp 153-162, 1992.

[2] Chow, W.K. and Fung, W.Y., Indoor Aerodynamics and Ventilation Design in Large Enclosed Spaces, International Symposium on Room Air Convection and Ventilation Effectiveness, ASHRAE, Atlanta, GA, pp 87-97, 1992.

[3] Kato, S., Murakami, S. and Kobayashi, H., New Scales for Evaluating Ventilation Efficiency as Affected by Supply and Exhaust Openings Based on Spatial Distribution of Contaminant, International Symposium on Room Air Convection and Ventilation Effectiveness, ASHRAE, Atlanta, GA, pp 177-186, 1992.

[4] Matsumoto, M., Hokol, S. and Hanibuchi, H., A Study of the Differential Reynolds Stress Model for Application to Airflow in a Room, International Symposium on Room Air Convection and Ventilation Effectiveness, ASHRAE, Atlanta, GA, pp 163-170, 1992.

[5] Nielsen, P.V., Stratified Flow in a Room With Displacement Ventilation and Wall-Mounted Air Terminal Devices, ASHRAE Transactions, Vol 100, Part 1, 1994.

[6] Skovgaard, M. and Nielsen, P.V., Modelling Complex Inlet Geometries in CFD - Applied to Air Flow in Ventilated Rooms, IET Paper No. 21, Aalborg Univ., Aalborg Denmark, 1991.

[7] Oakes, W.C., Experimental investigation of a Coanda jet, MS Thesis, Michigan State Univ, 1987.

[8] Straub, H. Telephone Conversation with John Klote, TITUS, Richardson TX, 1995.

[9] ASHRAE, Chapter 31: Space Air Diffusion, Fundamentals Handbook, American Society of Heating and Air-Conditioning Engineers, Atlanta, GA, 1993.

[10] Straub, H. Engineering Data: Grills, Registers, Diffusers, Terminals, Catalog T49, TITUS, Richardson TX, 1994.

[11] Tuve, G.L. Air Velocities in Ventilating Jets, ASHVE (predecessor society to ASHRAE) Transactions, Vol 59, 1953, pp 261-282. 
Table C1. Comparison of throws for commercial and idealized diffusers

\begin{tabular}{|l|ccc|crc||}
\hline & \multicolumn{2}{|c|}{ Throw to $0.75 \mathrm{~m} / \mathrm{s}(150 \mathrm{fpm}), L_{.75}$} & \multicolumn{2}{|c|}{ Throw to $0.5 \mathrm{~m} / \mathrm{s}(100 \mathrm{fpm}), L_{.5}$} \\
Diffuser Type & $\mathrm{m}$ & $\mathrm{ft}$ & Difference $^{\ddagger}$ & $\mathrm{m}$ & $\mathrm{ft}$ & Difference $^{\ddagger}$ \\
\hline \hline Commercial Slot A & 1.4 & 4.6 & $-7 \%$ & 2.9 & 9.5 & $-27 \%$ \\
Commercial Slot B & 1.6 & 5.2 & $6 \%$ & 3.5 & 11.5 & $-5 \%$ \\
Idealized Slot & 1.5 & 4.9 & $\mathrm{NA}$ & 3.7 & 12.1 & $\mathrm{NA}$ \\
Commercial Troffer & 0.6 & 2.0 & $33 \%$ & 0.9 & 3.0 & $-55 \%$ \\
Idealized Troffer & 0.4 & 1.3 & $\mathrm{NA}$ & 1.4 & 4.6 & $\mathrm{NA}$ \\
\hline
\end{tabular}

"Throw data for the commercial diffusers is from manufacturers catalogs and from CFD simulations for the idealized diffusers.

FThe difference is the throw of idealized from that of the commercial damper, which is $\left(L_{v c}-L_{v i}\right) / L_{v c}$ where subscripts $c, I$ and $v$ represent commercial, idealized and velocity respectively. 

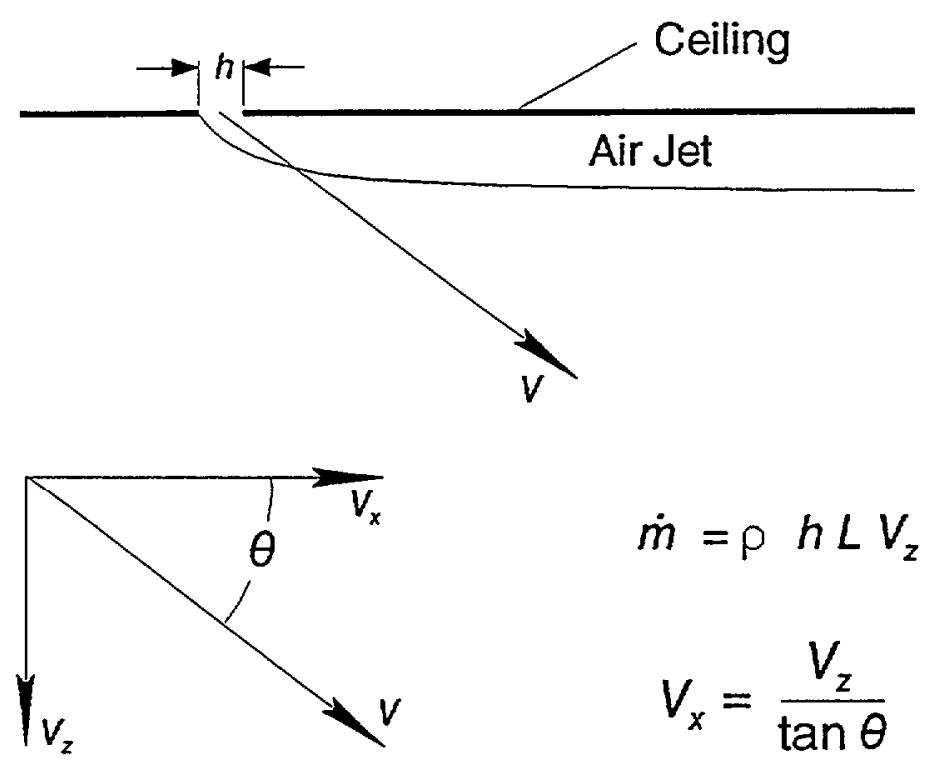

$$
\begin{gathered}
\dot{m}=\rho h L V_{z} \\
V_{x}=\frac{V_{z}}{\tan \theta}
\end{gathered}
$$

Figure C1. Idealized slot flow model

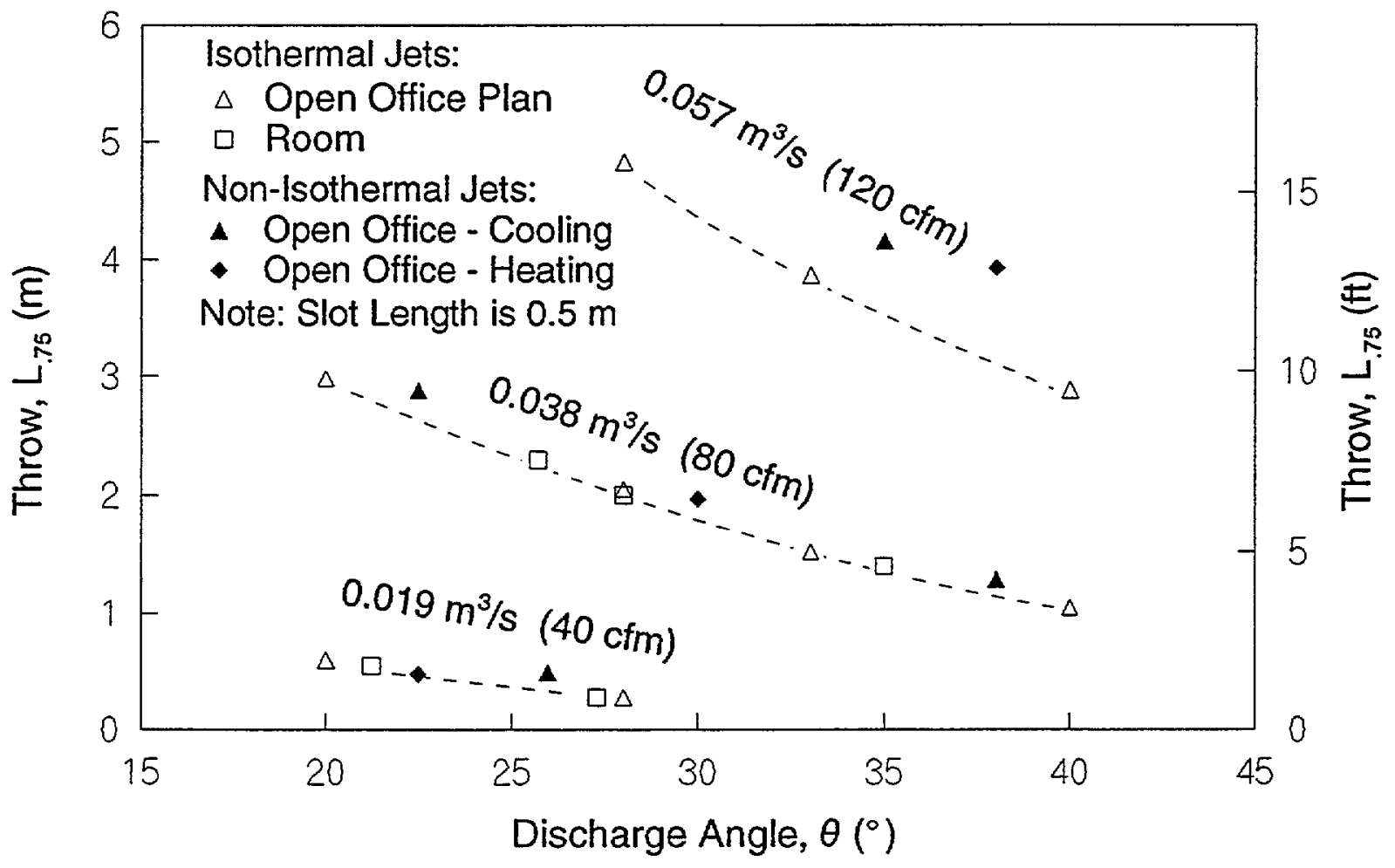

Figure C2. Effect of discharge angle on the $0.75 \mathrm{~m} / \mathrm{s}(150 \mathrm{fpm})$ throw 


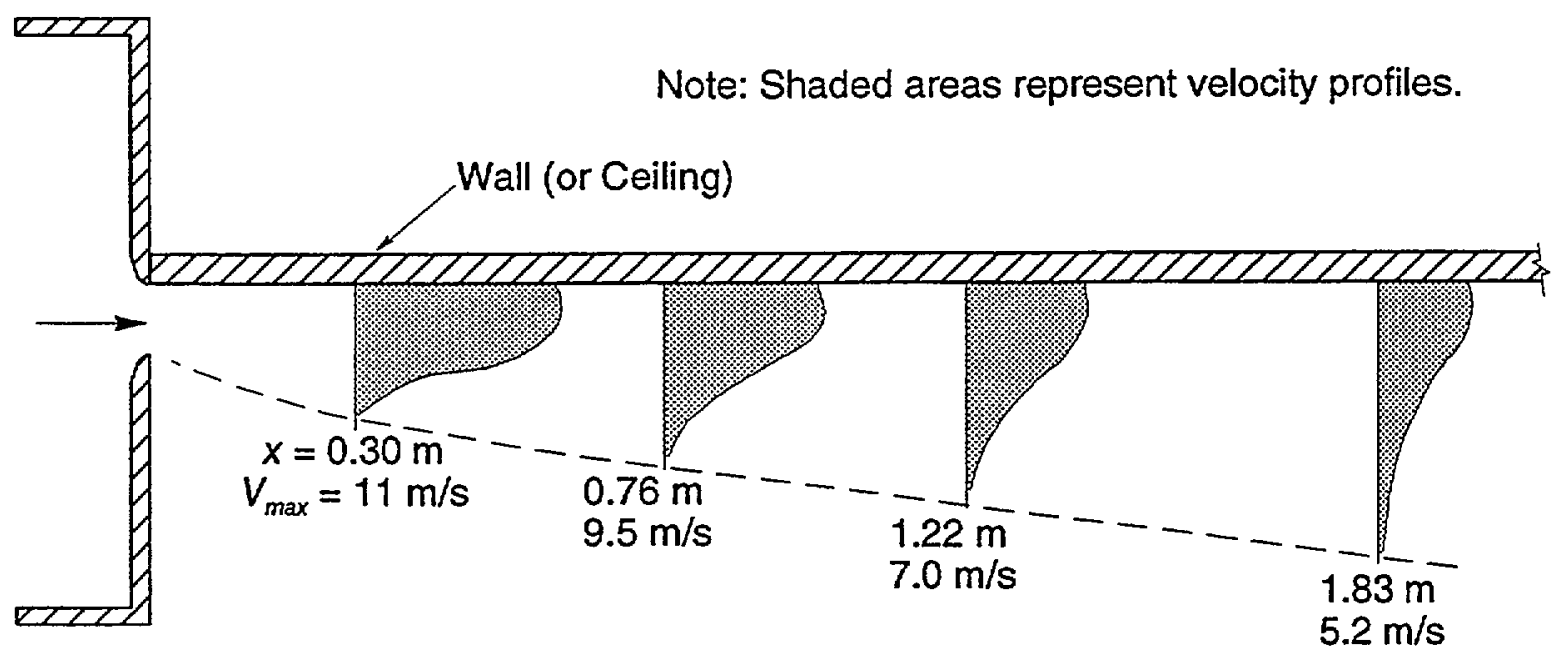

(a) Measured velocity for square outlet (Tuve 1953)

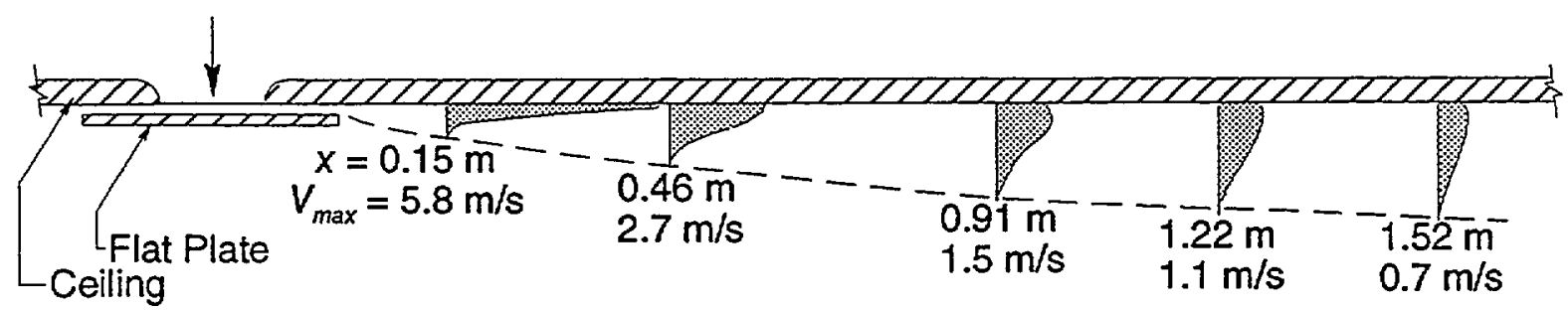

(b) Measured velocity for double slot outlet (Tuve 1953)

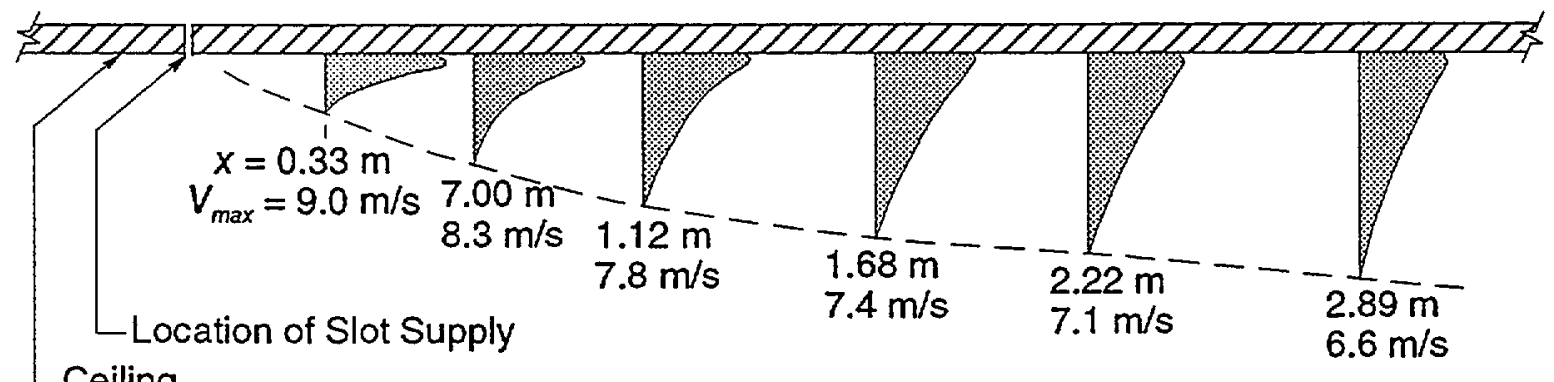

(c) Velocity claculated by CFD model for idealized slot supply

Figure C3. Velocity profiles of air jets attached to surfaces 


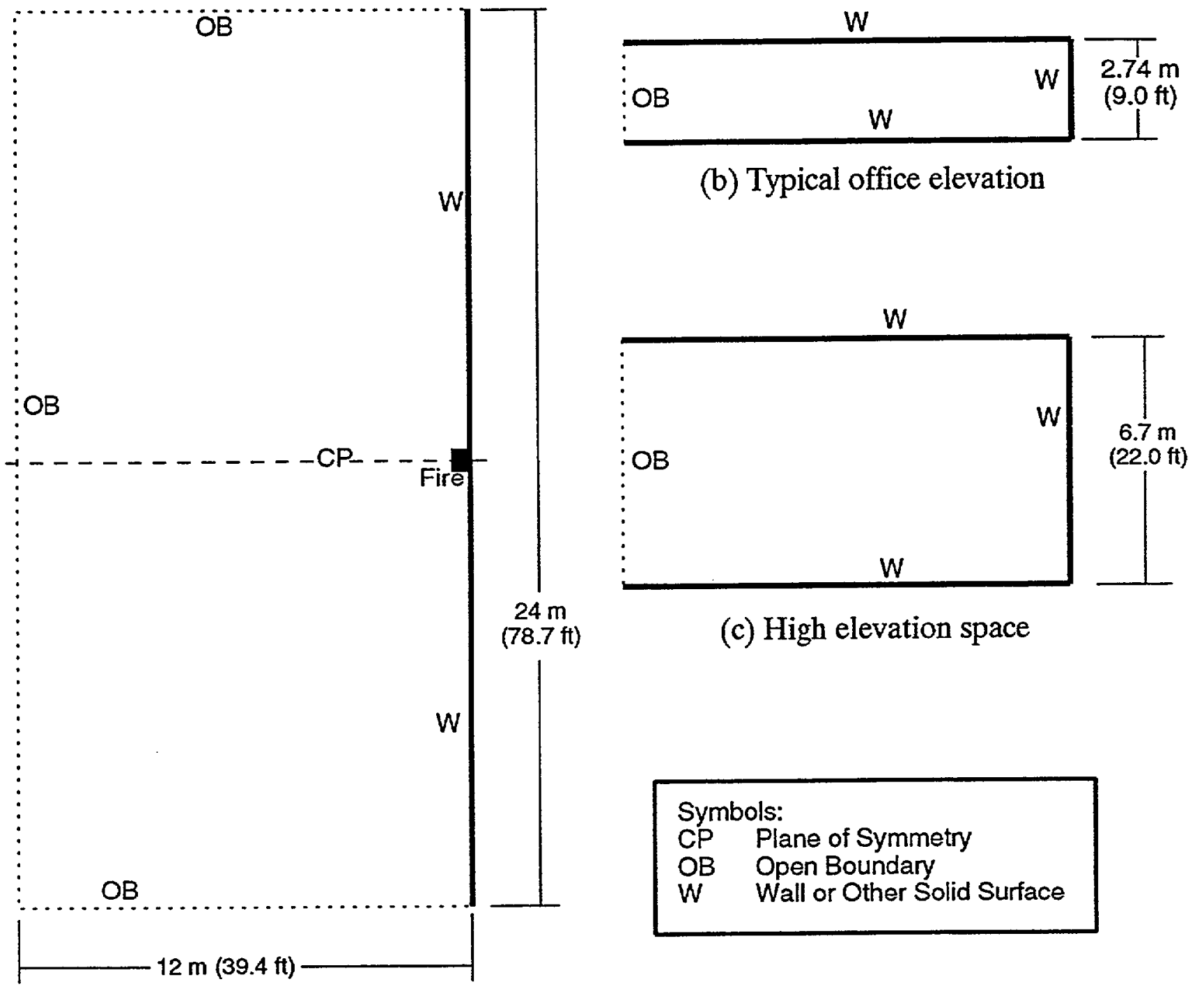

(a) Plan for both elevations

Figure 1: Layout of mass density calibration simulations 


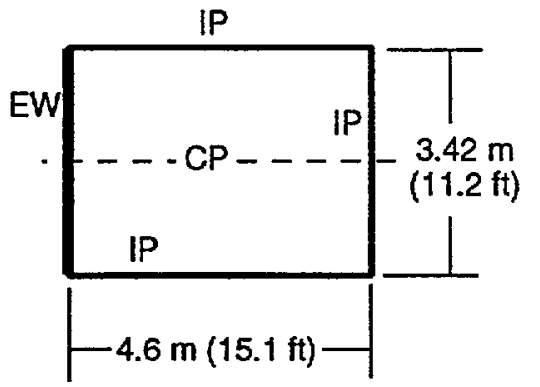

(a) Small room

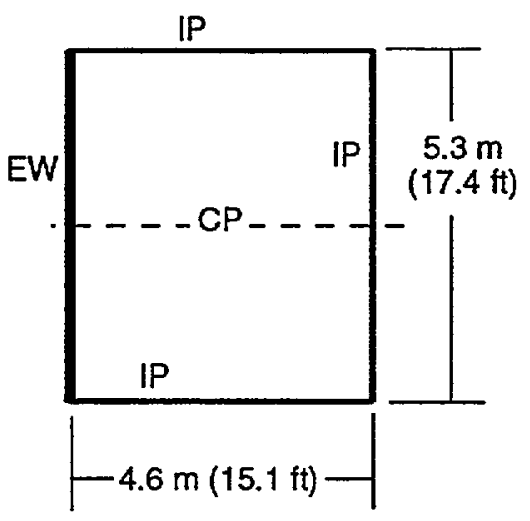

(b) Medium room

$$
\begin{array}{ll}
\multicolumn{3}{l}{\text { Symbols: }} \\
\text { CP } & \text { Plane of Symmetry } \\
\text { EW } & \text { Exterior Wall } \\
\text { IP } & \text { Interior Partition } \\
\text { OB } & \text { Open Boundary }
\end{array}
$$

Note: Floor to ceiling height is $2.74 \mathrm{~m}(9.0 \mathrm{ft})$ for all rooms.

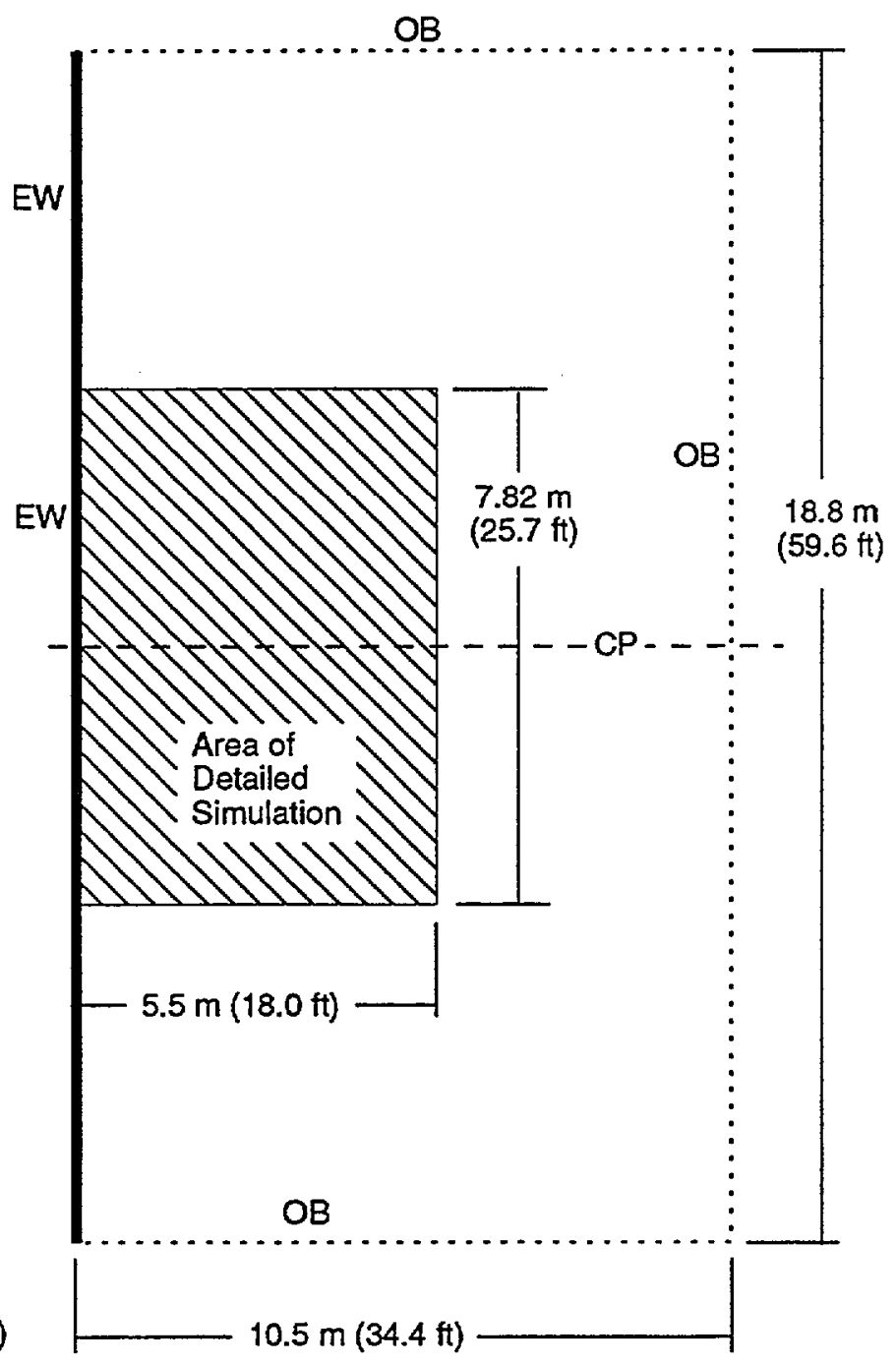

(c) Open plan room

Figure 2: Plans of rooms for detector activation simulations 


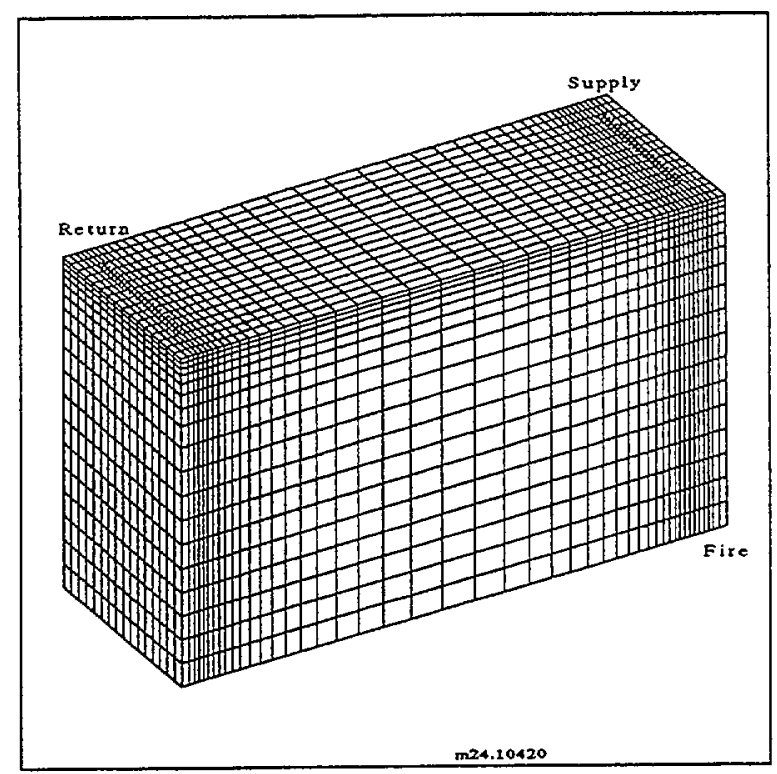

(a) small room

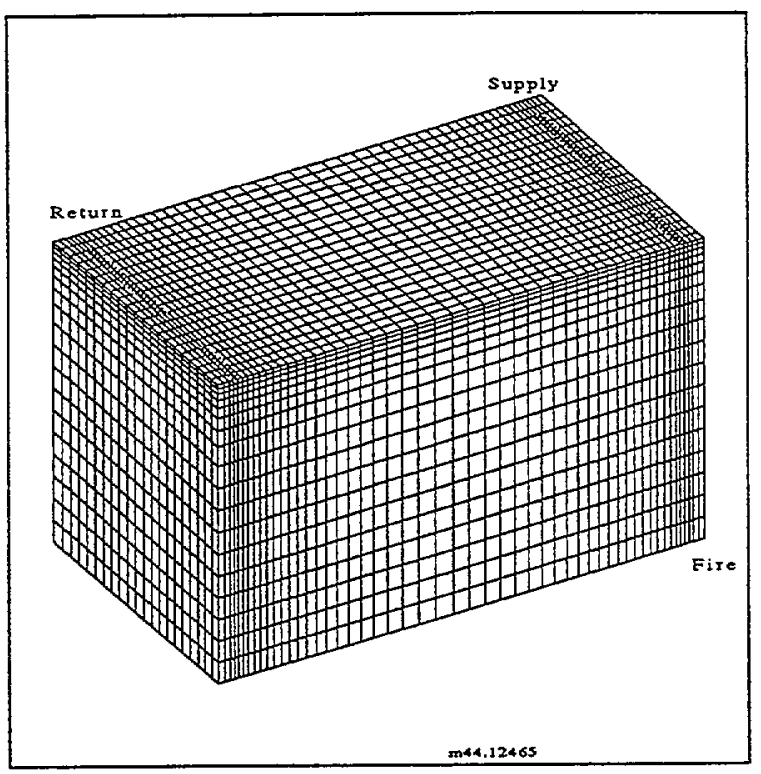

(b) medum room

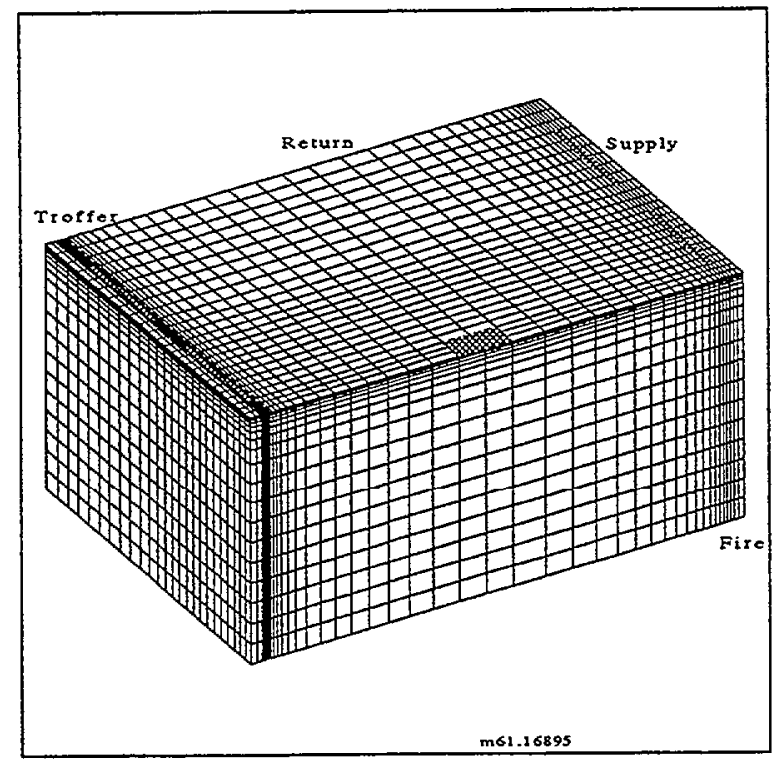

(c) open plan room

Figure 3: Grids typical of those used for simulations 


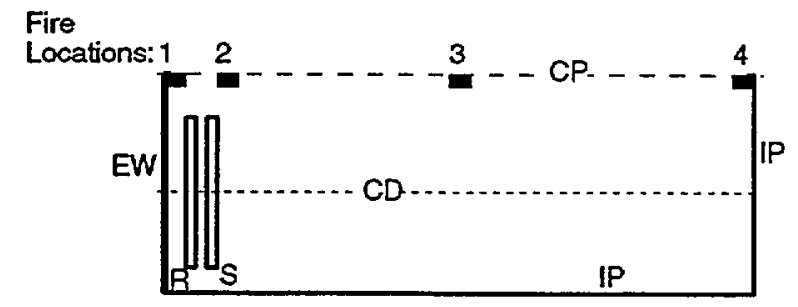

(a) Return arrangement 1

Fire

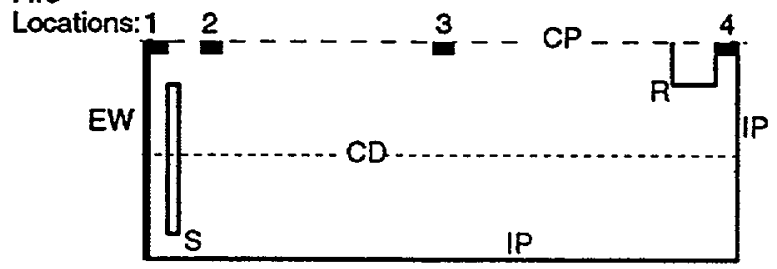

(c) Return arrangement 3
Fire

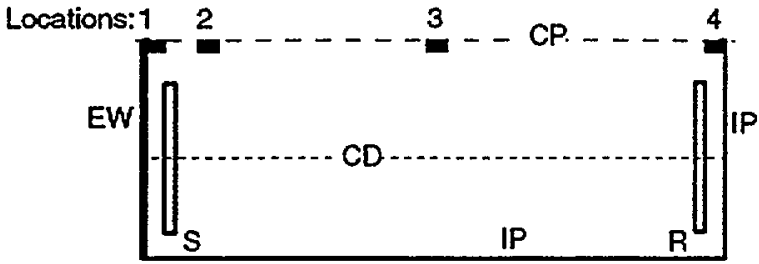

(b) Return arrangement 2

\begin{tabular}{|ll|}
\hline \multicolumn{2}{|l|}{ Symbols: } \\
CD & Centertine of Diffuser \\
CP & Plane of Symmetry \\
EW & Exterior Wall \\
IP & Interior Partition \\
R & Heating \& Cooling Retum \\
S & Heating \& Cooling Supply \\
\hline
\end{tabular}

Figure 4: Small room plans showing location of fires and supply and return arrangements

\begin{tabular}{|llll|}
\hline Symbols: & & \\
CD & Centerline of Diffuser & IP & Interior Partition \\
CP & Plane of Symmetry & R & Heating \& Cooling Return \\
EW & Exterior Wall & S & Heating \& Cooling Supply \\
\hline
\end{tabular}

Fire

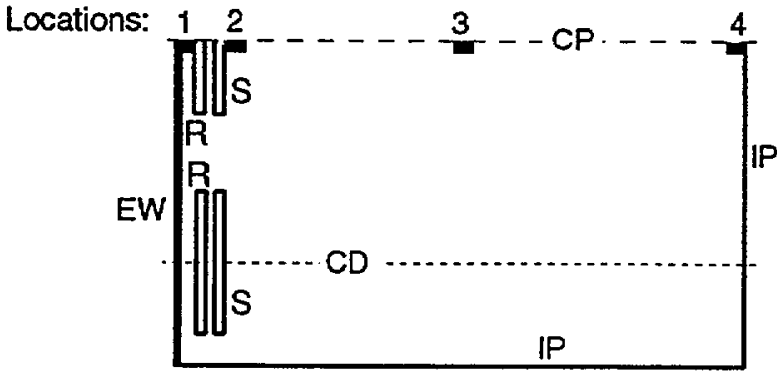

(a) Return arrangement 1
Fire

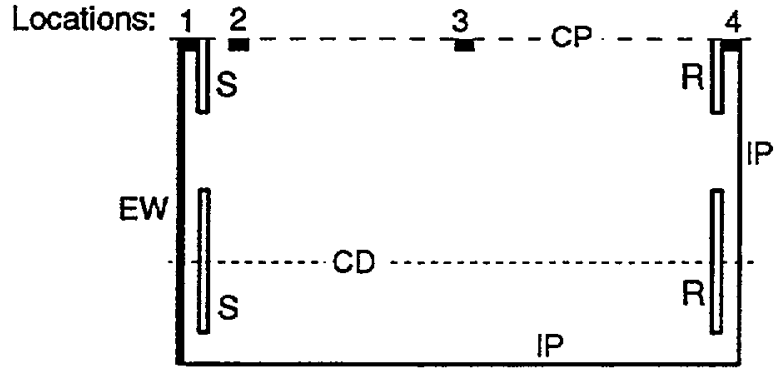

(b) Return arrangement 2

Figure 5: Medium room plans showing location of fires and supply and return arrangements 


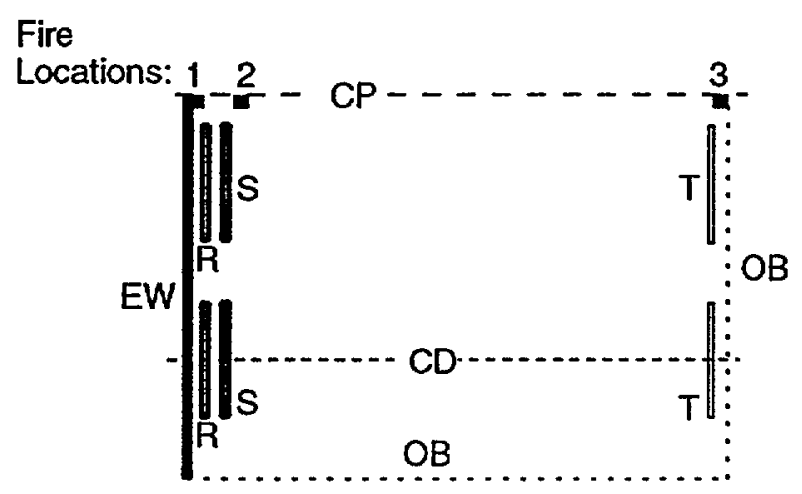

(a) Return arrangement 1

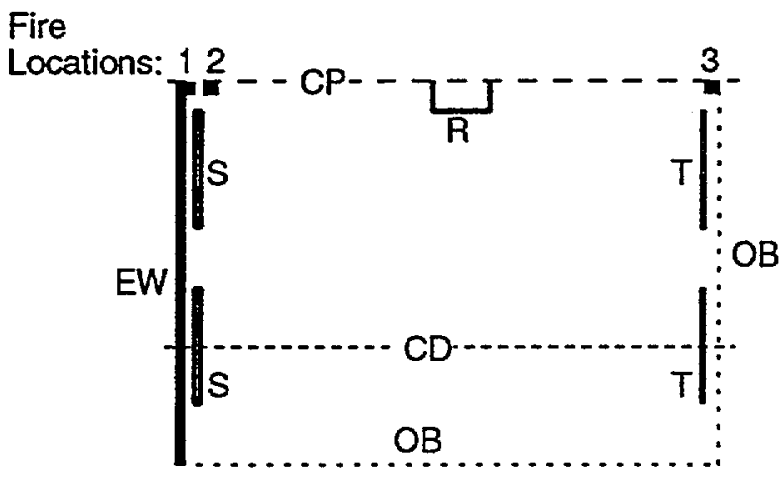

(b) Return arrangement 2

Fire

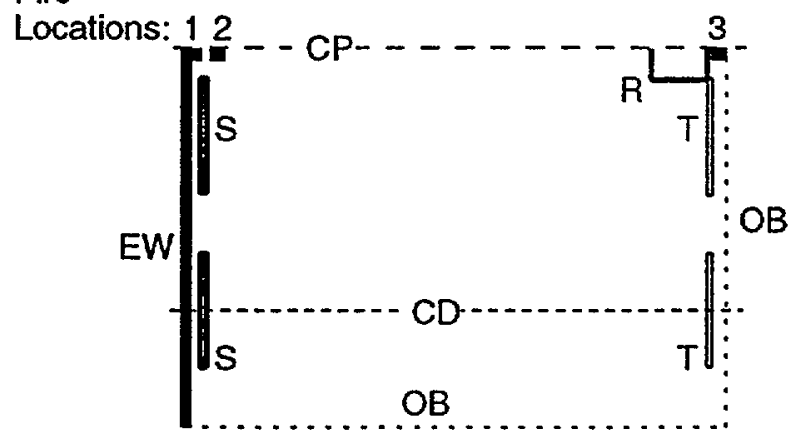

\begin{tabular}{ll}
\hline \multicolumn{2}{l}{ Symbols: } \\
CD & Centerline of Diffuser \\
CP & Plane of Symmetry \\
EW & Exterior Wall \\
IP & Interior Partition \\
OB & Open Boundary \\
R & Heating \& Cooling Return \\
S & Heating \& Cooling Supply \\
T & Heating \& Cooling Troffer
\end{tabular}

(c) Return arrangement 3

Figure 6: Open plan room plans (detailed area only) showing location of fires and and supply and return arrangements 


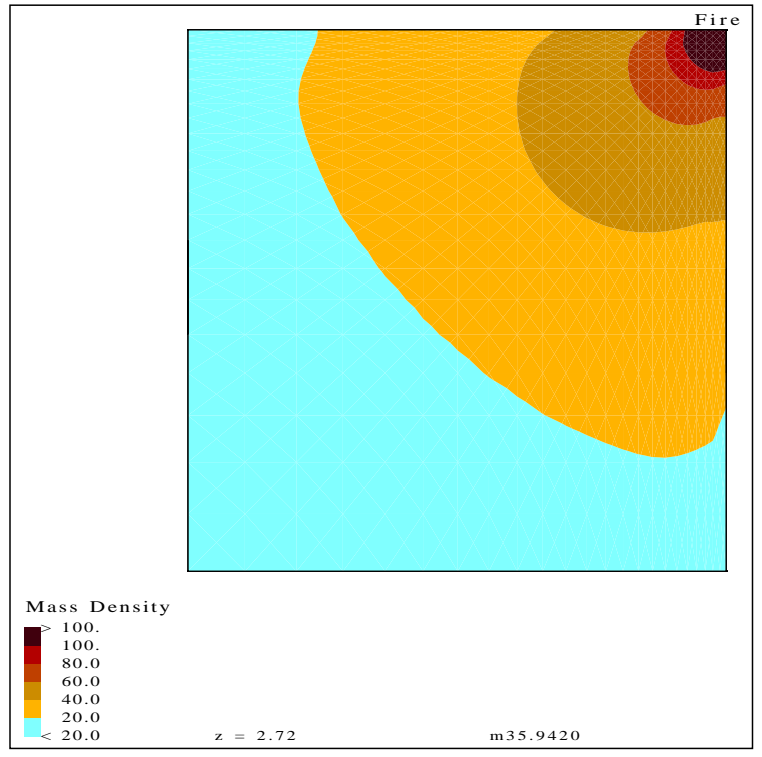

(a) At $0.02 \mathrm{~m}$ ( 0.79 in) below the ceiling

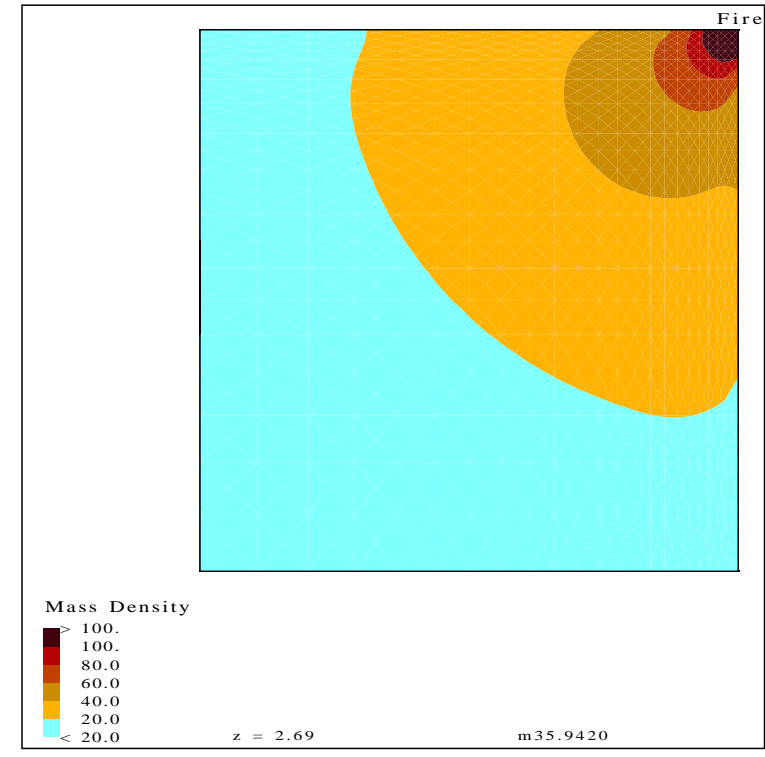

(b) At $0.05 \mathrm{~m}$ ( 2.0 in) below the ceiling

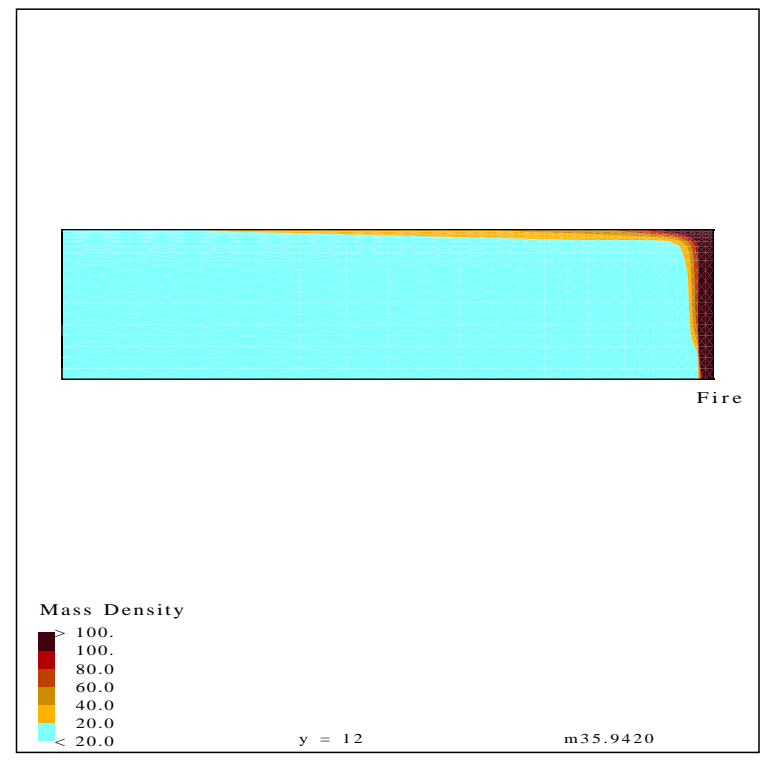

(c) At the plane of symmetry

Figure 7: Simulated mass density at $100 \mathrm{~kW}$ from the first mass density calibration (run 1) 


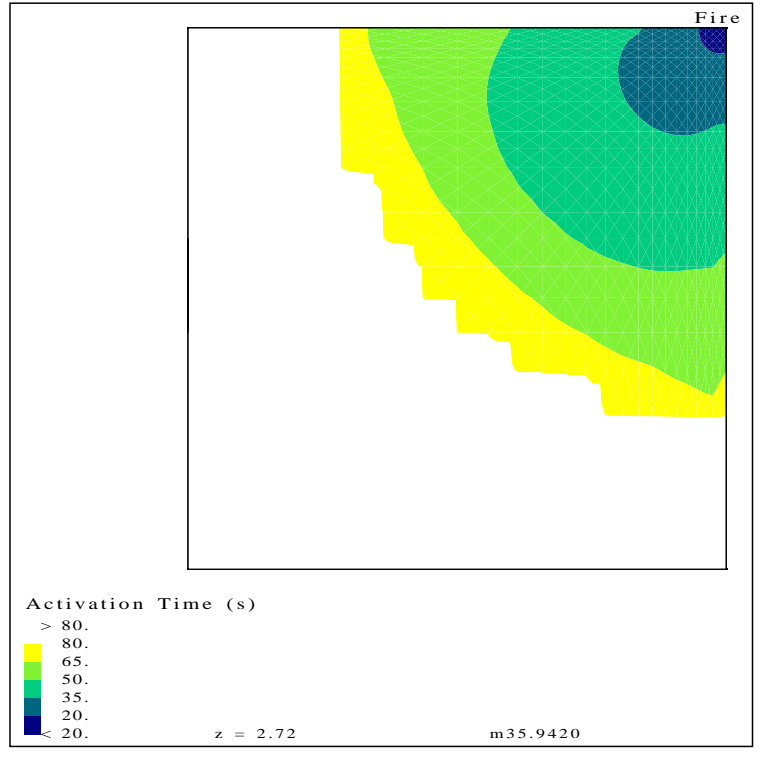

(a) At $0.02 \mathrm{~m}$ ( 0.79 in) below the ceiling

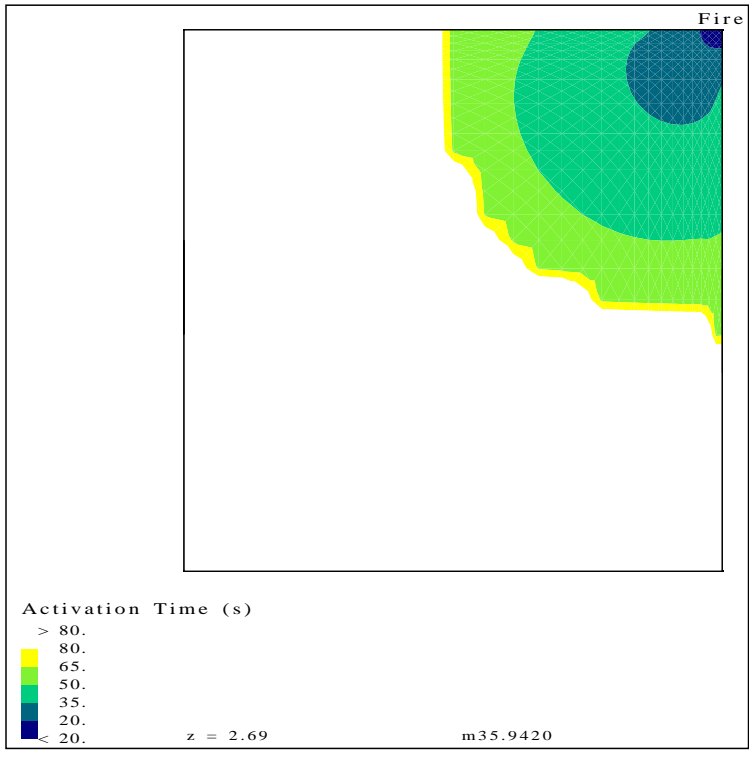

(b) At $0.05 \mathrm{~m}$ (2.0 in) below the ceiling

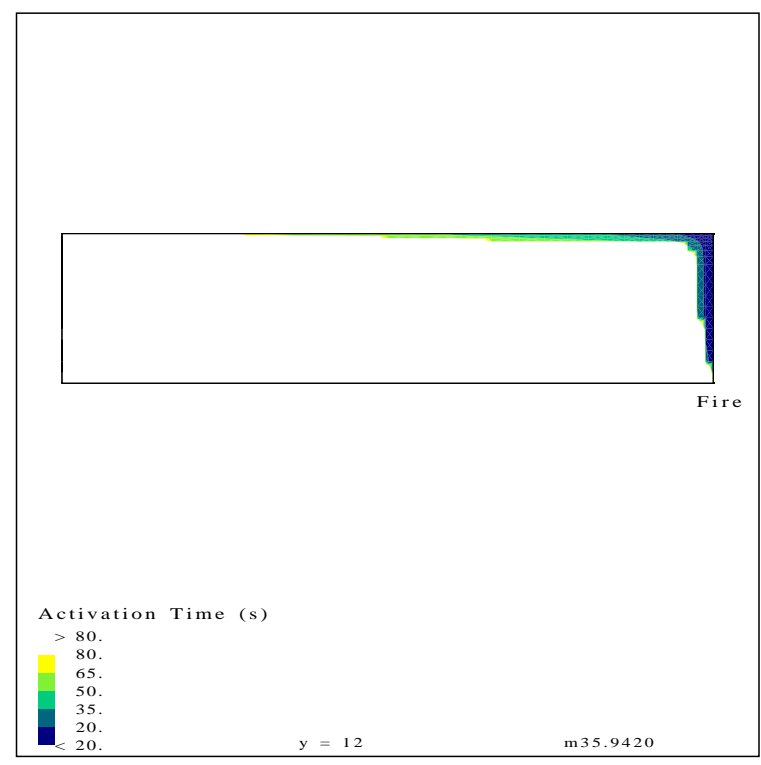

(c) At the plane of symmetry

Figure 8: Simulated activation time from the first mass density calibration run (run 1) 


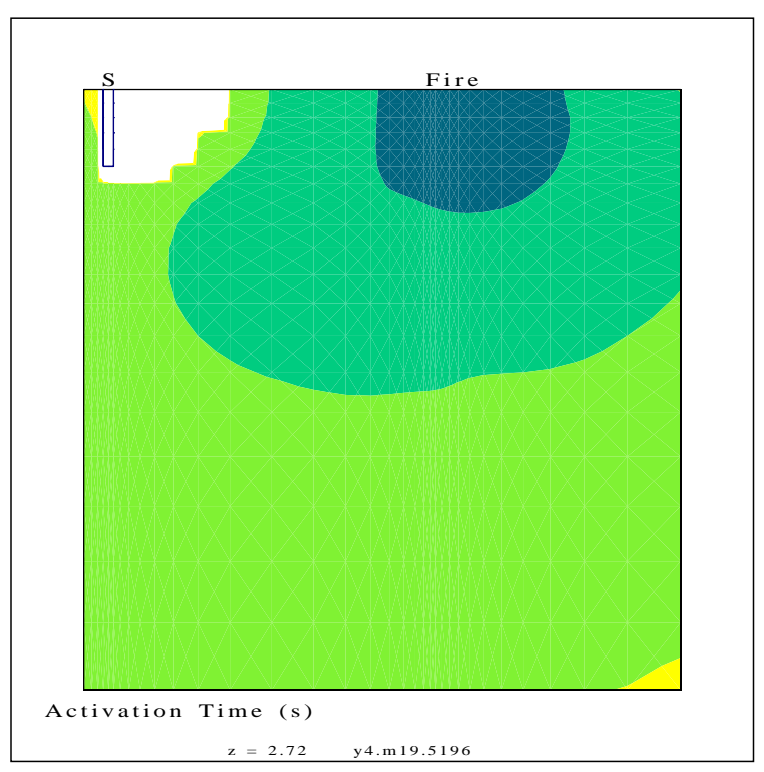

(a) At $0.02 \mathrm{~m}$ (0.79 in) below the ceiling

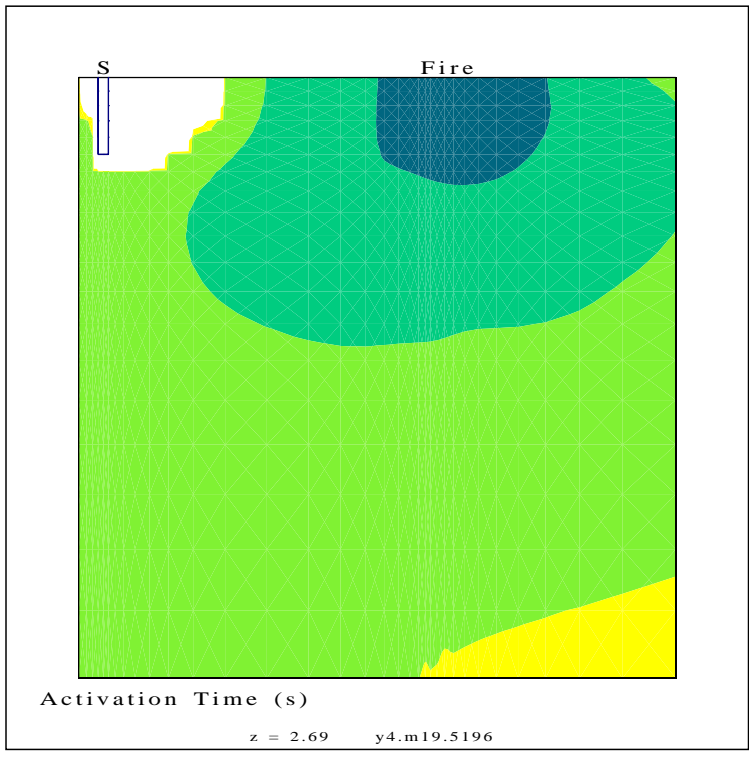

(b) At $0.05 \mathrm{~m}$ (2.0 in) below the ceiling

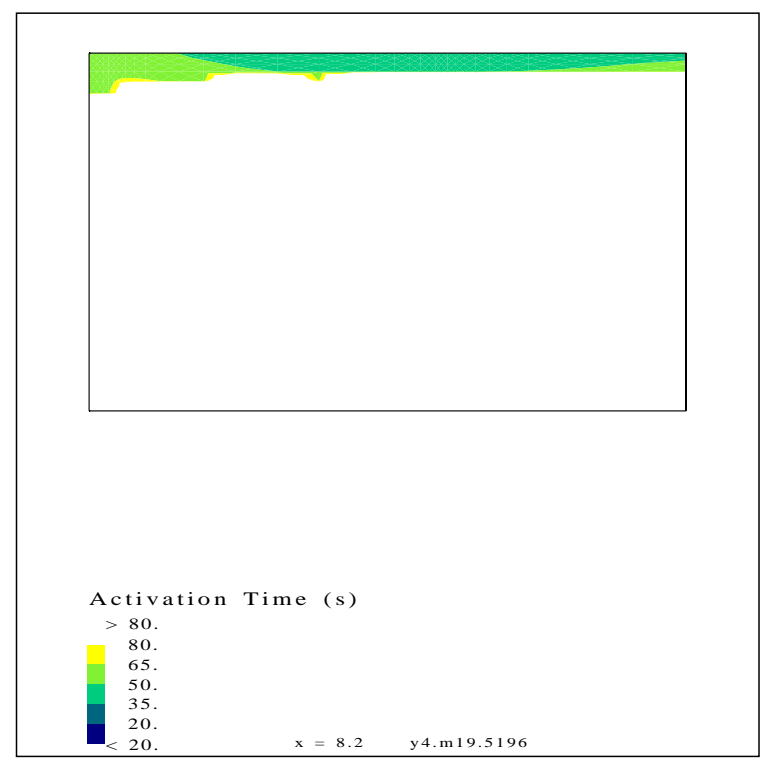

(c) At the plane of symmetry

Figure 9: Simulated mass density at activation time from the first mass density calibration (run 1) 


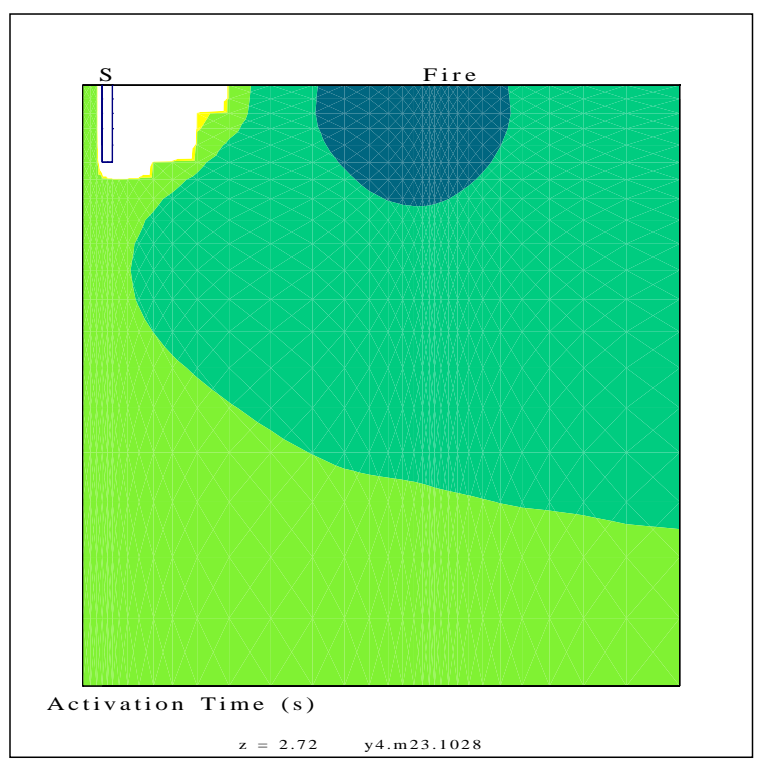

(a) At $0.02 \mathrm{~m}(0.79 \mathrm{in})$ below the ceiling

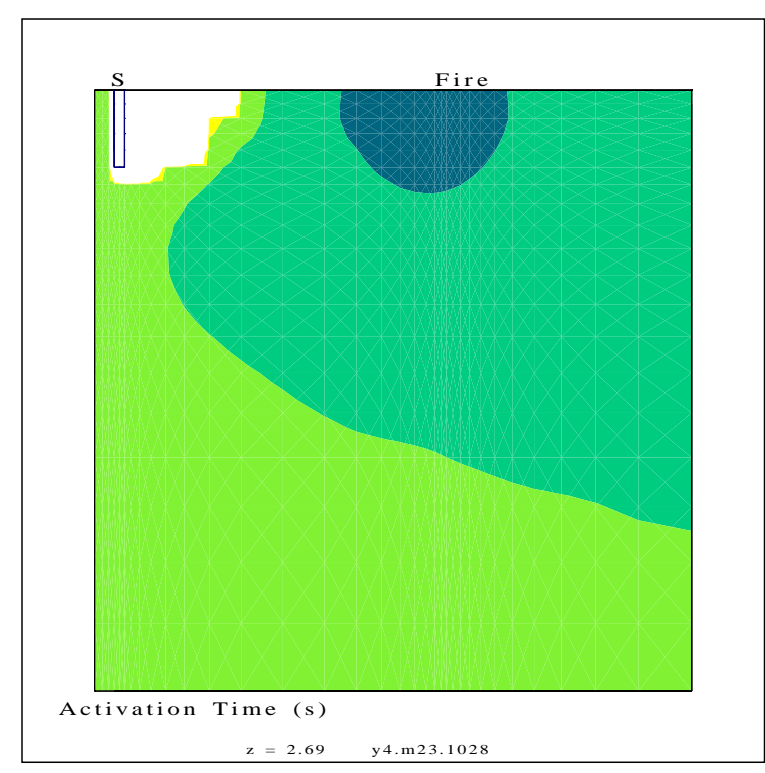

(b) At $0.05 \mathrm{~m}$ ( 2.0 in) below the ceiling

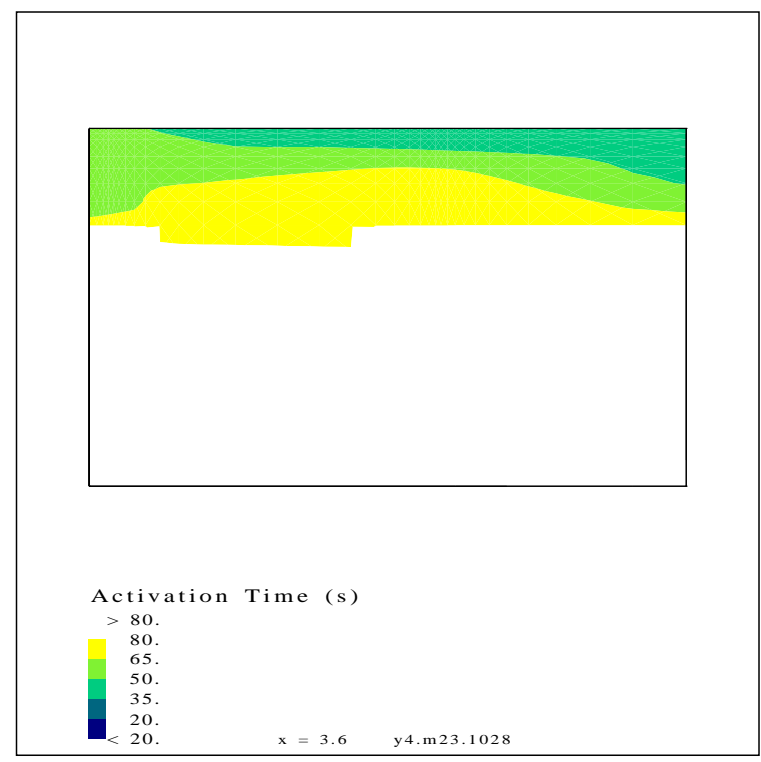

(c) At the plane of symmetry

Figure 10: Simulated mass density at activation time from the second mass density calibration (run 2) 


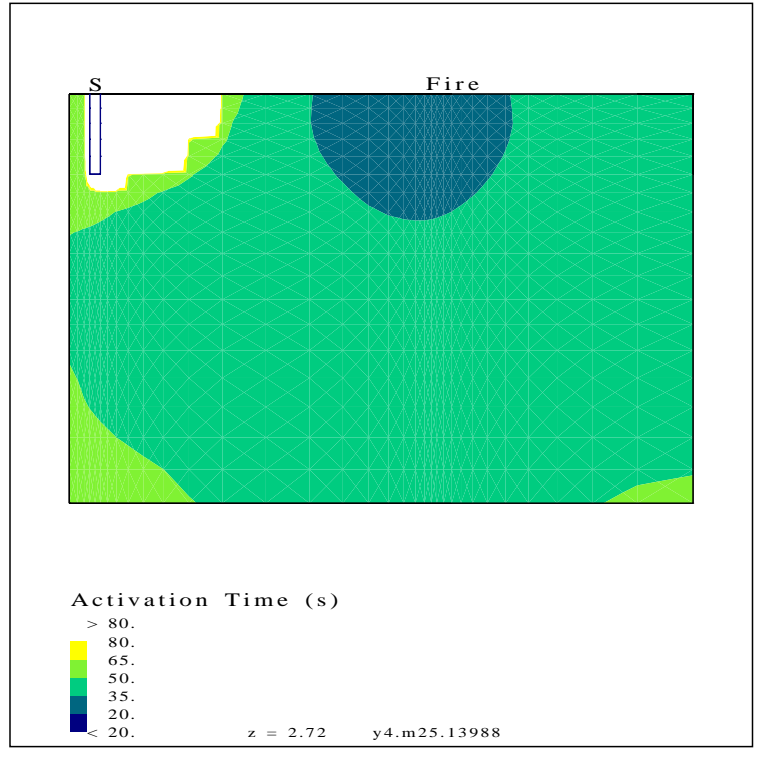

(a) At $0.02 \mathrm{~m}$ (0.79 in) below the ceiling

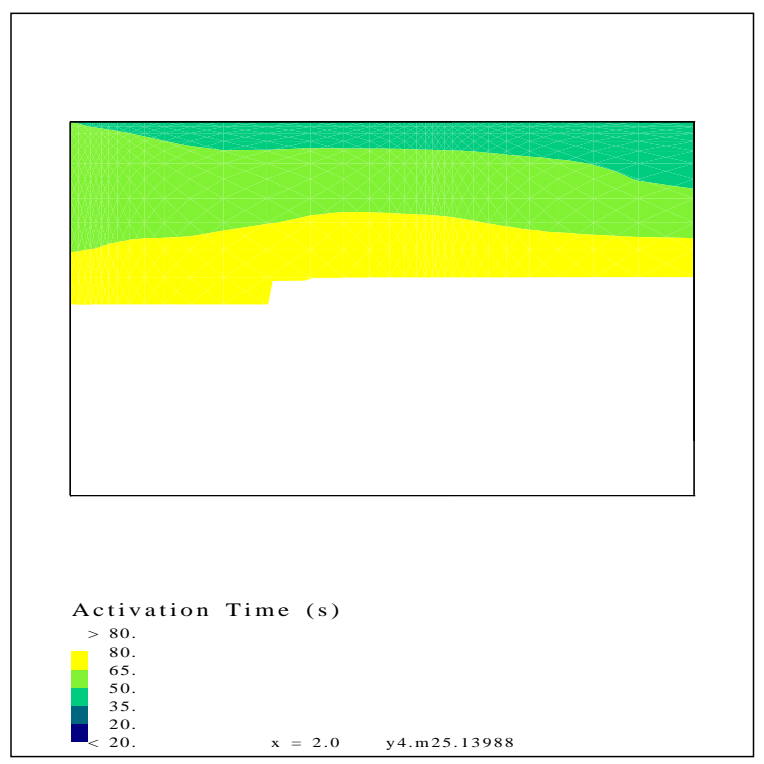

(c) Centerline of the diffuser

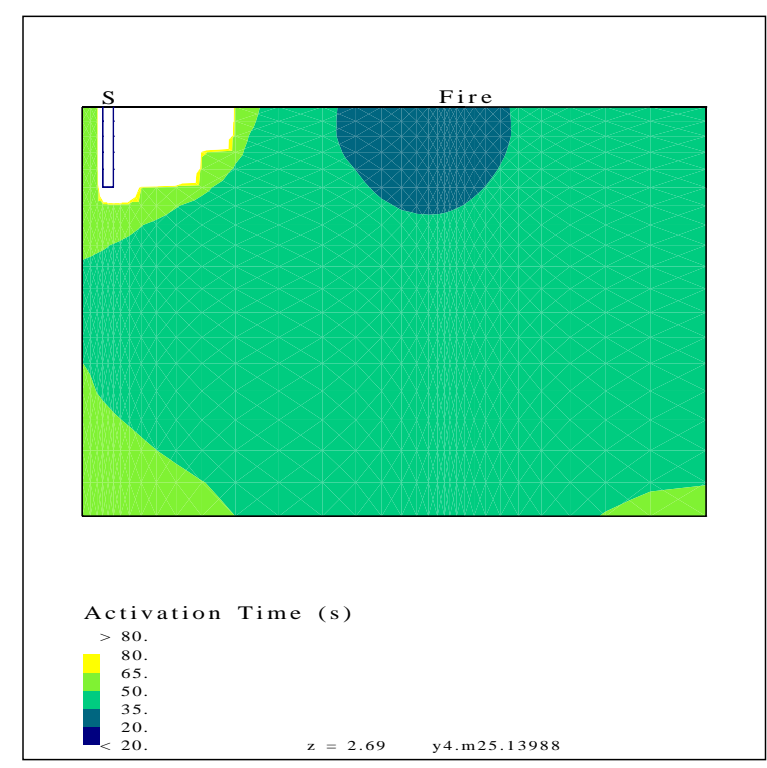

(b) At $0.05 \mathrm{~m}$ (2.0 in) below the ceiling

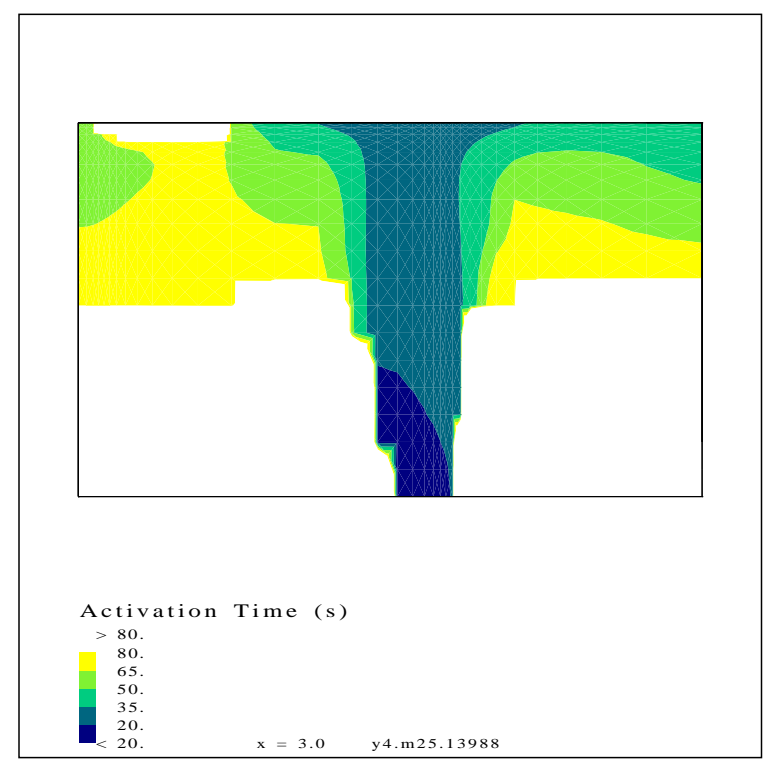

(d) Plane of symmetry

Figure 11: Simulated activation time in the small room from run 3.

Note: See figure 4 for the location of the plane of symmetry and the plane at the centerline of the diffuser. 


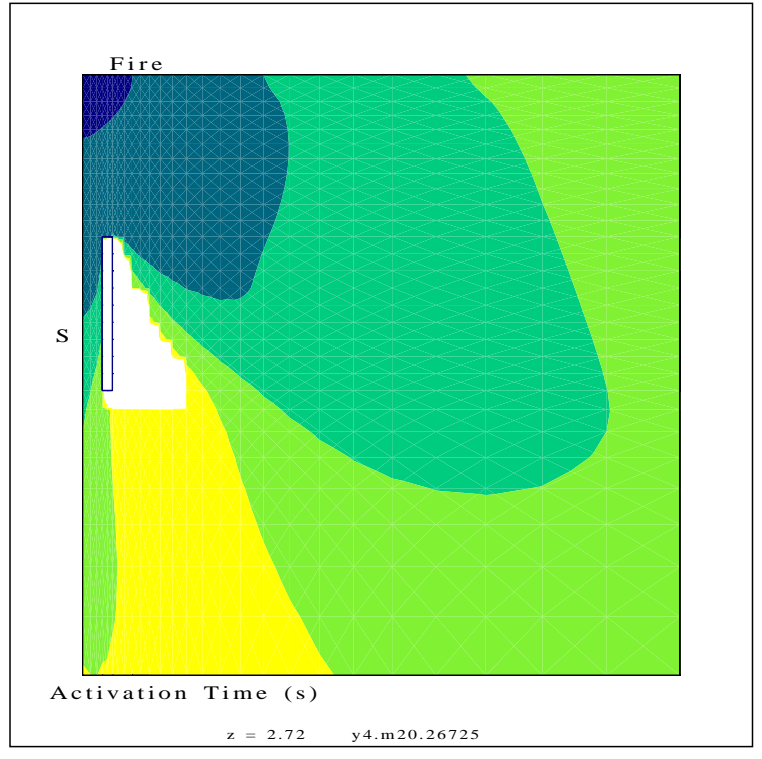

(a) At $0.02 \mathrm{~m}$ (0.79 in) below the ceiling

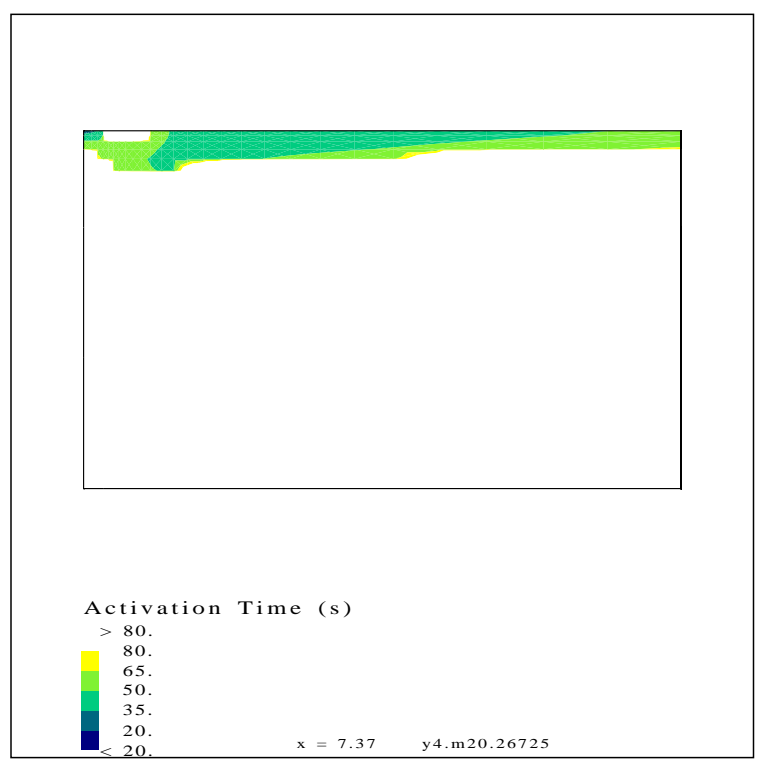

(c) Centerline of the diffuser

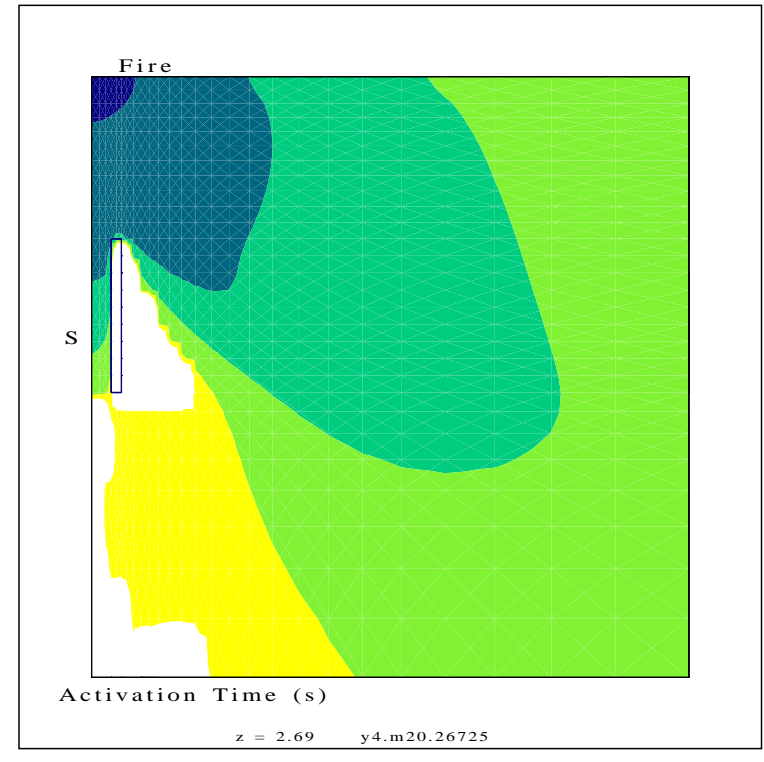

(b) At $0.05 \mathrm{~m}$ (2.0 in) below the ceiling

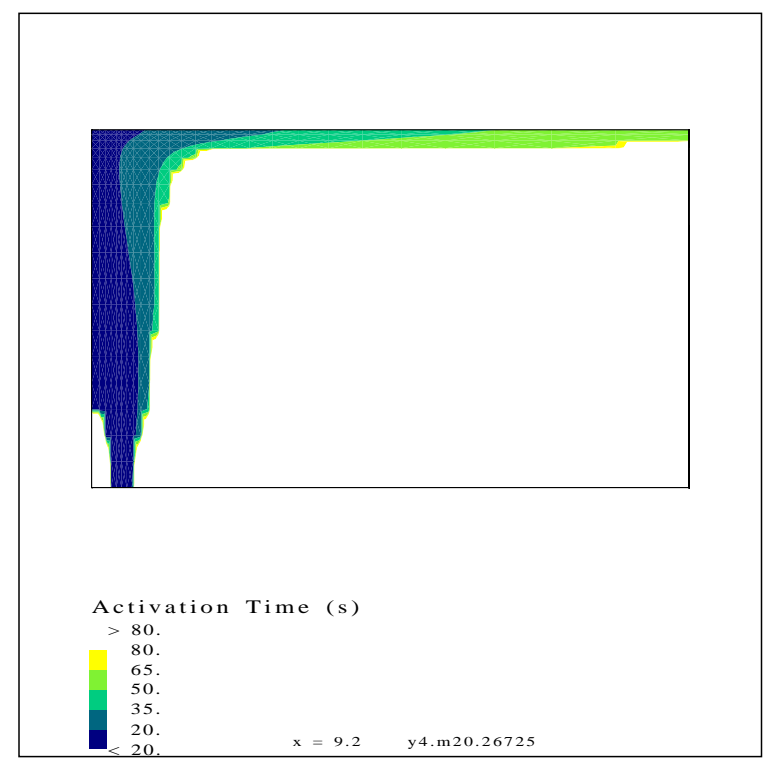

(d) Plane of symmetry

Figure 12: Simulated activation time in the small room from run 4.

Note: See figure 4 for the location of the plane of symmetry and the plane at the centerline of the diffuser. 


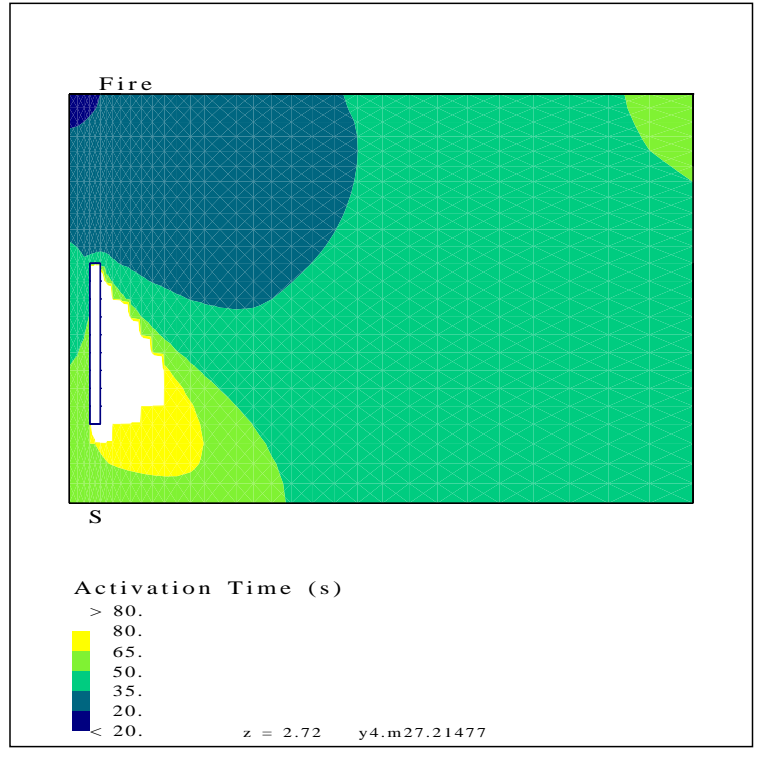

(a) At $0.02 \mathrm{~m}$ (0.79 in) below the ceiling

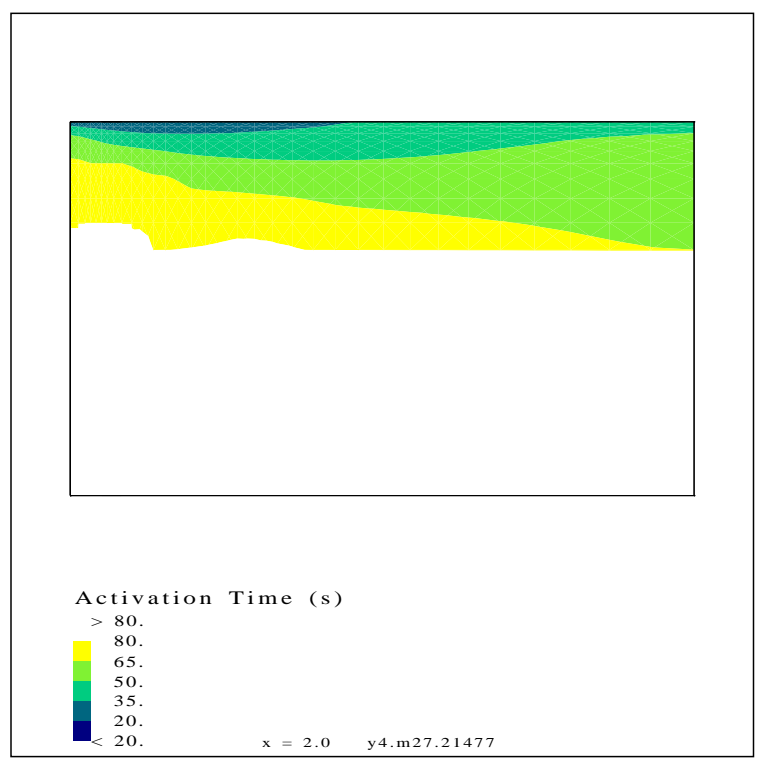

(c) Centerline of the diffuser

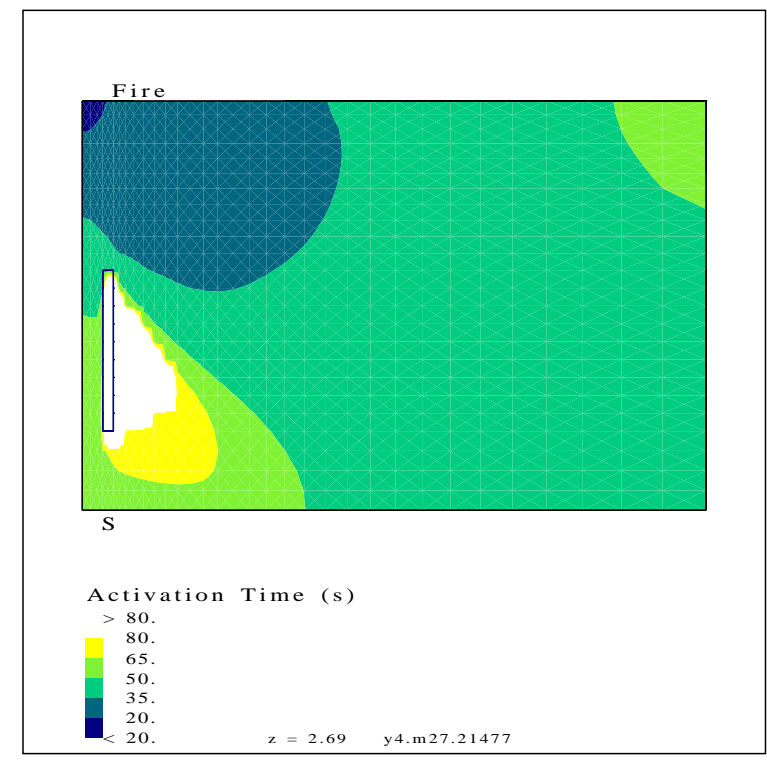

(b) At $0.05 \mathrm{~m}$ (2.0 in) below the ceiling

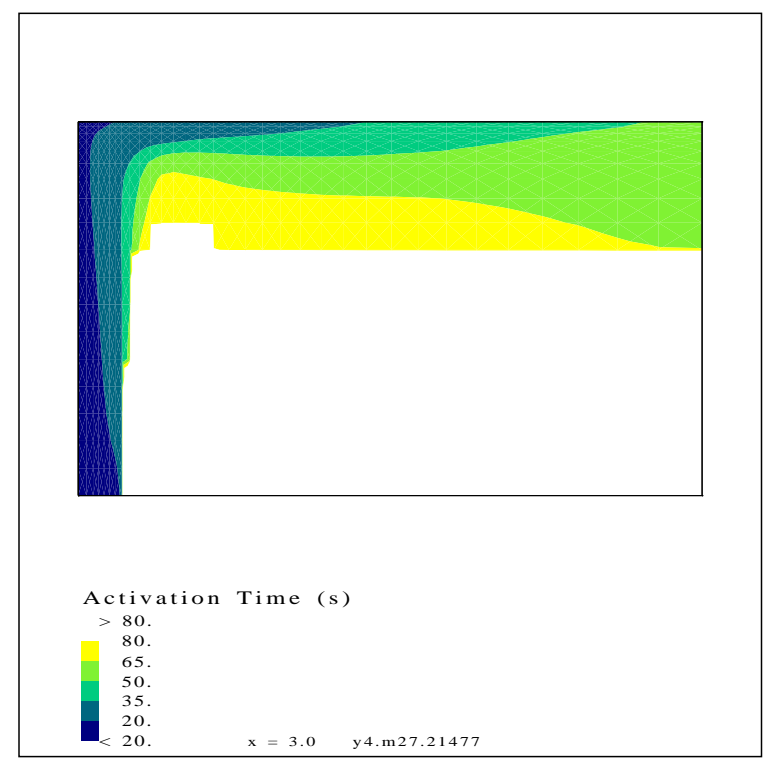

(d) Plane of symmetry

Figure 13: Simulated activation time in the small room from run 5.

Note: See figure 4 for the location of the plane of symmetry and the plane at the centerline of the diffuser. 


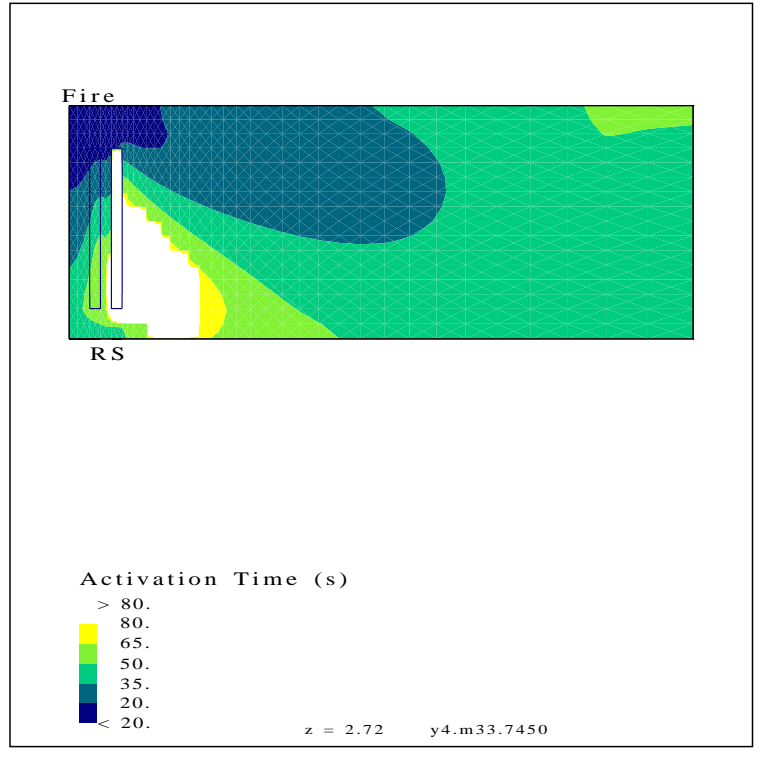

(a) At $0.02 \mathrm{~m}$ (0.79 in) below the ceiling

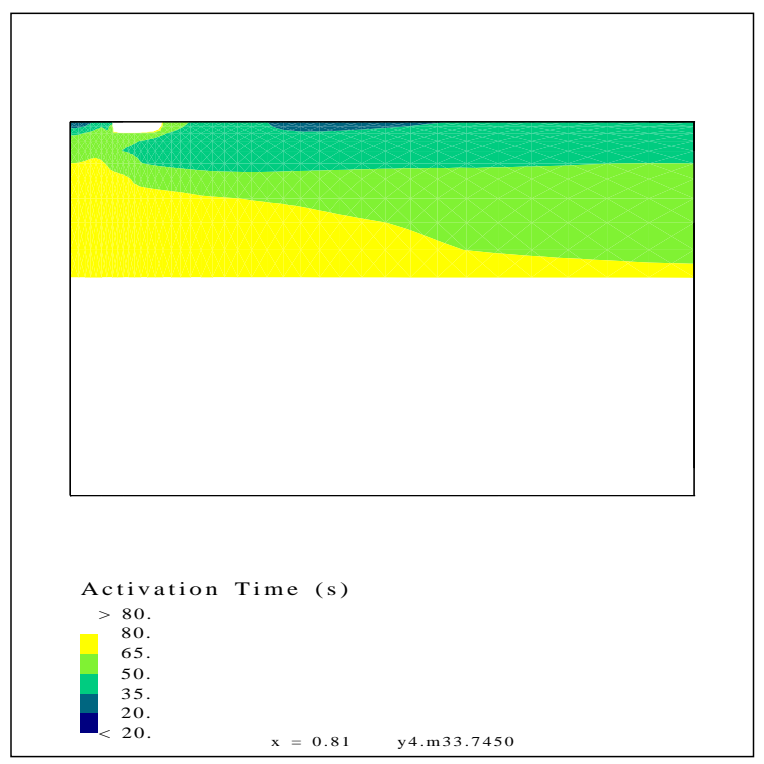

(c) Centerline of the diffuser

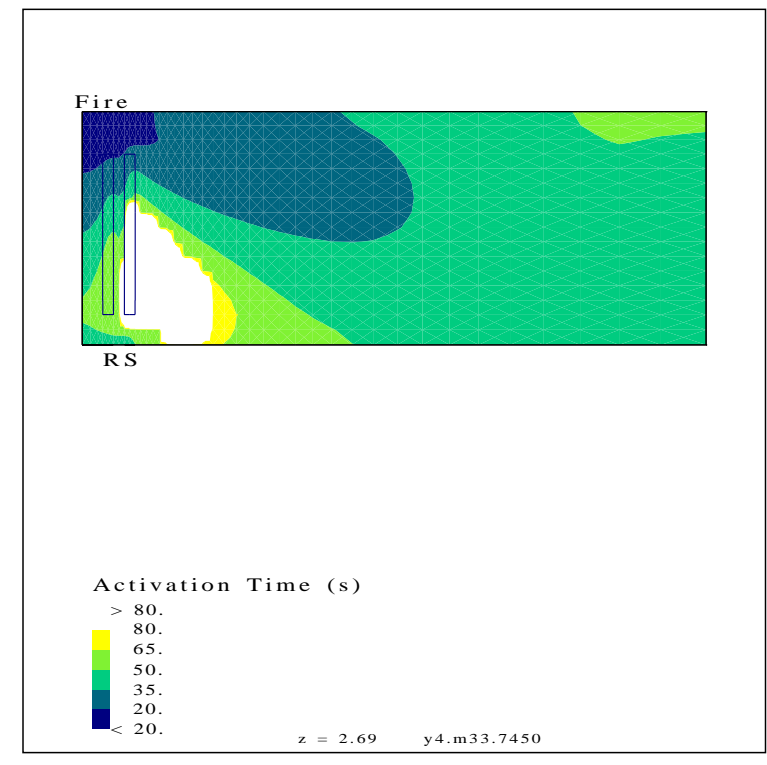

(b) At $0.05 \mathrm{~m}$ (2.0 in) below the ceiling

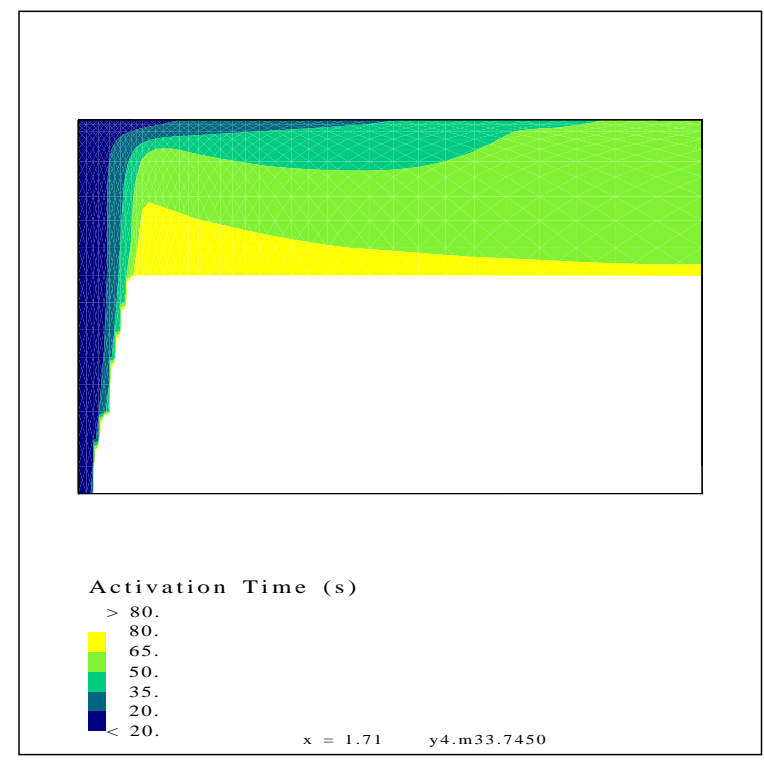

(d) Plane of symmetry

Figure 14: Simulated activation time in the small room from run 6.

Note: See figure 4 for the location of the plane of symmetry and the plane at the centerline of the diffuser. 


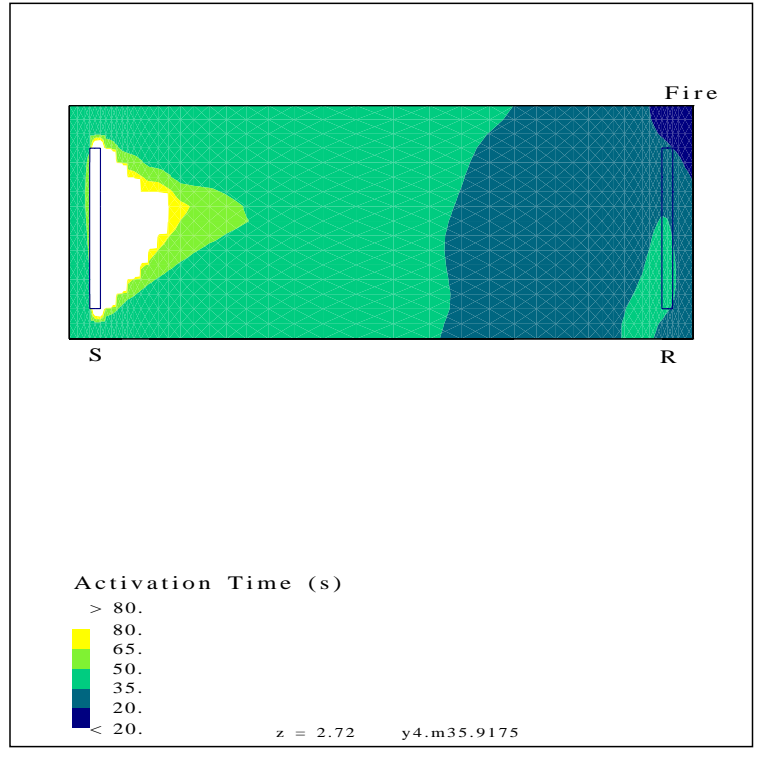

(a) At $0.02 \mathrm{~m}$ (0.79 in) below the ceiling

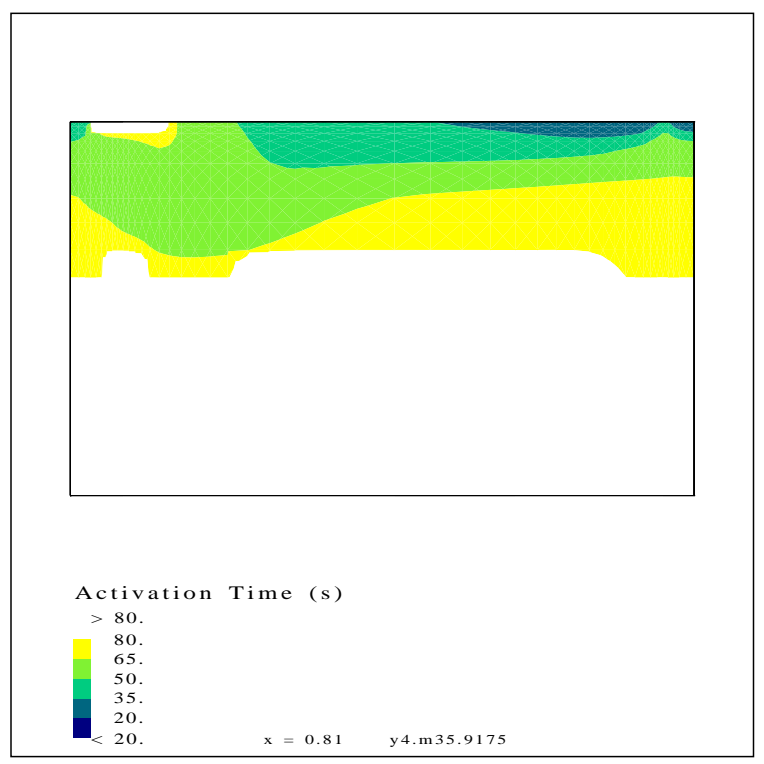

(c) Centerline of the diffuser

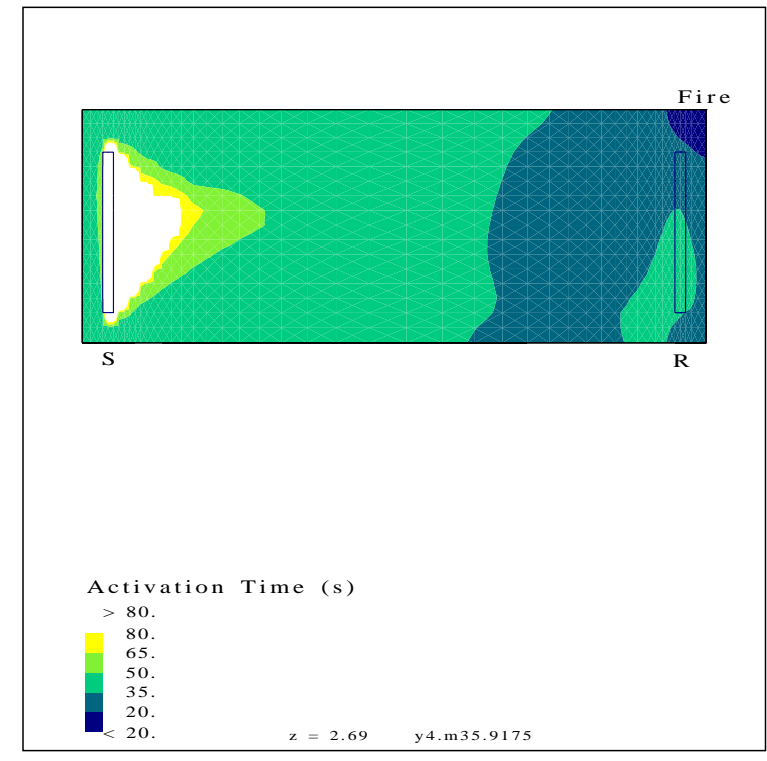

(b) At $0.05 \mathrm{~m}$ (2.0 in) below the ceiling

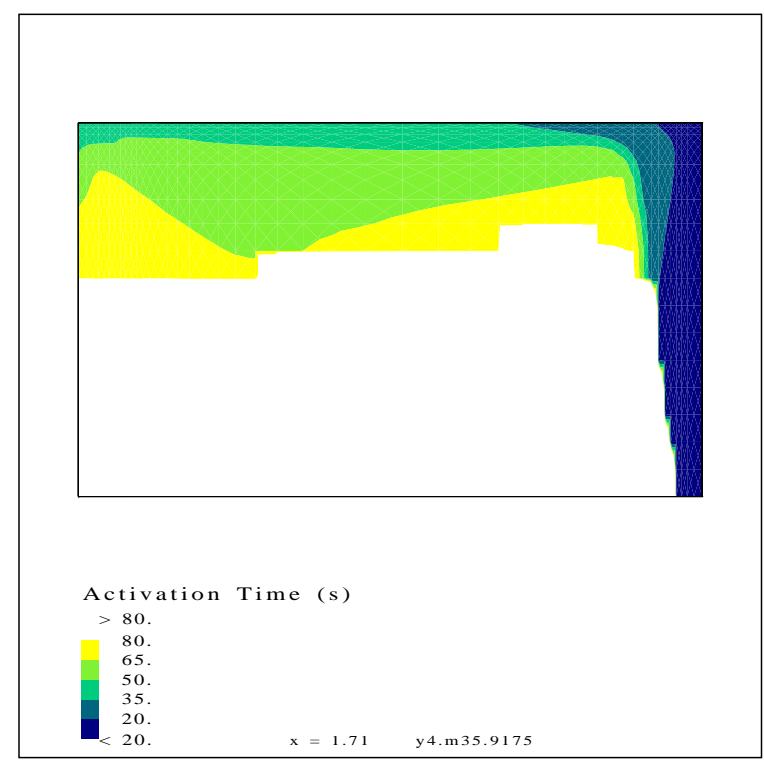

(d) Plane of symmetry

Figure 15: Simulated activation time in the small room from run 7.

Note: See figure 4 for the location of the plane of symmetry and the plane at the centerline of the diffuser. 


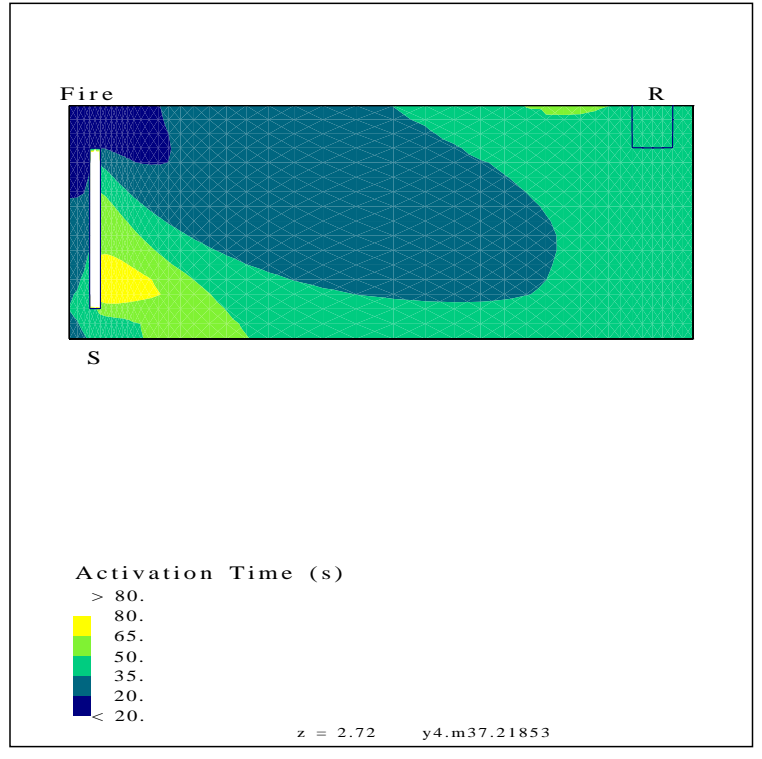

(a) At $0.02 \mathrm{~m}$ (0.79 in) below the ceiling

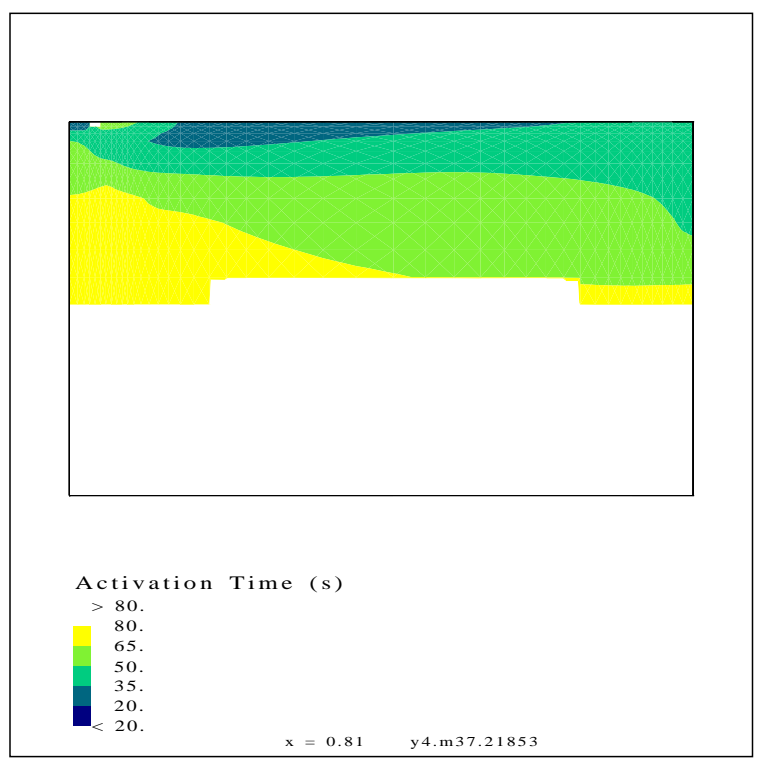

(c) Centerline of the diffuser

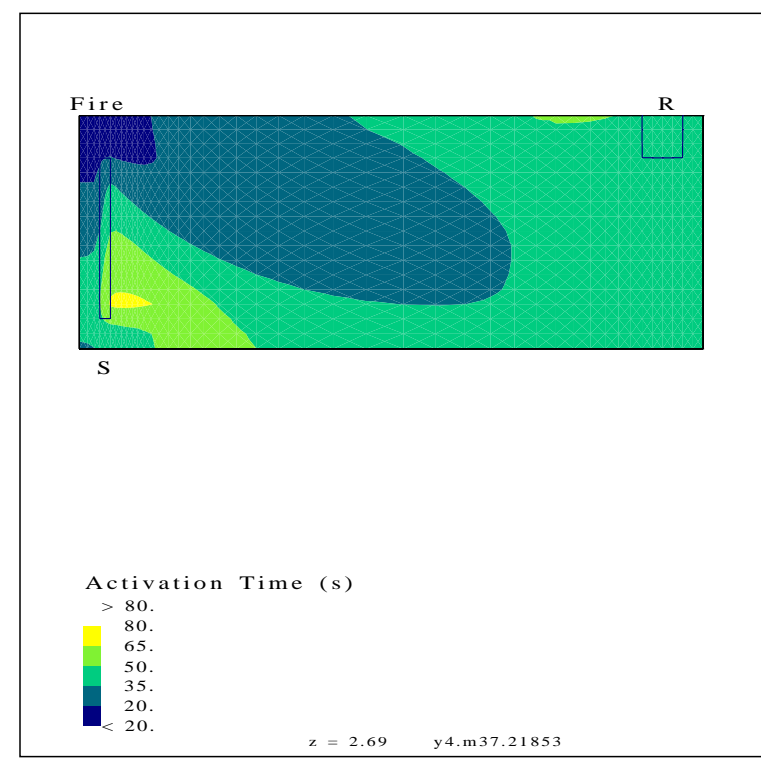

(b) At $0.05 \mathrm{~m}$ (2.0 in) below the ceiling

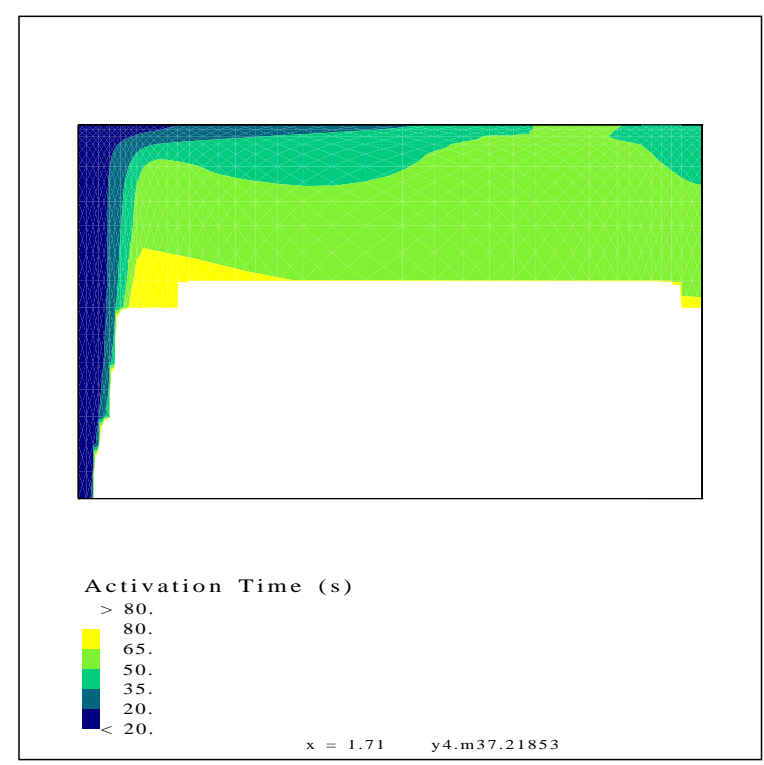

(d) Plane of symmetry

Figure 16: Simulated activation time in the small room from run 8.

Note: See figure 4 for the location of the plane of symmetry and the plane at the centerline of the diffuser. 


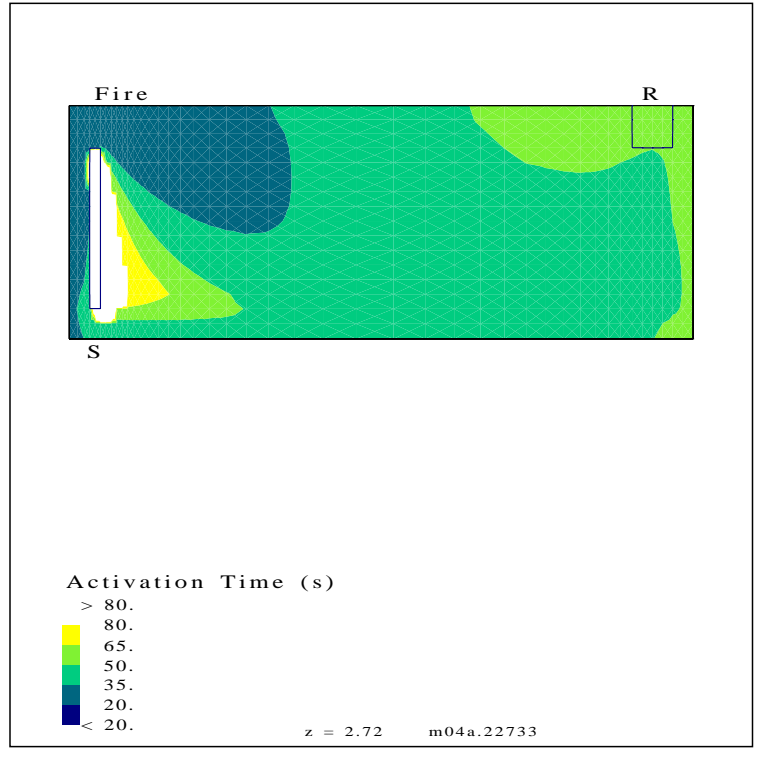

(a) At $0.02 \mathrm{~m}$ (0.79 in) below the ceiling

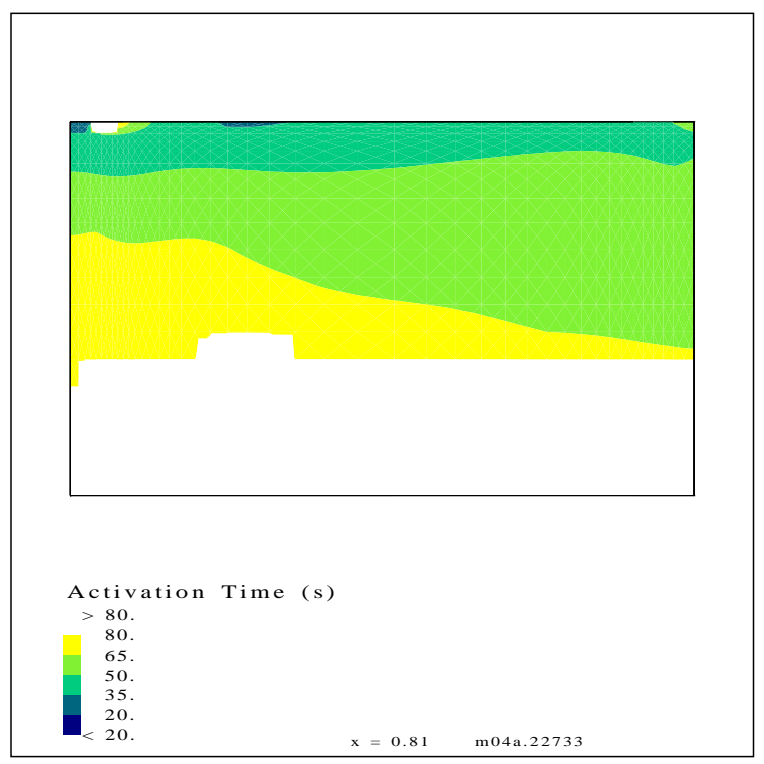

(c) Centerline of the diffuser

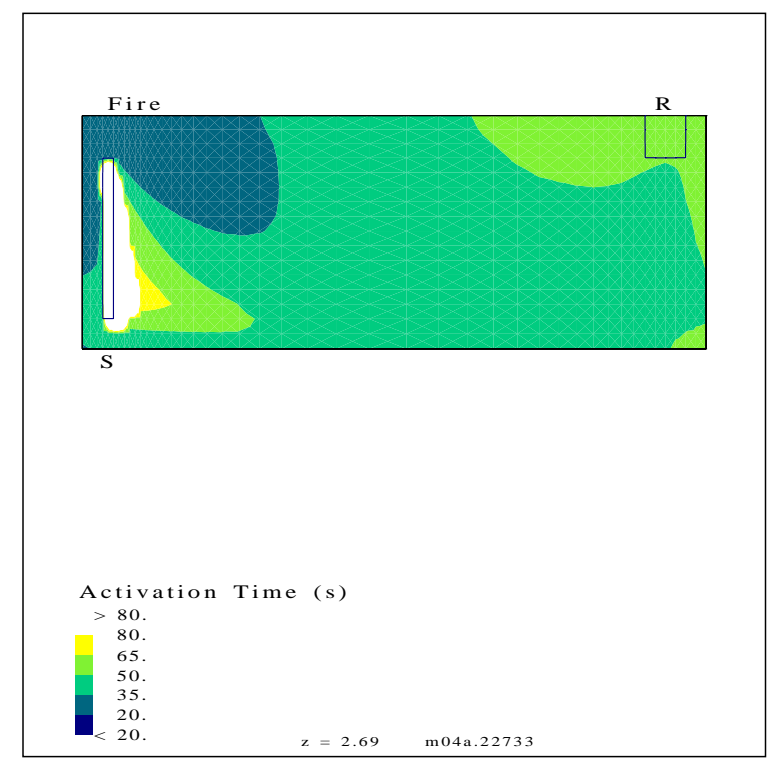

(b) At $0.05 \mathrm{~m}$ (2.0 in) below the ceiling

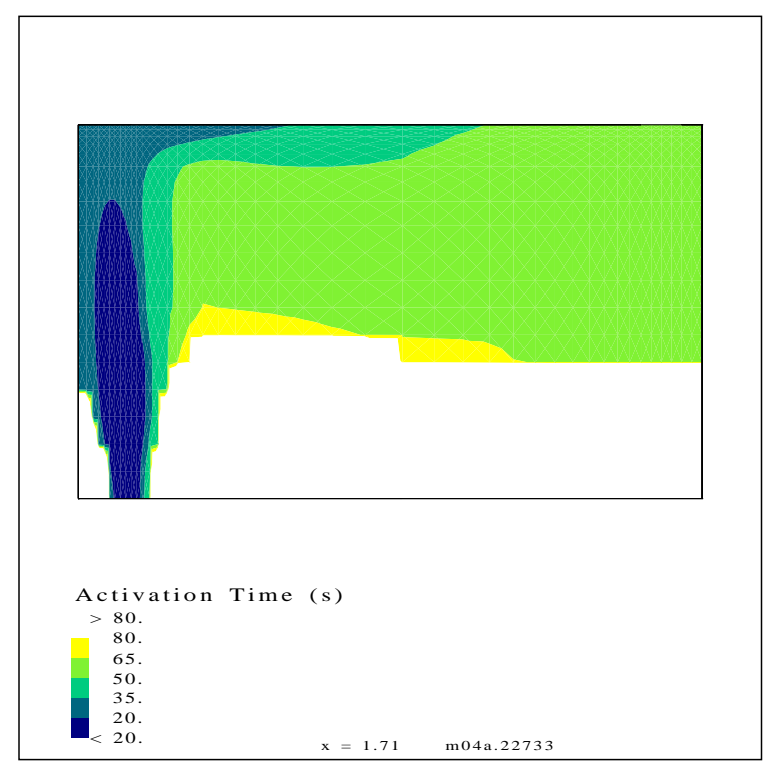

(d) Plane of symmetry

Figure 17: Simulated activation time in the small room from run 9.

Note: See figure 4 for the location of the plane of symmetry and the plane at the centerline of the diffuser. 


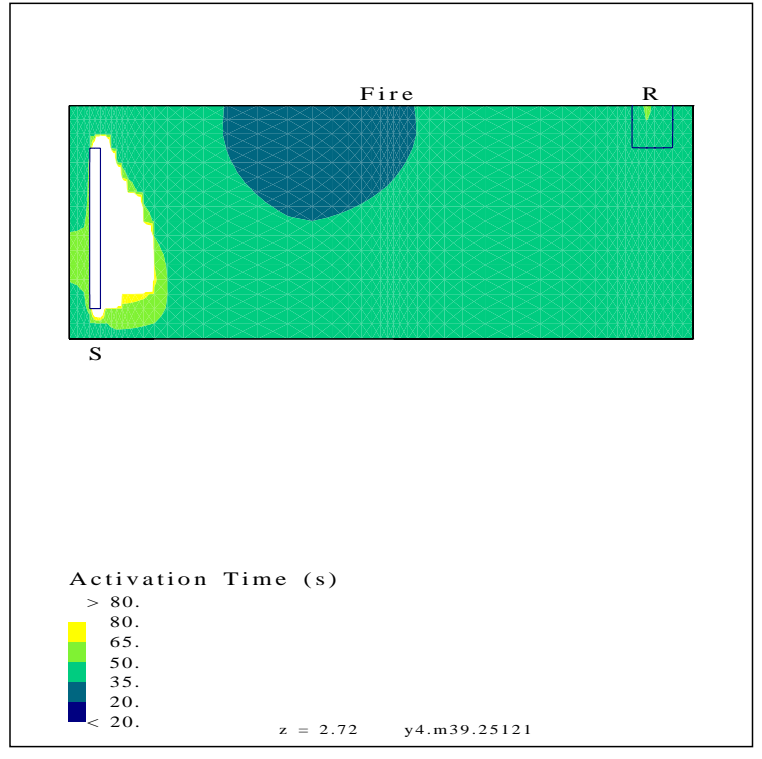

(a) At $0.02 \mathrm{~m}$ (0.79 in) below the ceiling

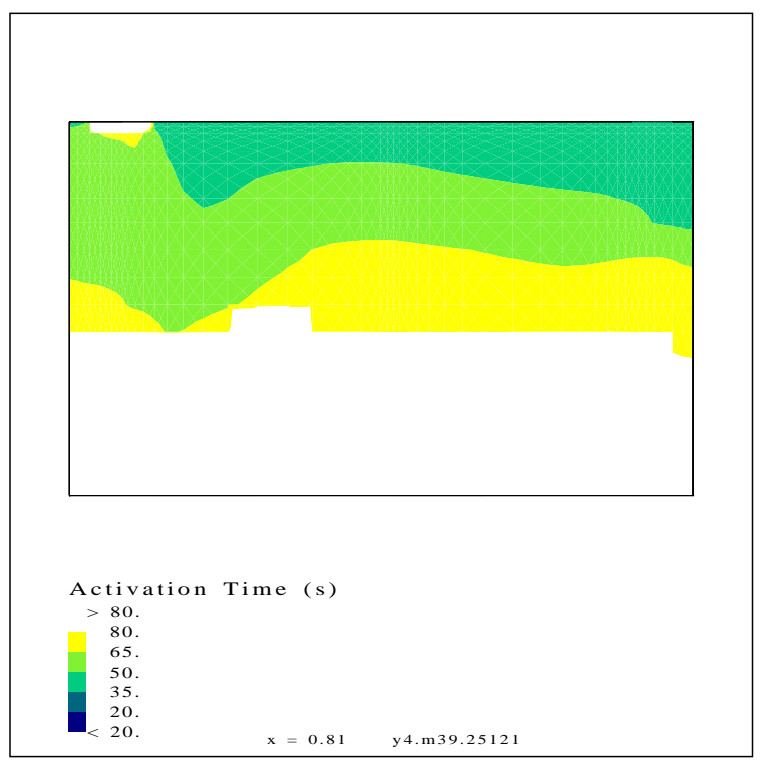

(c) Centerline of the diffuser

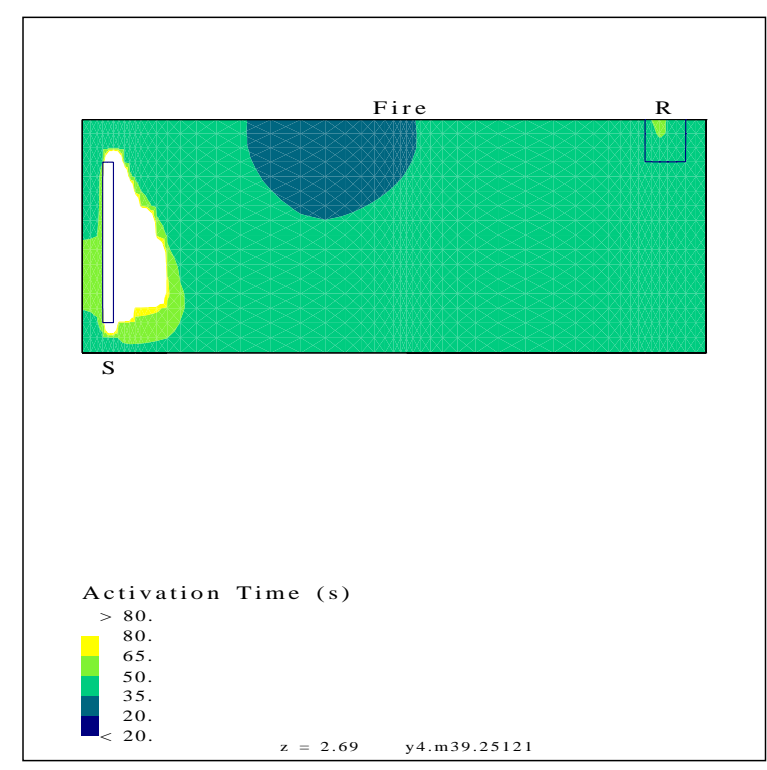

(b) At $0.05 \mathrm{~m}$ (2.0 in) below the ceiling

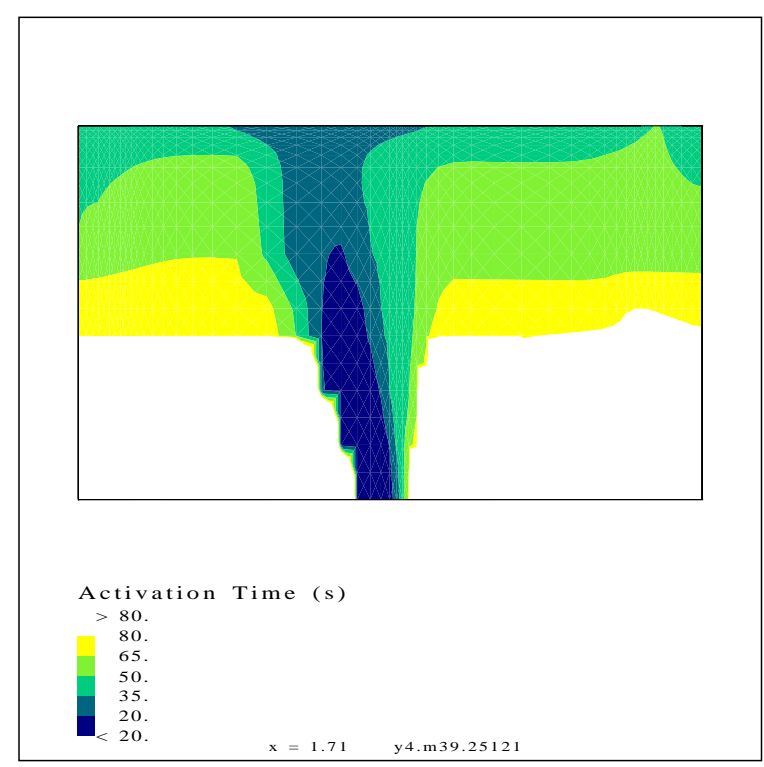

(d) Plane of symmetry

Figure 18: Simulated activation time in the small room from run 10.

Note: See figure 4 for the location of the plane of symmetry and the plane at the centerline of the diffuser. 


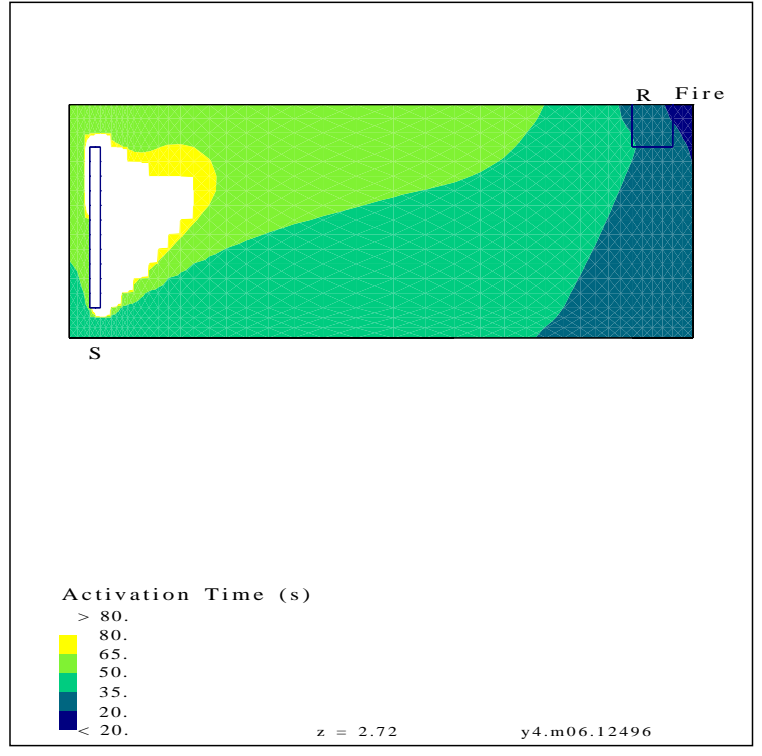

(a) At $0.02 \mathrm{~m}$ (0.79 in) below the ceiling

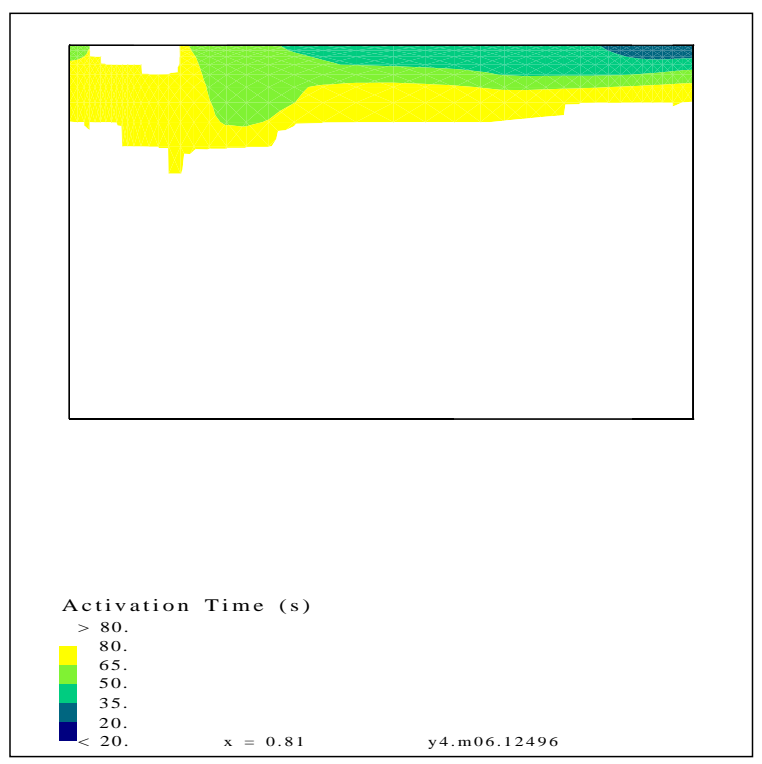

(c) Centerline of the diffuser

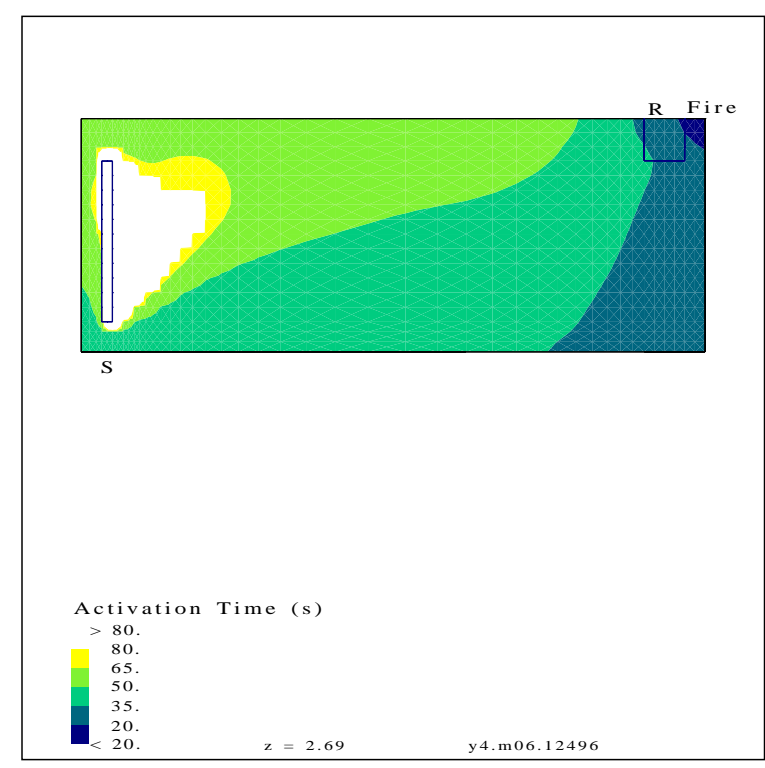

(b) At $0.05 \mathrm{~m}$ (2.0 in) below the ceiling

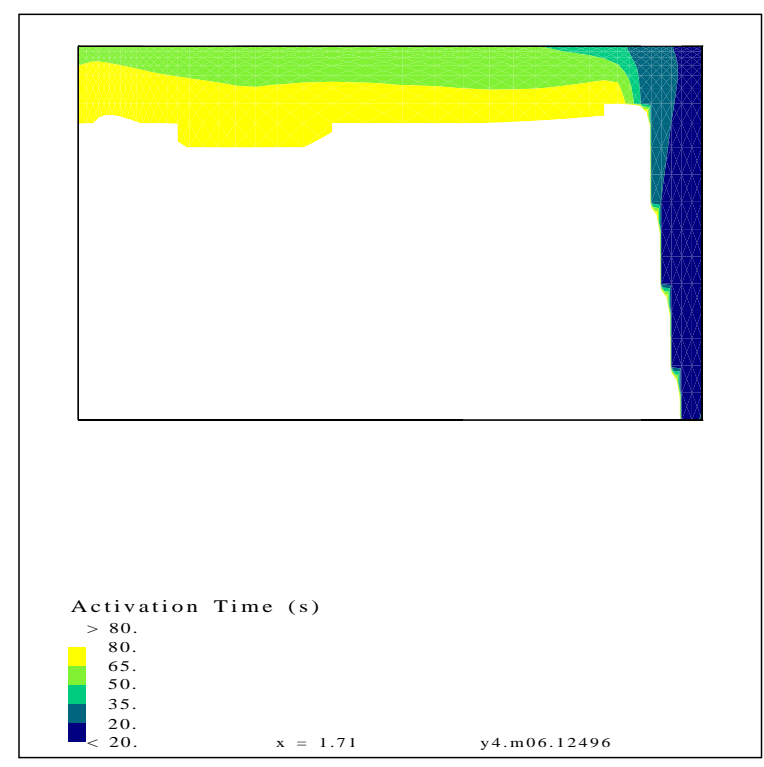

(d) Plane of symmetry

Figure 19: Simulated activation time in the small room from run 11.

Note: See figure 4 for the location of the plane of symmetry and the plane at the centerline of the diffuser. 


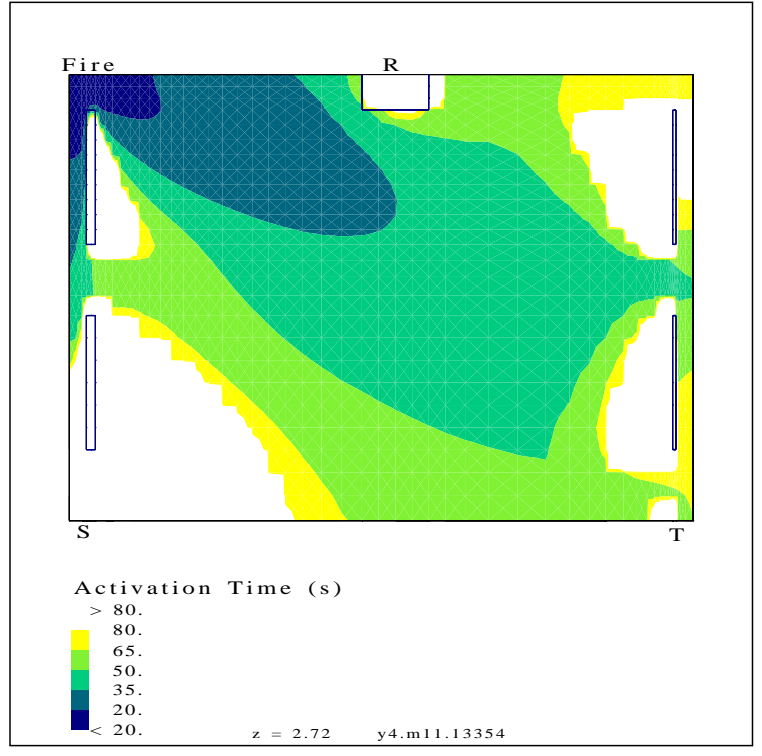

(a) At $0.02 \mathrm{~m}$ (0.79 in) below the ceiling

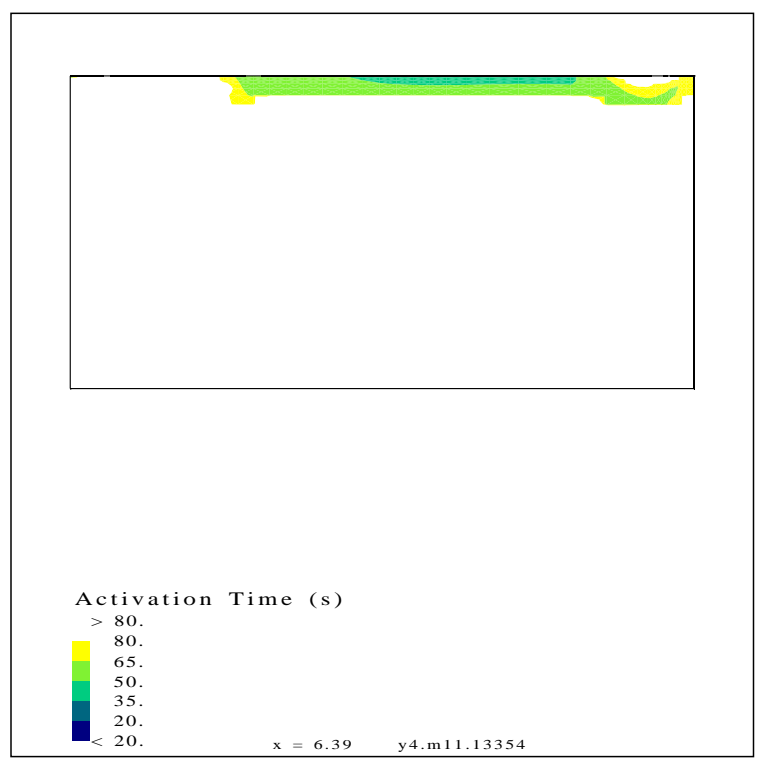

(c) Centerline of the diffuser

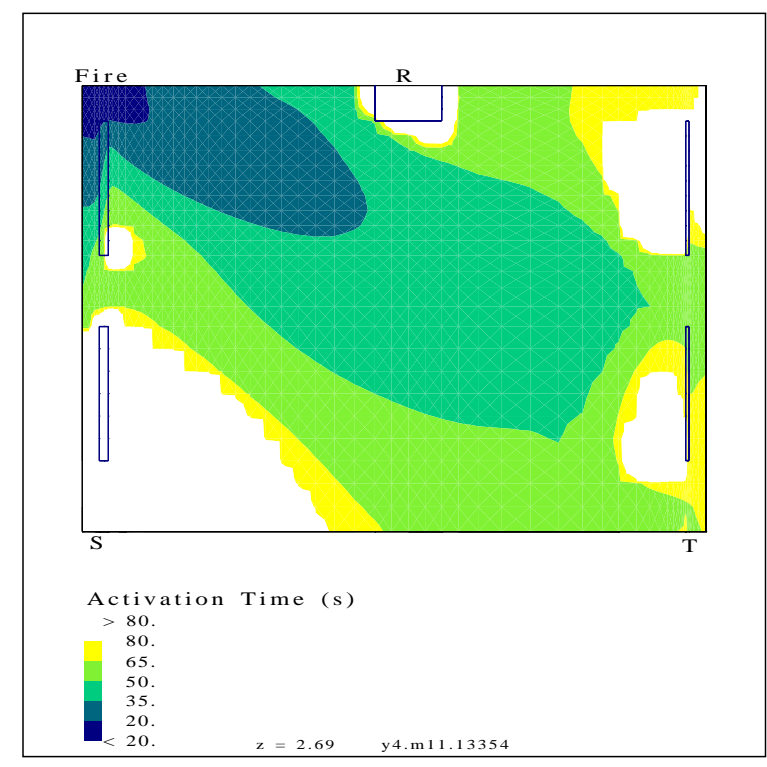

(b) At $0.05 \mathrm{~m}$ (2.0 in) below the ceiling

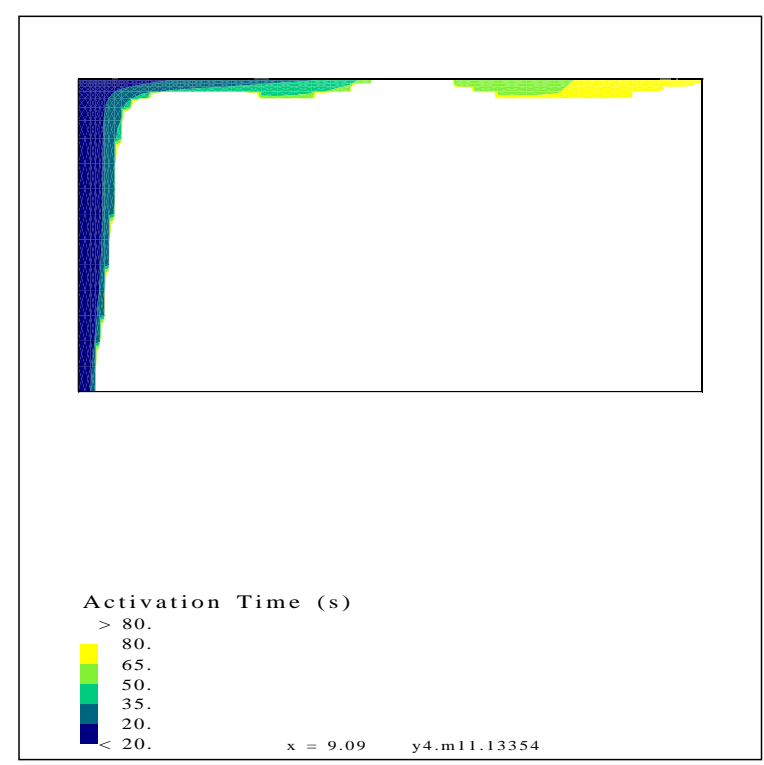

(d) Plane of symmetry

Figure 20: Simulated activation time in the small room from run 12.

Note: See figure 4 for the location of the plane of symmetry and the plane at the centerline of the diffuser. 


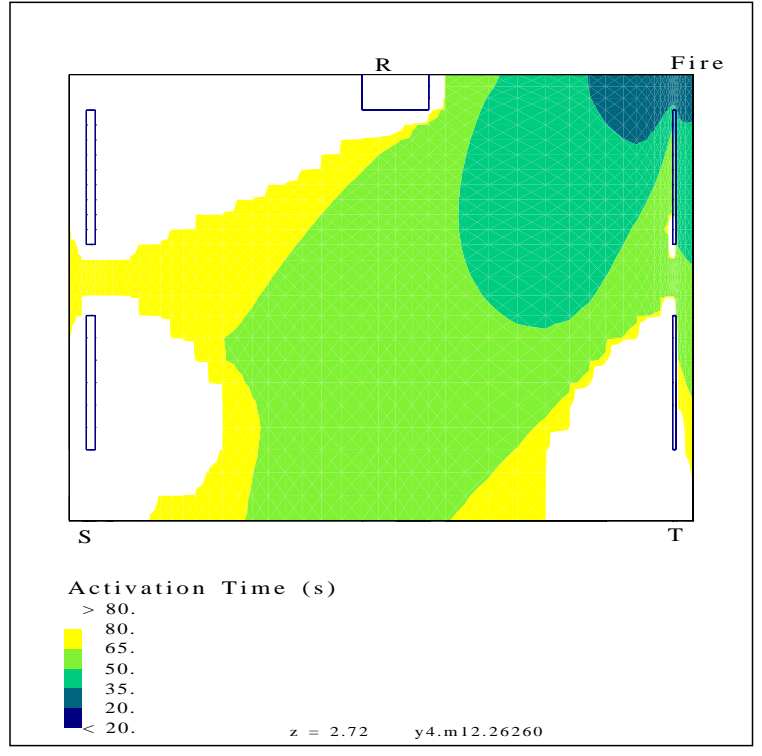

(a) At $0.02 \mathrm{~m}$ (0.79 in) below the ceiling

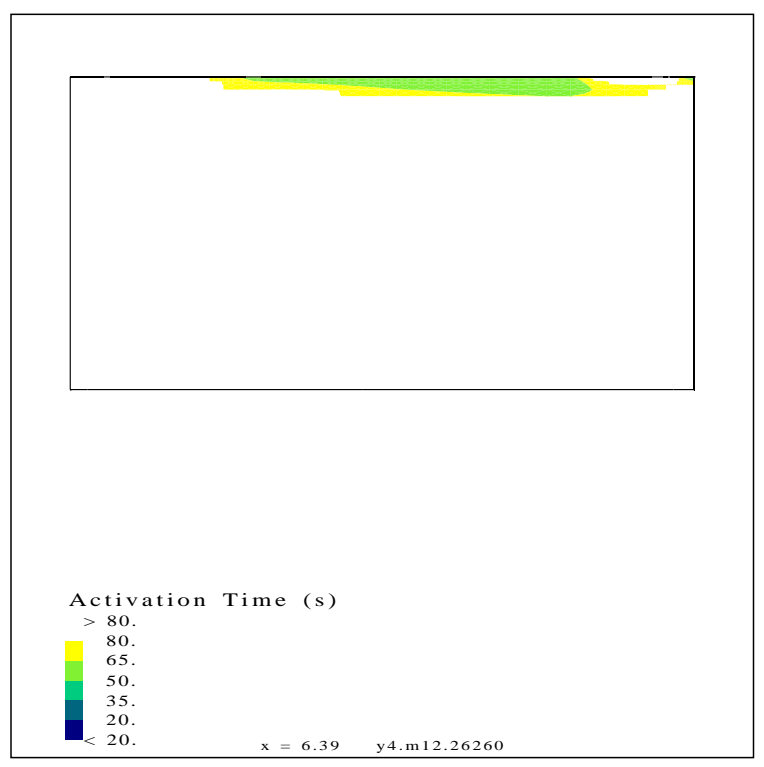

(c) Centerline of the diffuser

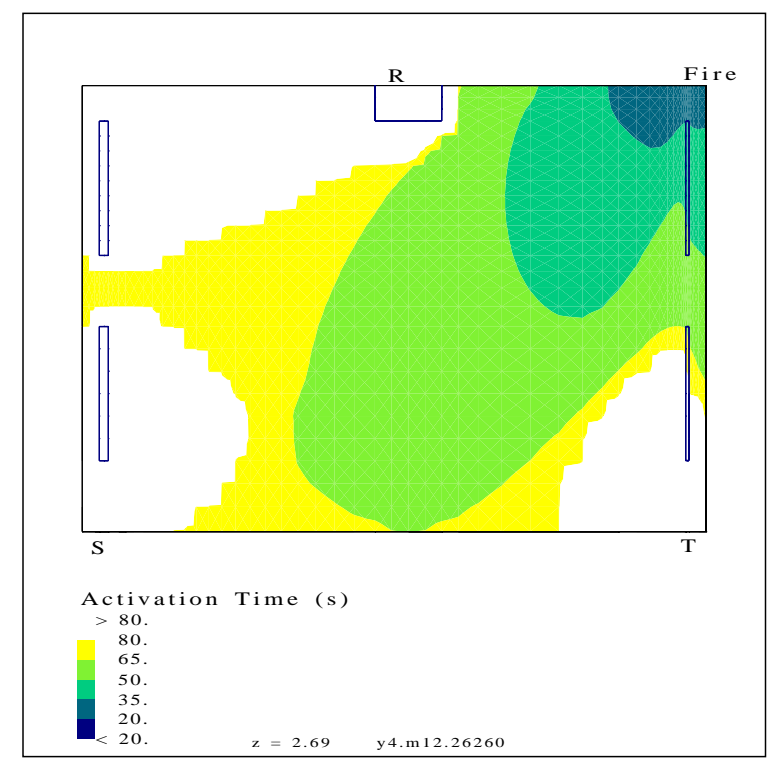

(b) At $0.05 \mathrm{~m}$ (2.0 in) below the ceiling

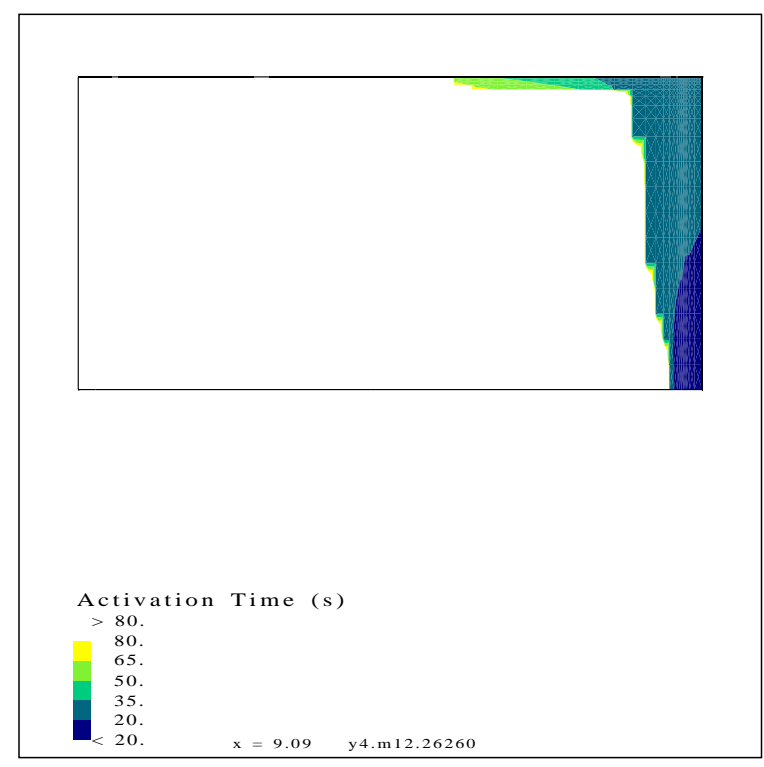

(d) Plane of symmetry

Figure 21: Simulated activation time in the small room from run 13.

Note: See figure 4 for the location of the plane of symmetry and the plane at the centerline of the diffuser. 


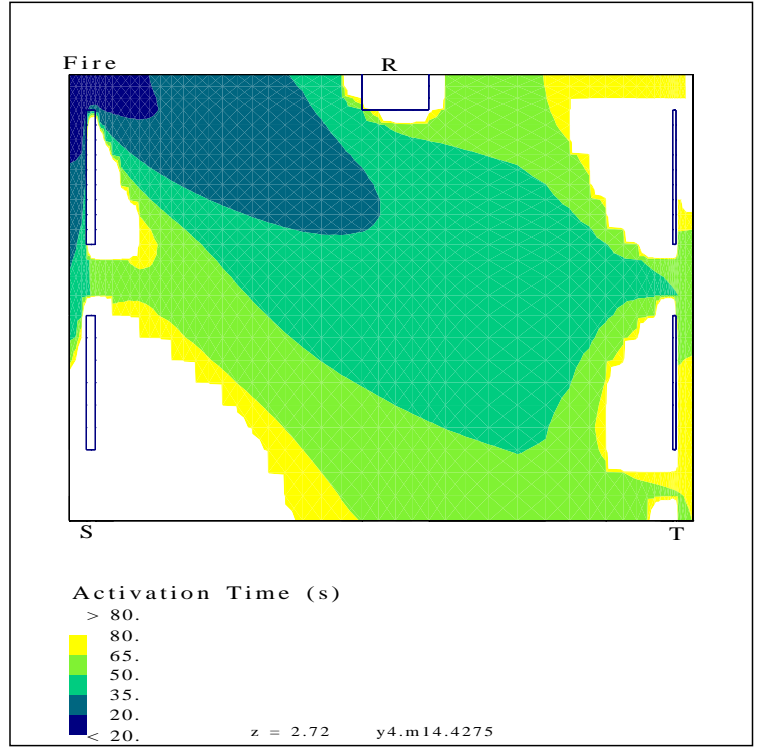

(a) At $0.02 \mathrm{~m}$ (0.79 in) below the ceiling

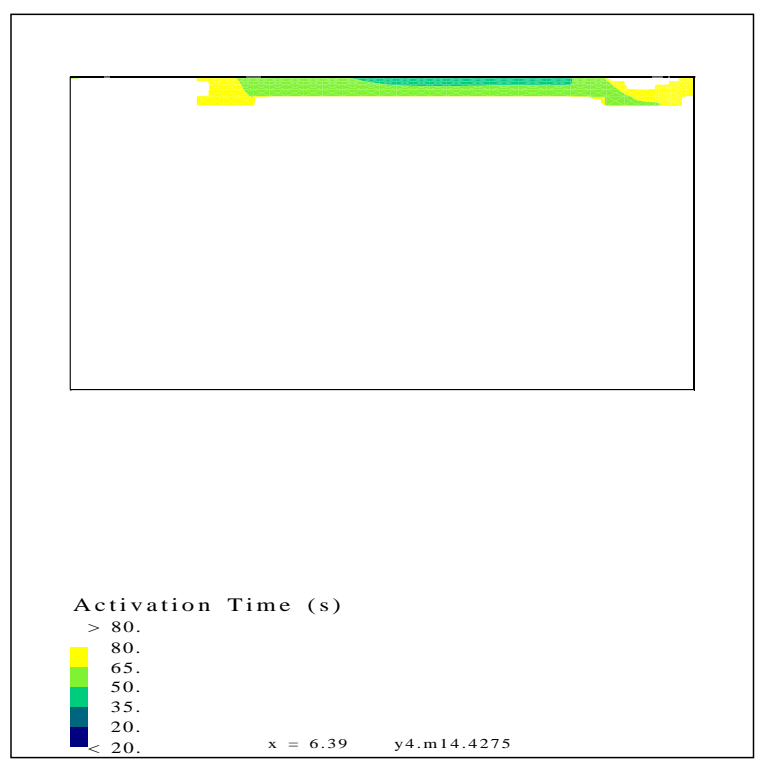

(c) Centerline of the diffuser

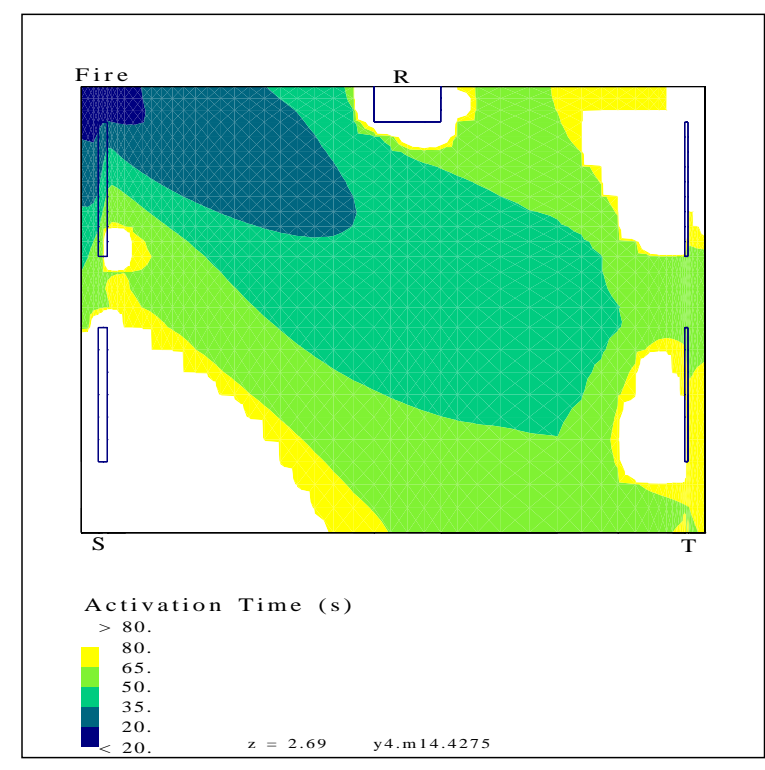

(b) At $0.05 \mathrm{~m}$ (2.0 in) below the ceiling

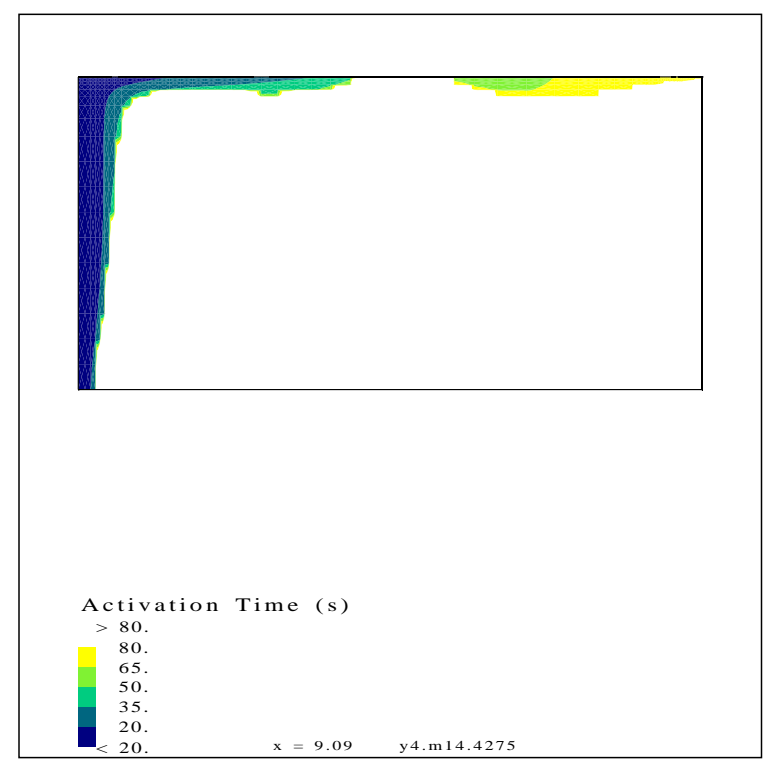

(d) Plane of symmetry

Figure 22: Simulated activation time in the small room from run 14.

Note: See figure 4 for the location of the plane of symmetry and the plane at the centerline of the diffuser. 


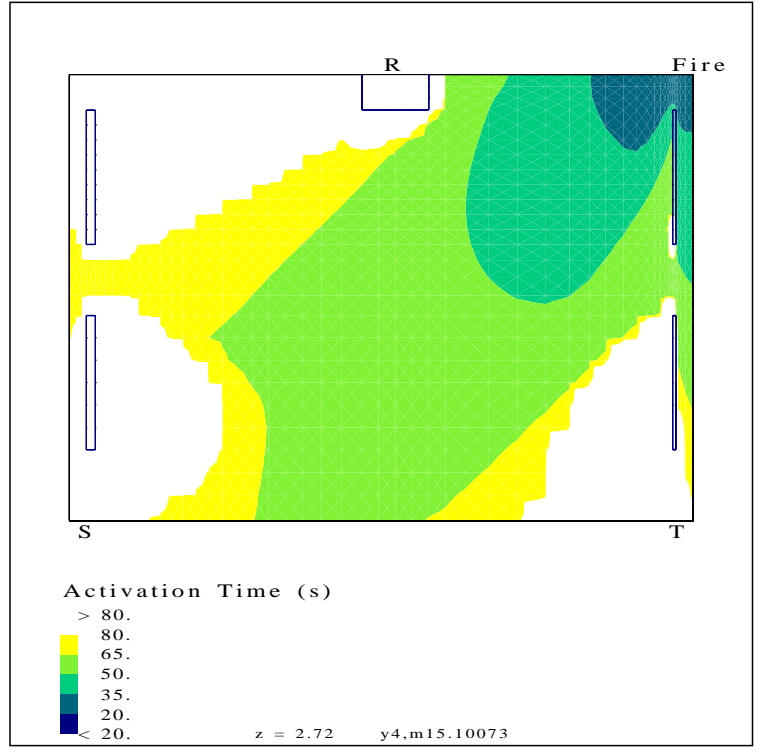

(a) At $0.02 \mathrm{~m}$ (0.79 in) below the ceiling

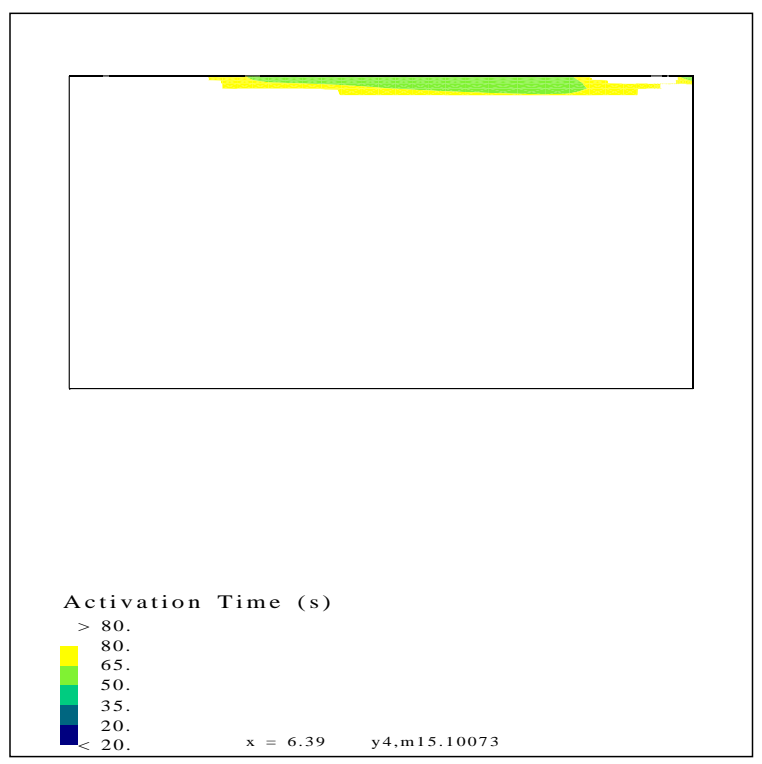

(c) Centerline of the diffuser

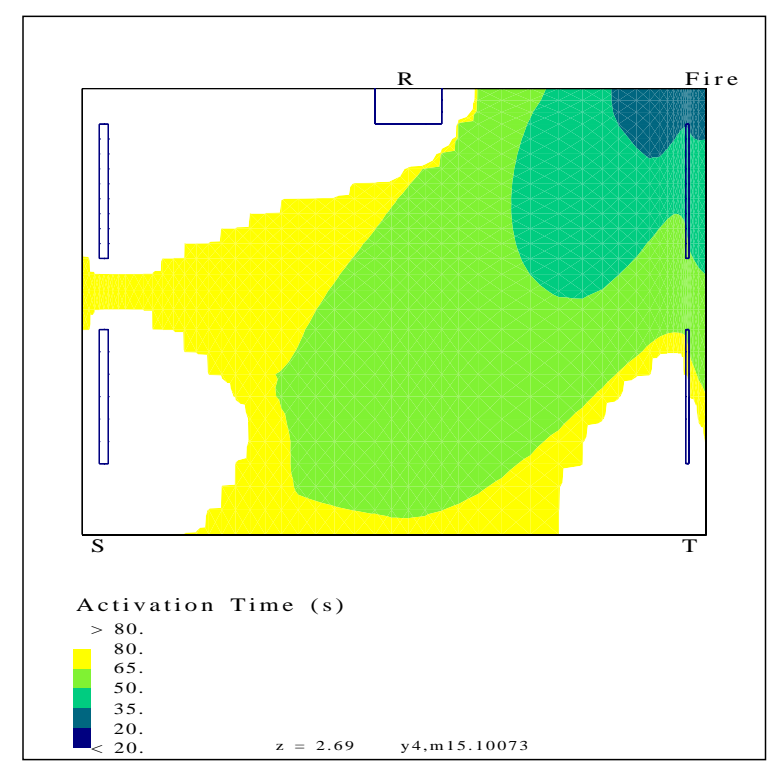

(b) At $0.05 \mathrm{~m}$ (2.0 in) below the ceiling

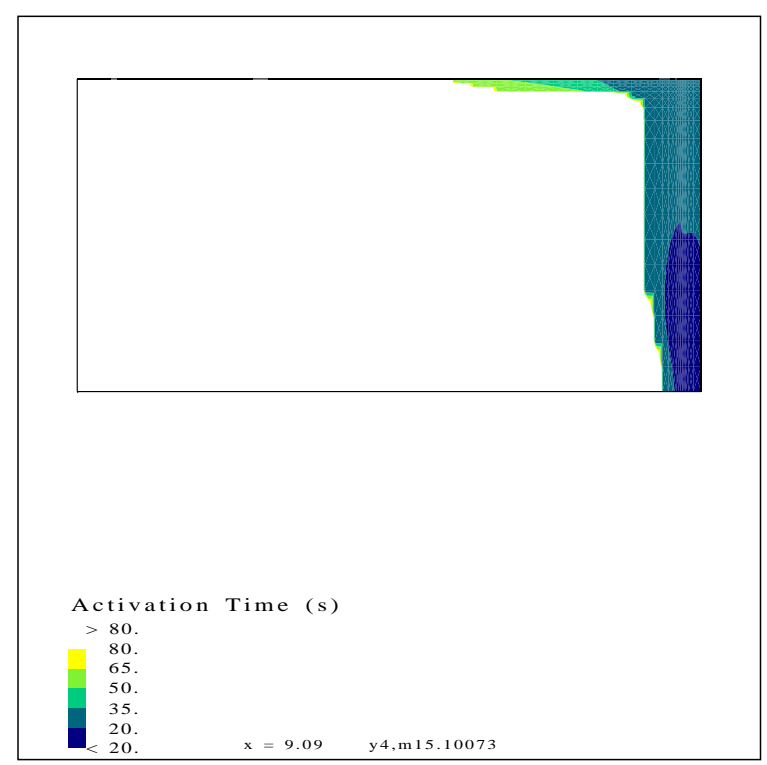

(d) Plane of symmetry

Figure 23: Simulated activation time in the medium room from run 15.

Note: See figure 5 for the location of the plane of symmetry and the plane at the centerline of the diffuser. 


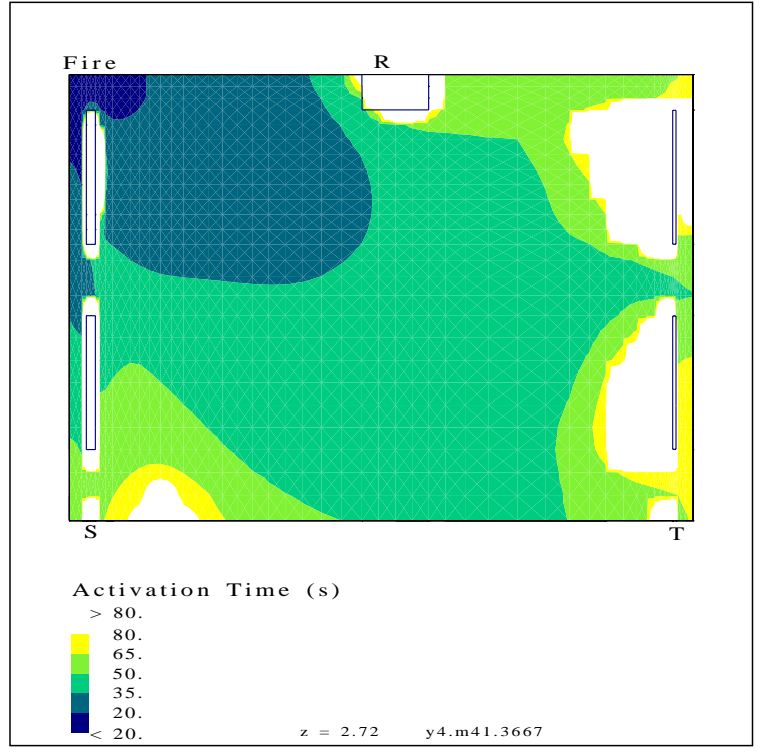

(a) At $0.02 \mathrm{~m}$ (0.79 in) below the ceiling

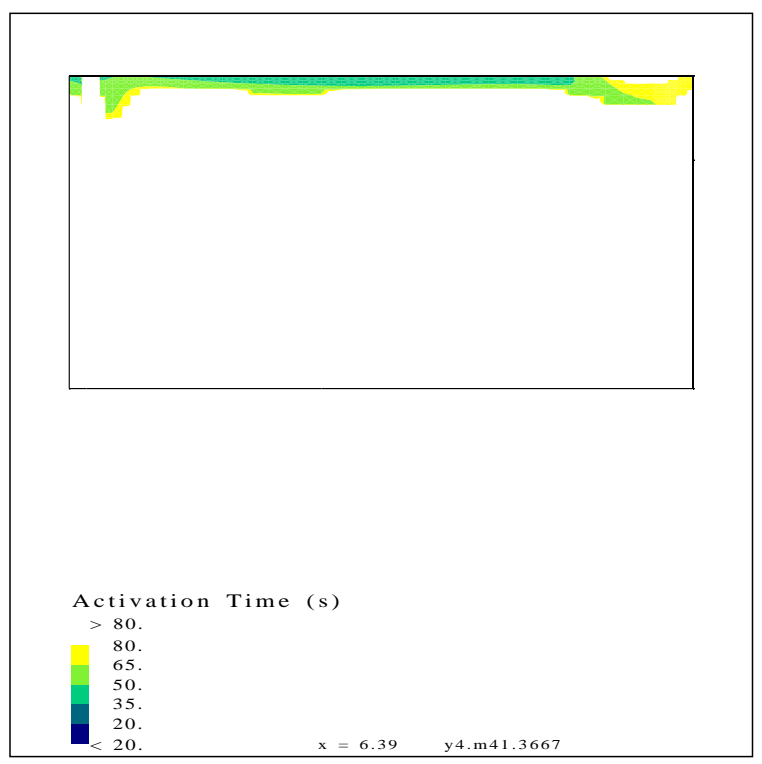

(c) Centerline of the diffuser

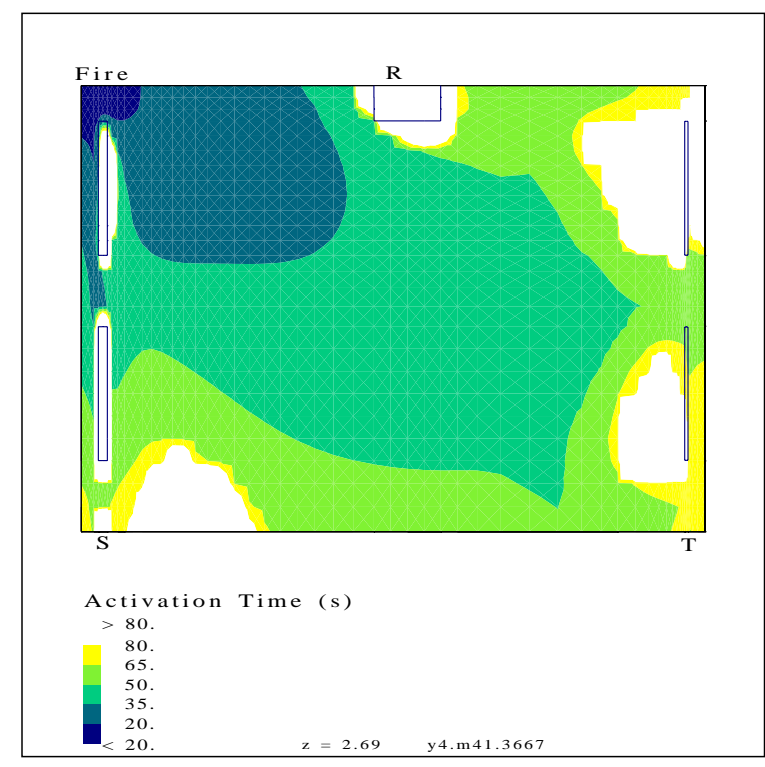

(b) At $0.05 \mathrm{~m}$ ( $2.0 \mathrm{in})$ below the ceiling

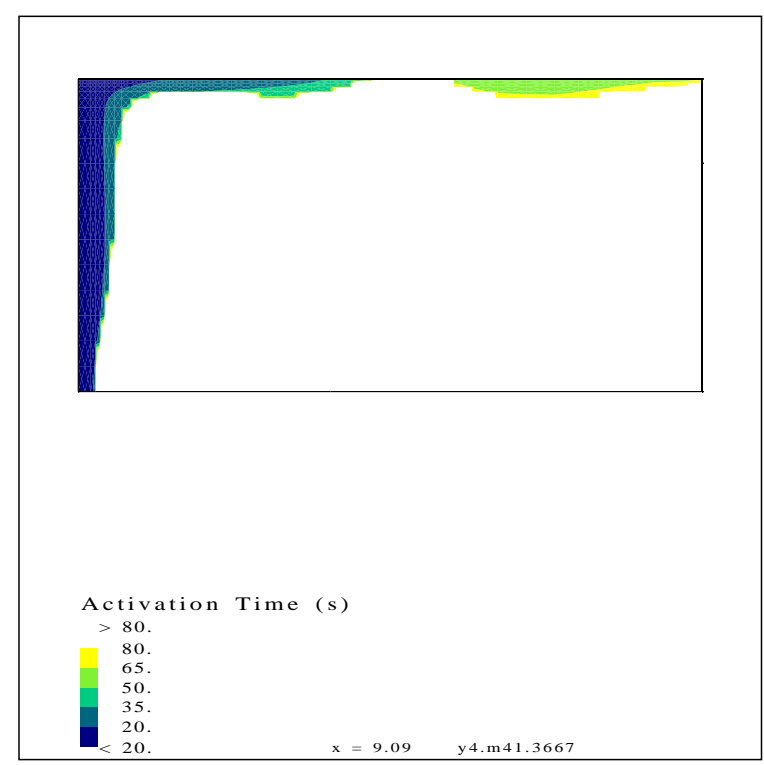

(d) Plane of symmetry

Figure 24: Simulated activation time in the medium room from run 16.

Note: See figure 5 for the location of the plane of symmetry and the plane at the centerline of the diffuser. 


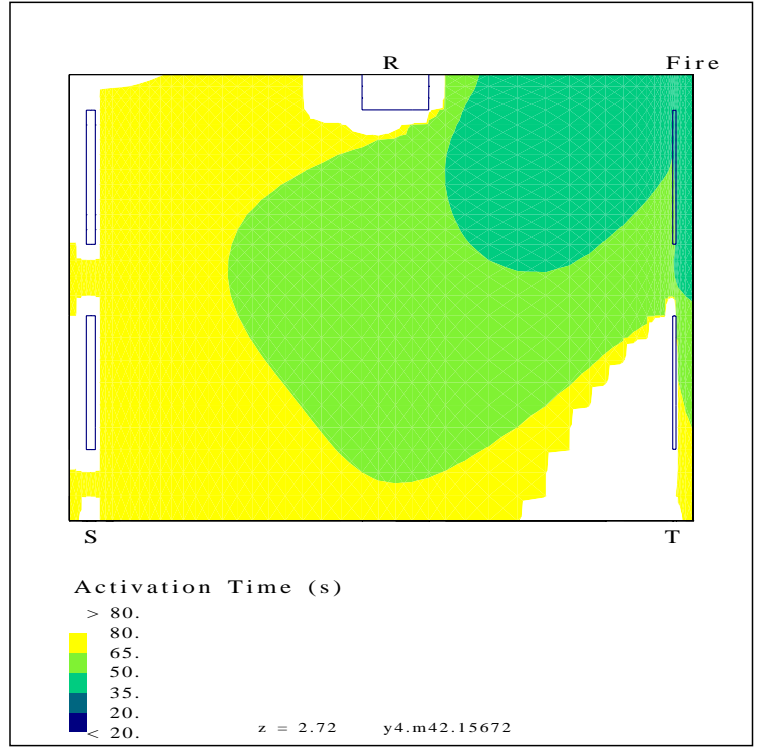

(a) At $0.02 \mathrm{~m}$ ( $0.79 \mathrm{in})$ below the ceiling

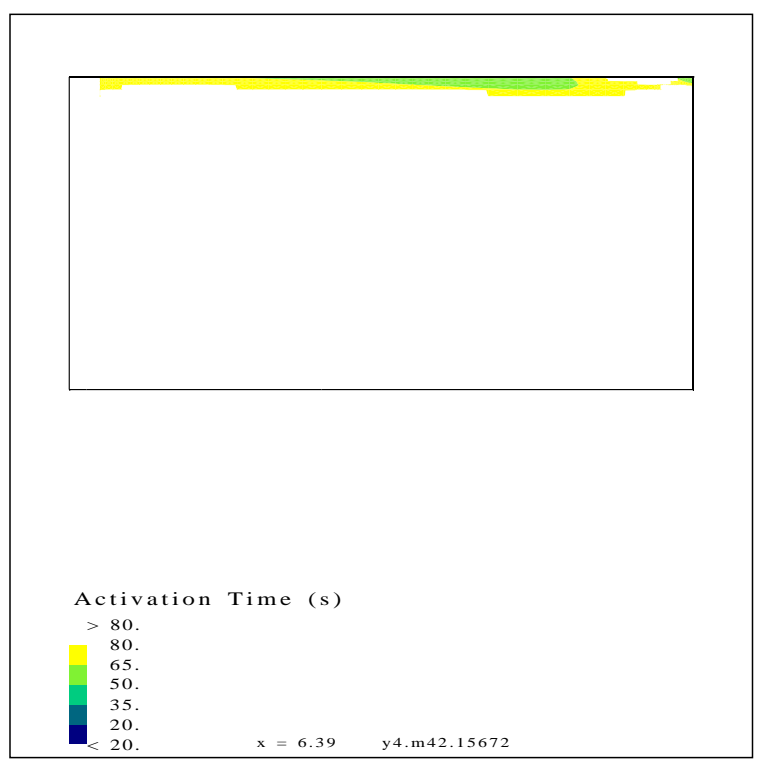

(c) Centerline of the diffuser

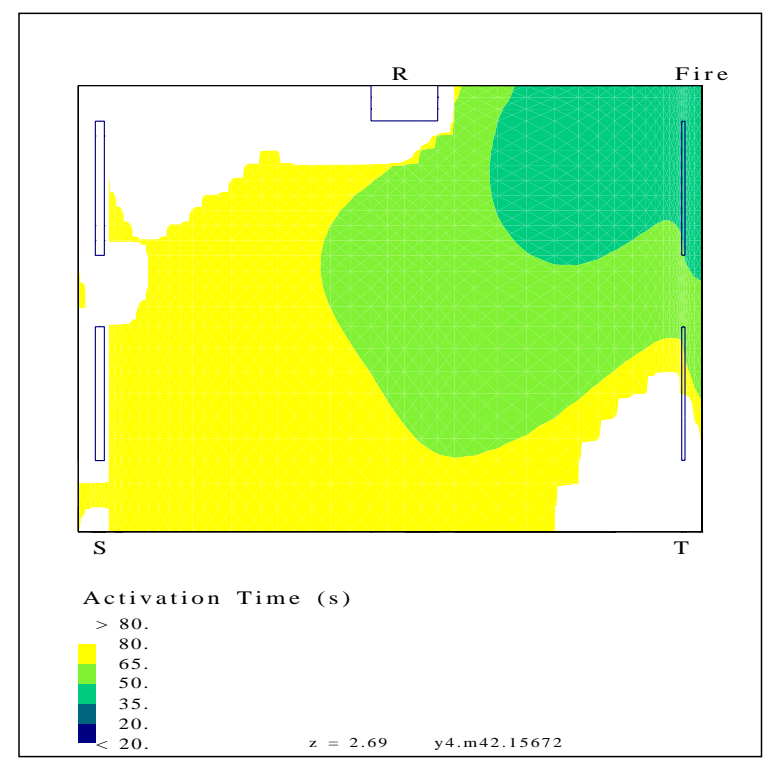

(b) At $0.05 \mathrm{~m}$ (2.0 in) below the ceiling

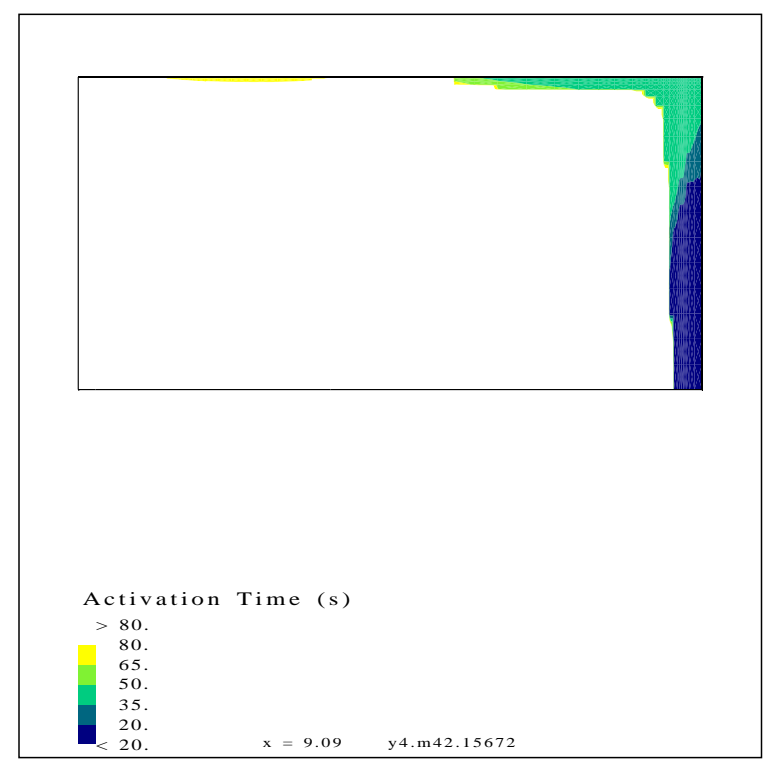

(d) Plane of symmetry

Figure 25: Simulated activation time in the medium room from run 17.

Note: See figure 5 for the location of the plane of symmetry and the plane at the centerline of the diffuser. 


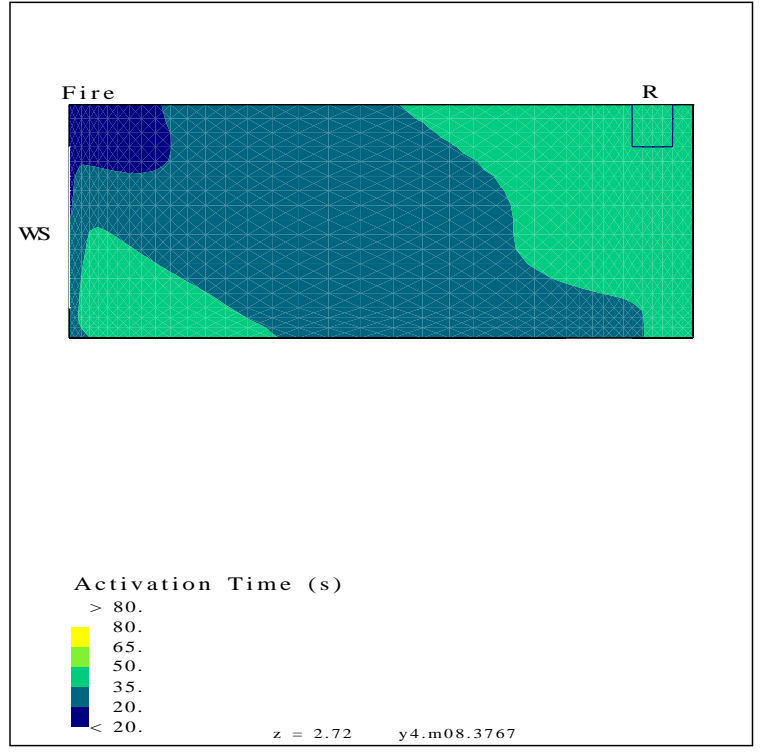

(a) At $0.02 \mathrm{~m}$ (0.79 in) below the ceiling

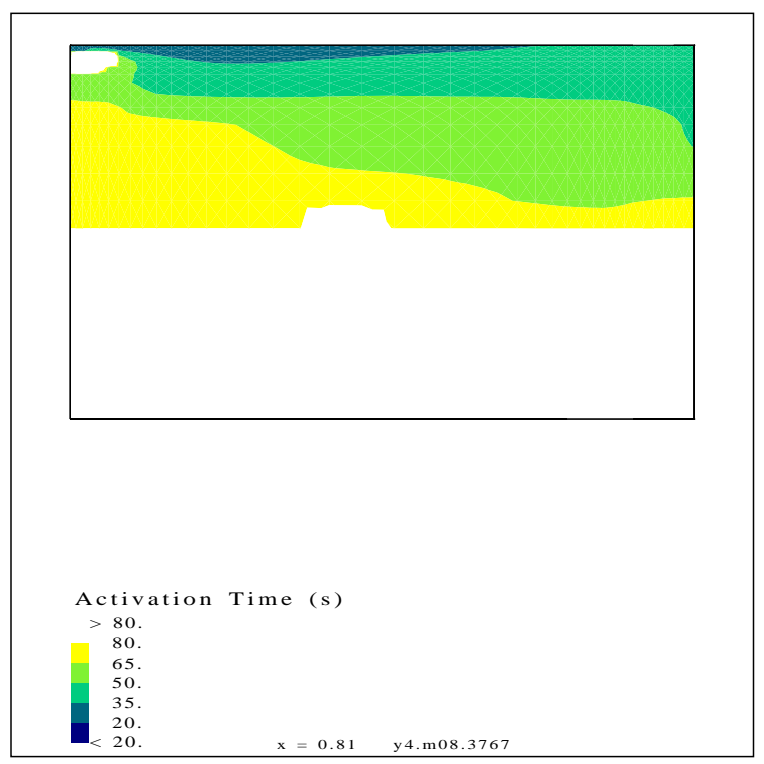

(c) Centerline of the diffuser

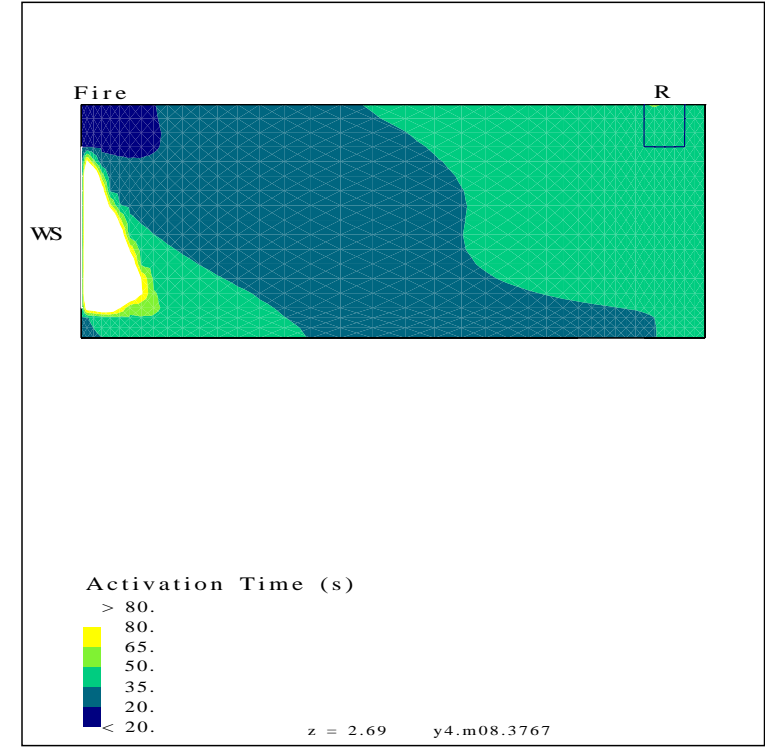

(b) At $0.05 \mathrm{~m}$ (2.0 in) below the ceiling

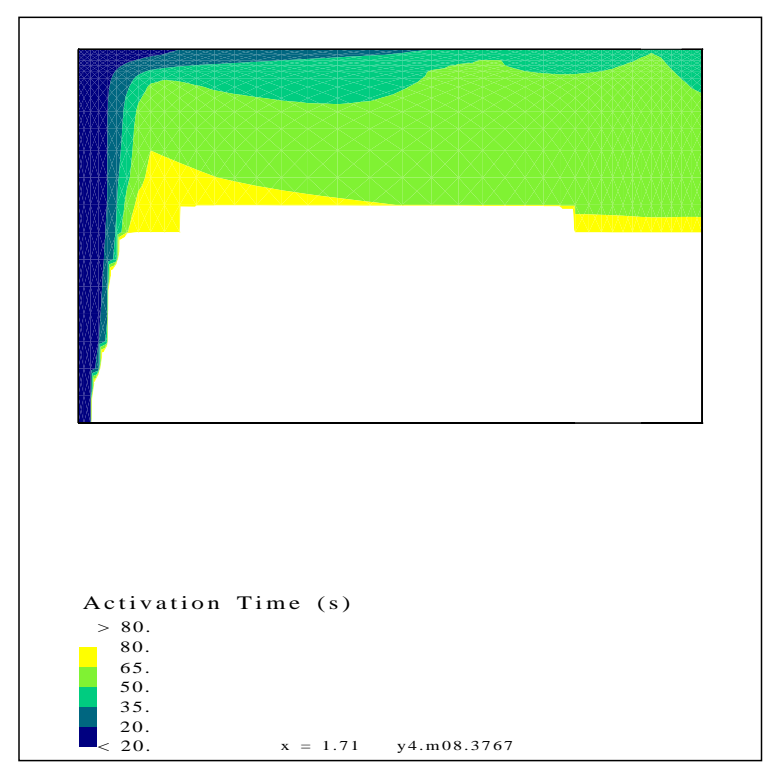

(d) Plane of symmetry

Figure 26: Simulated activation time in the medium room from run 18.

Note: See figure 5 for the location of the plane of symmetry and the plane at the centerline of the diffuser. 


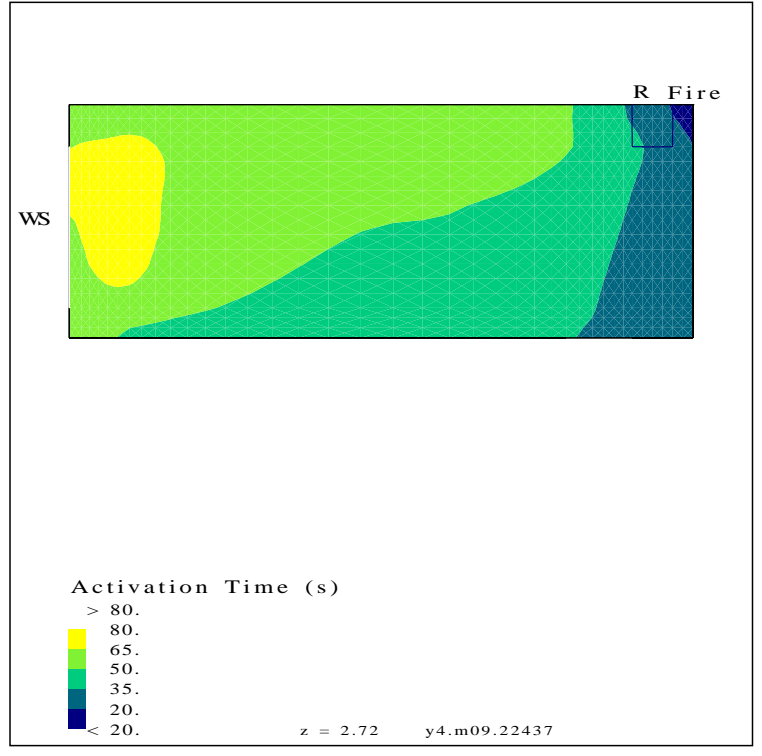

(a) At $0.02 \mathrm{~m}$ (0.79 in) below the ceiling

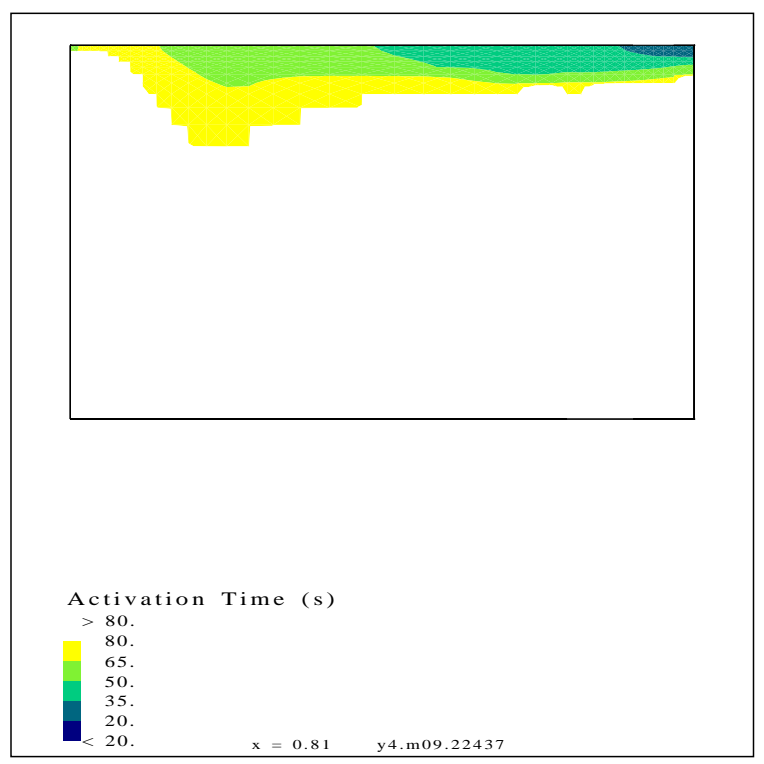

(c) Centerline of the diffuser

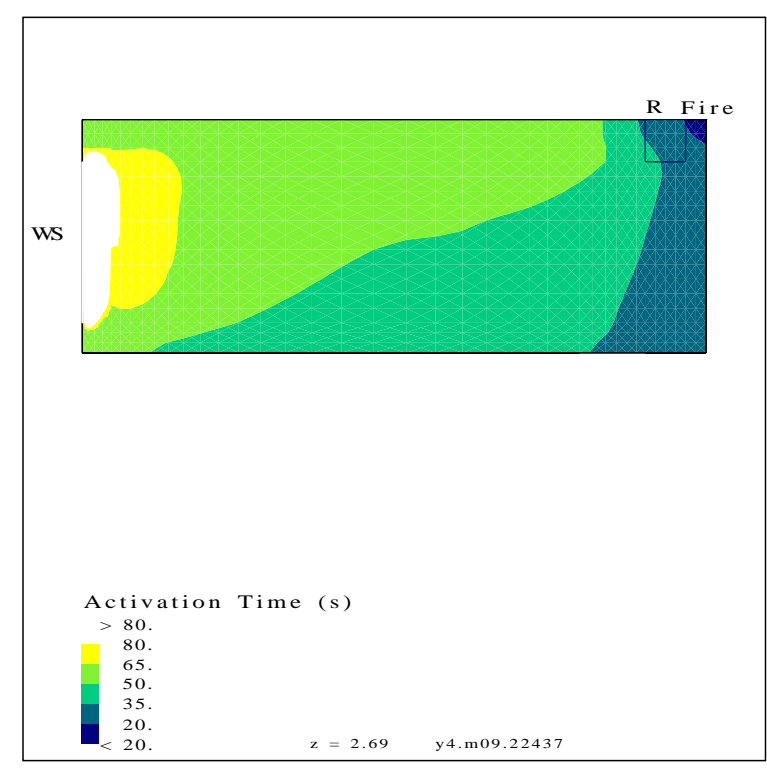

(b) At $0.05 \mathrm{~m}$ (2.0 in) below the ceiling

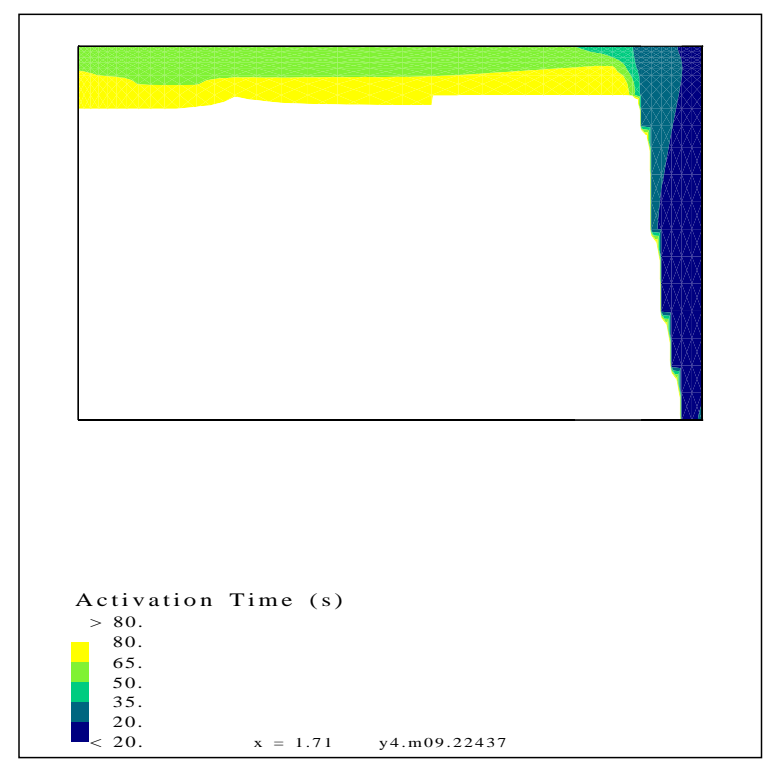

(d) Plane of symmetry

Figure 27: Simulated activation time in the medium room from run 19.

Note: See figure 5 for the location of the plane of symmetry and the plane at the centerline of the diffuser. 


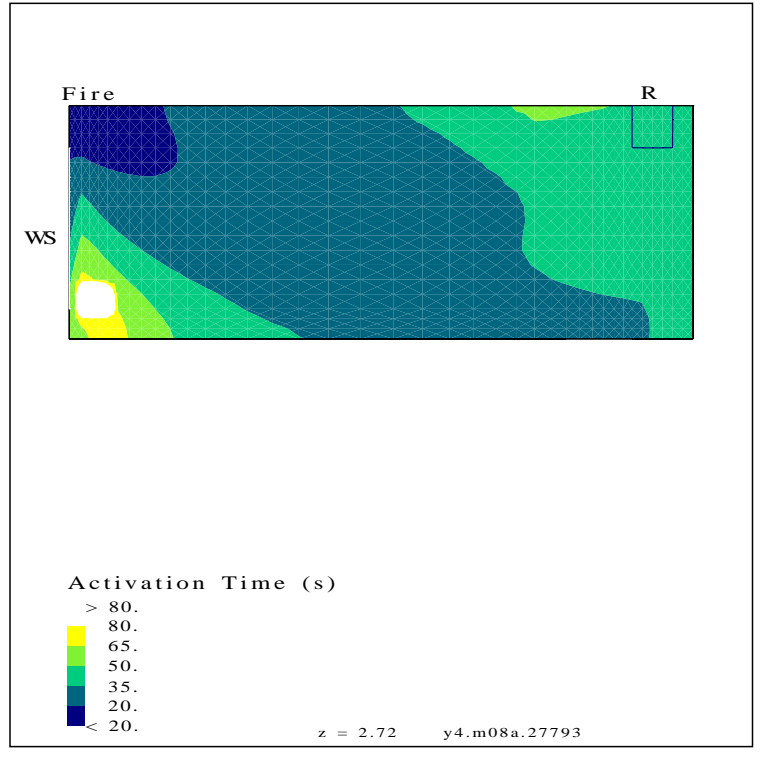

(a) At $0.02 \mathrm{~m}$ (0.79 in) below the ceiling

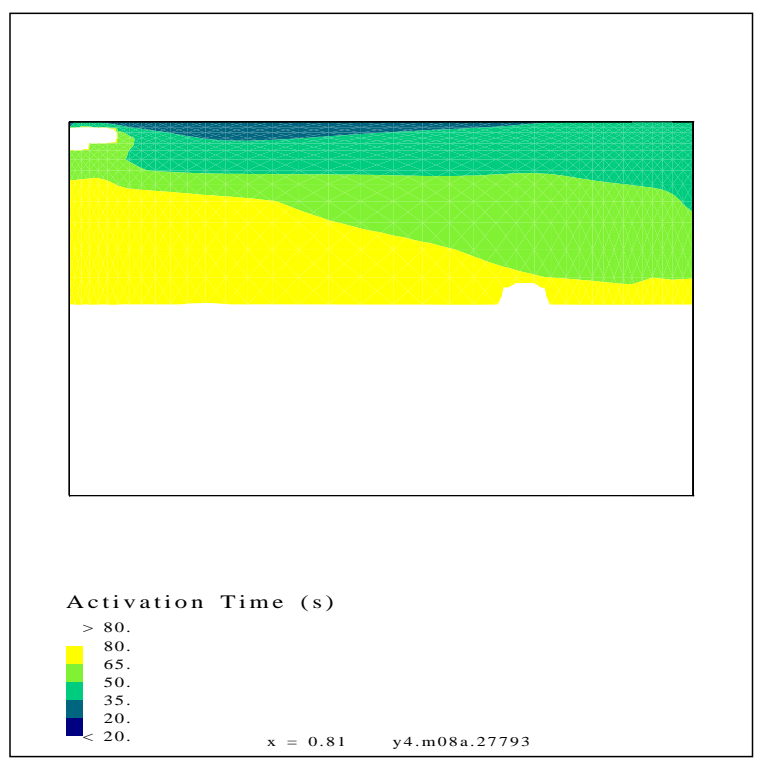

(c) Centerline of the diffuser

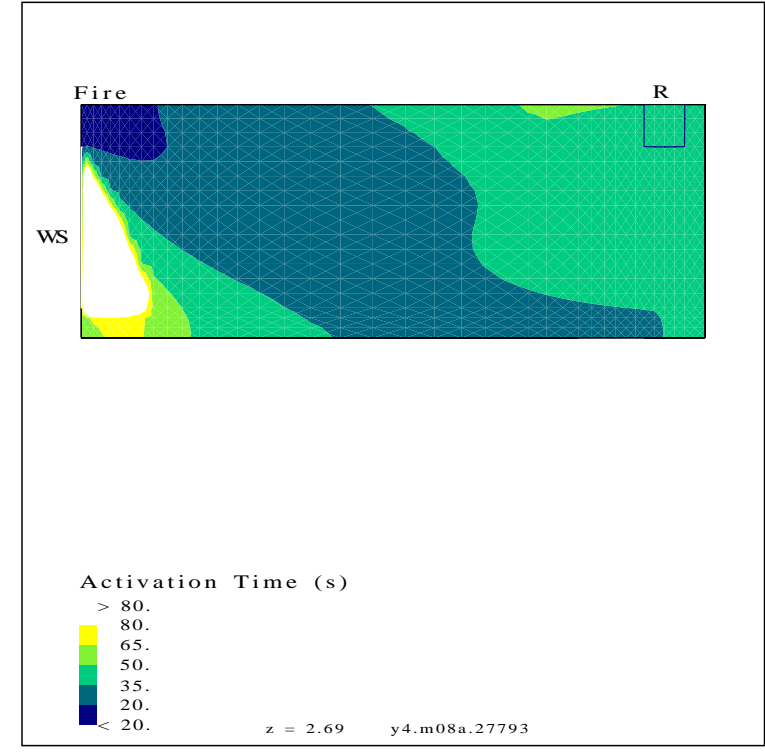

(b) At $0.05 \mathrm{~m}$ (2.0 in) below the ceiling

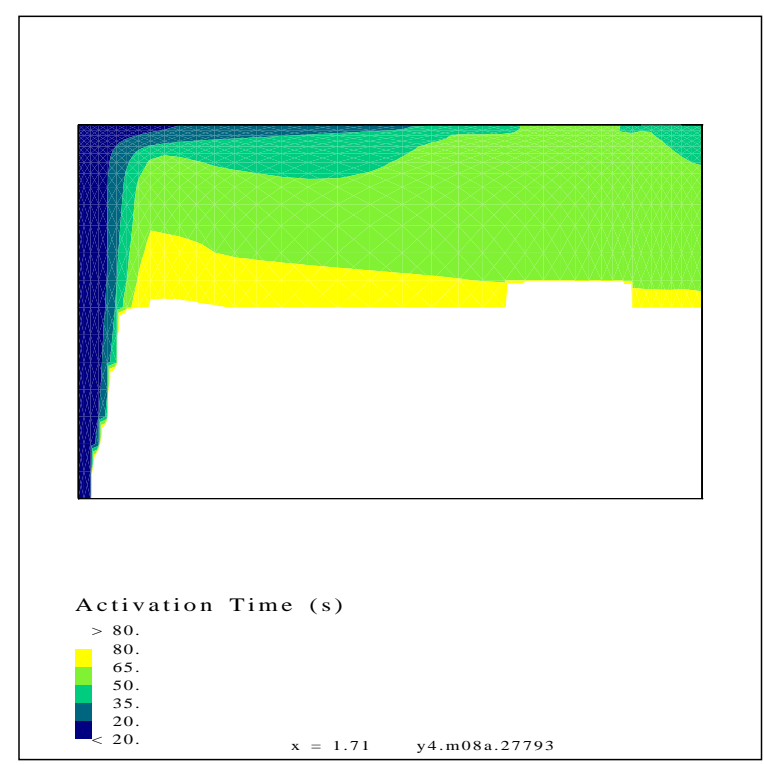

(d) Plane of symmetry

Figure 28: Simulated activation time in the medium room from run 20.

Note: See figure 5 for the location of the plane of symmetry and the plane at the centerline of the diffuser. 


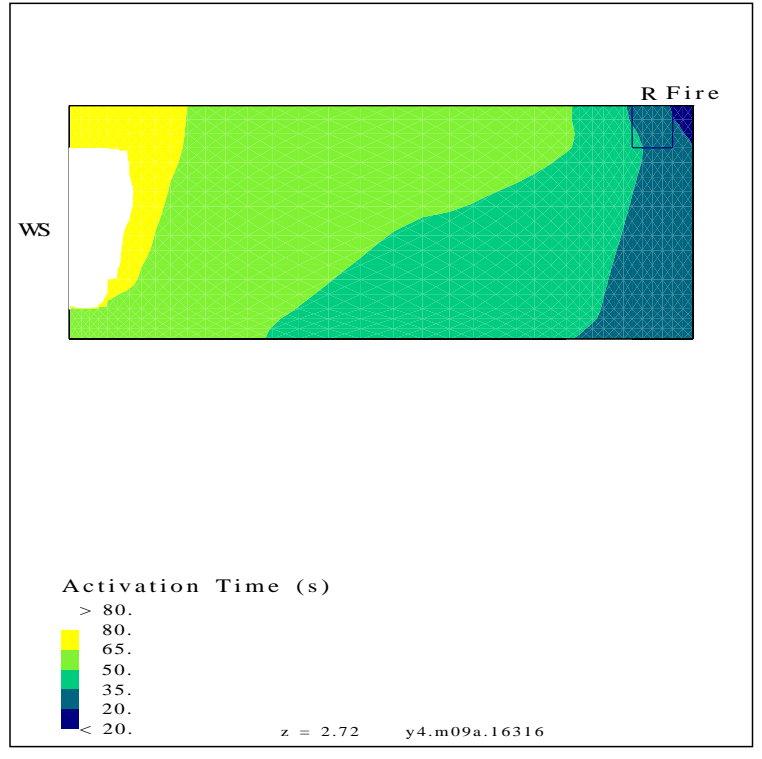

(a) At $0.02 \mathrm{~m}$ (0.79 in) below the ceiling

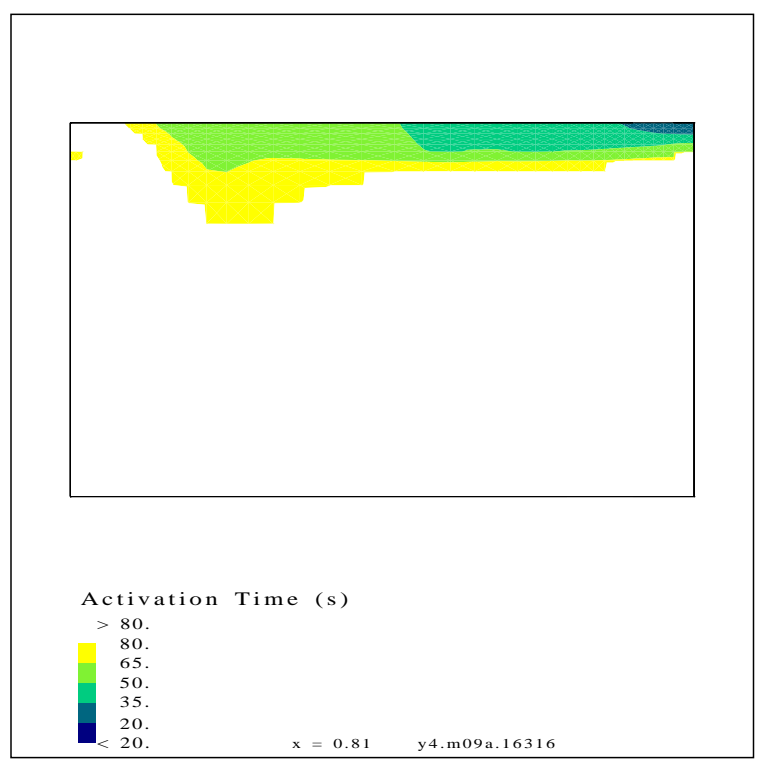

(c) Centerline of the diffuser

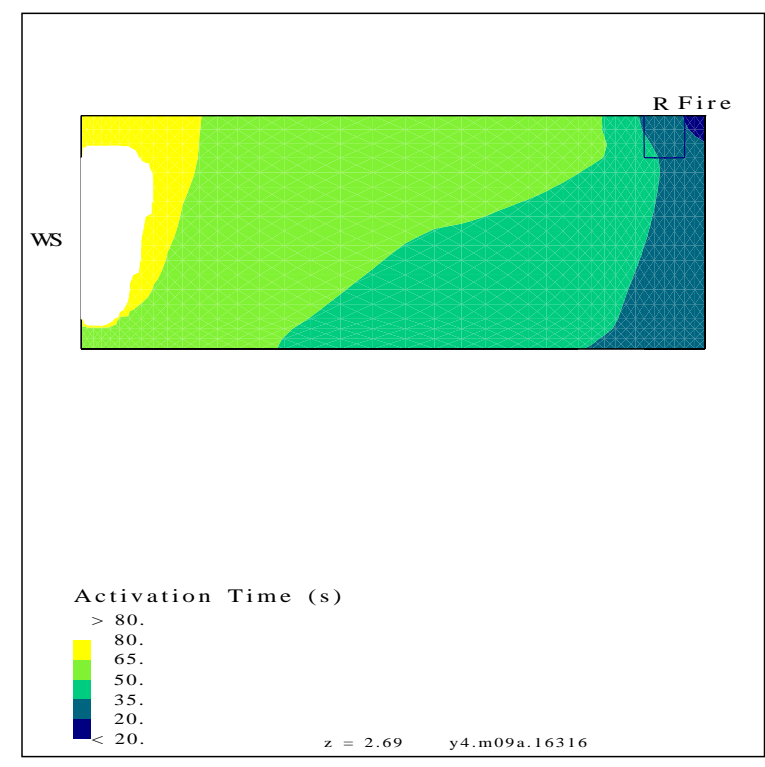

(b) At $0.05 \mathrm{~m}$ (2.0 in) below the ceiling

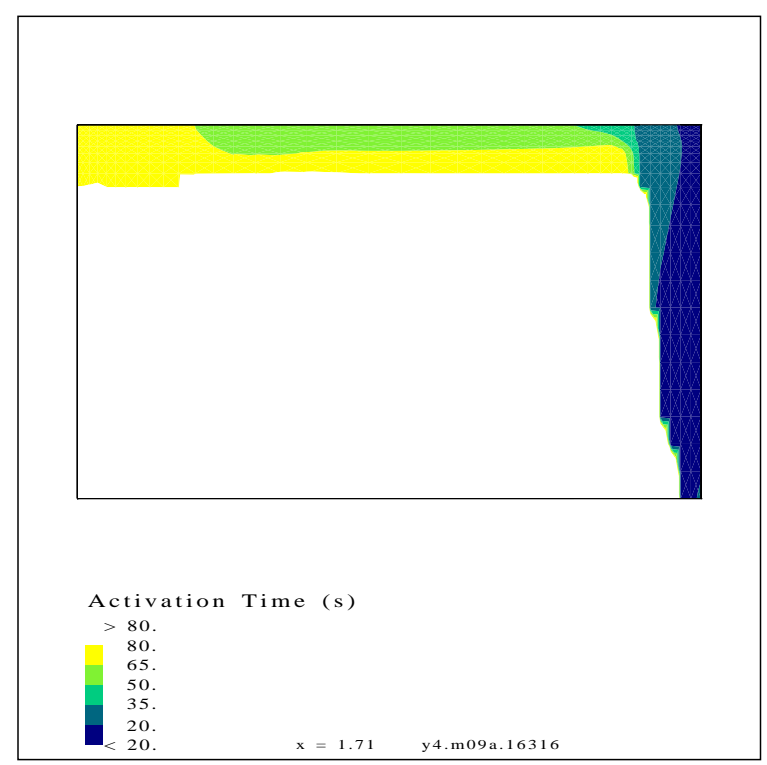

(d) Plane of symmetry

Figure 29: Simulated activation time in the medium room from run 21.

Note: See figure 5 for the location of the plane of symmetry and the plane at the centerline of the diffuser. 


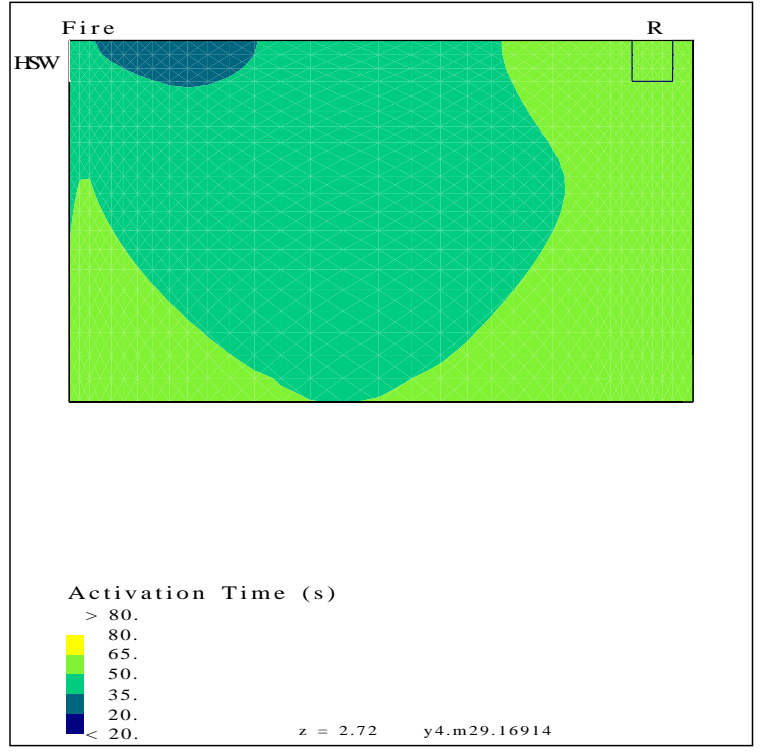

(a) At $0.02 \mathrm{~m}$ (0.79 in) below the ceiling

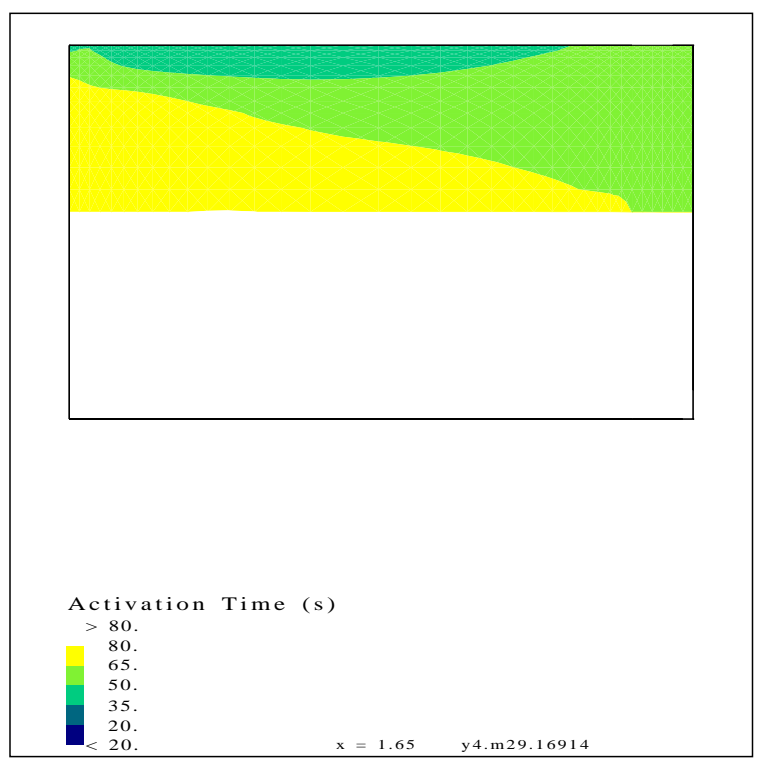

(c) Centerline of the diffuser

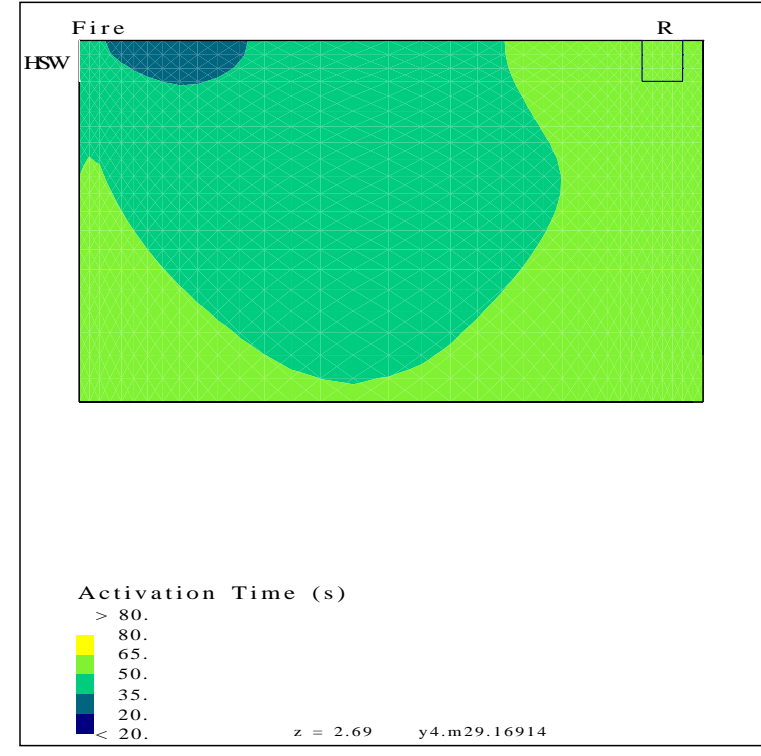

(b) At $0.05 \mathrm{~m}$ (2.0 in) below the ceiling

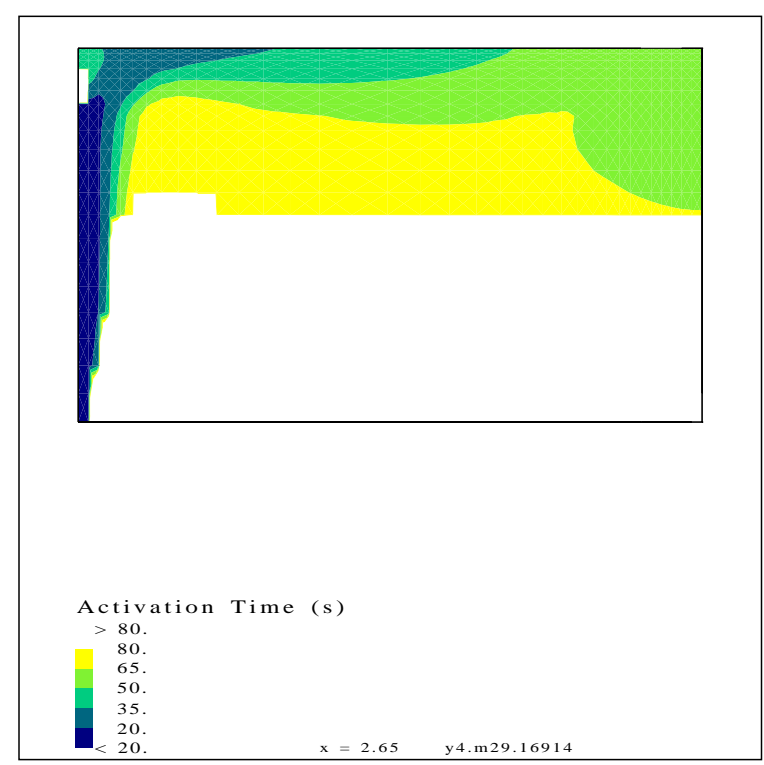

(d) Plane of symmetry

Figure 30: Simulated activation time in the medium room from run 22.

Note: See figure 5 for the location of the plane of symmetry and the plane at the centerline of the diffuser. 


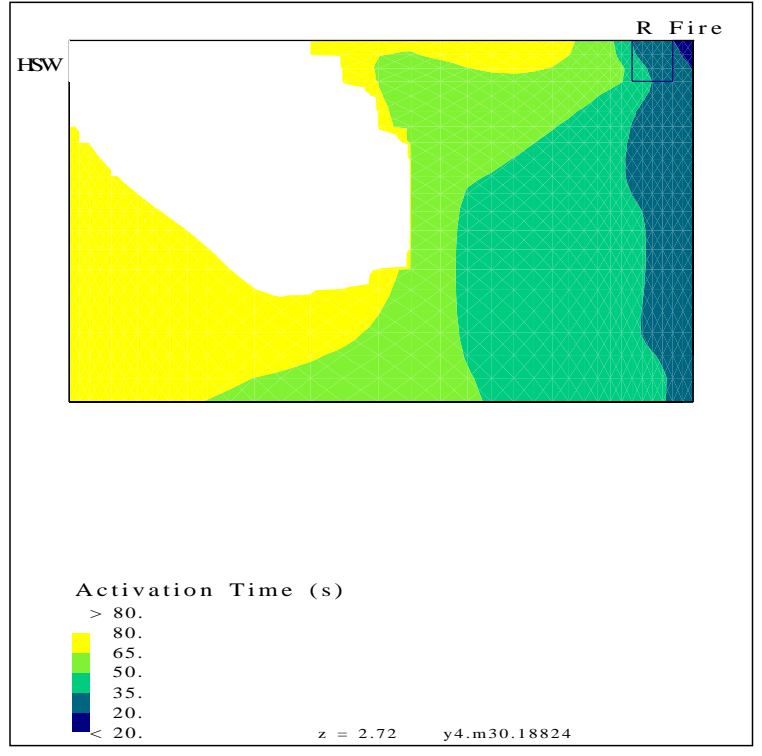

(a) At $0.02 \mathrm{~m}$ (0.79 in) below the ceiling

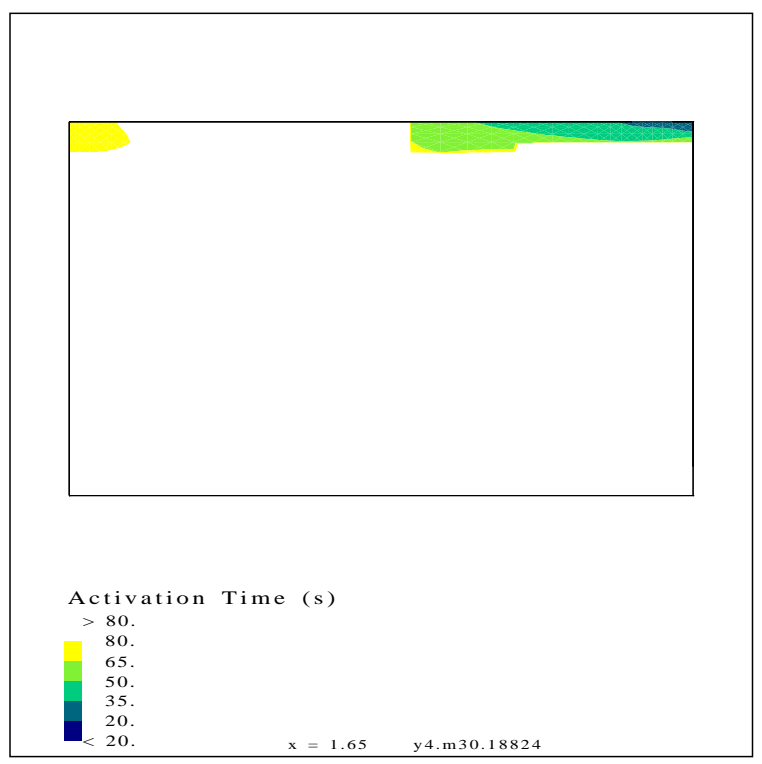

(c) Centerline of the diffuser

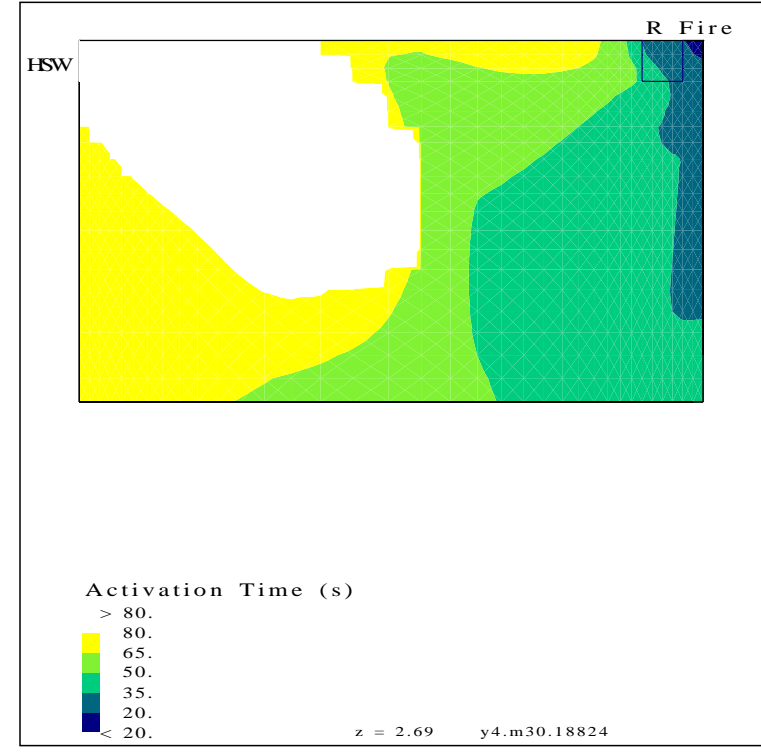

(b) At $0.05 \mathrm{~m}$ (2.0 in) below the ceiling

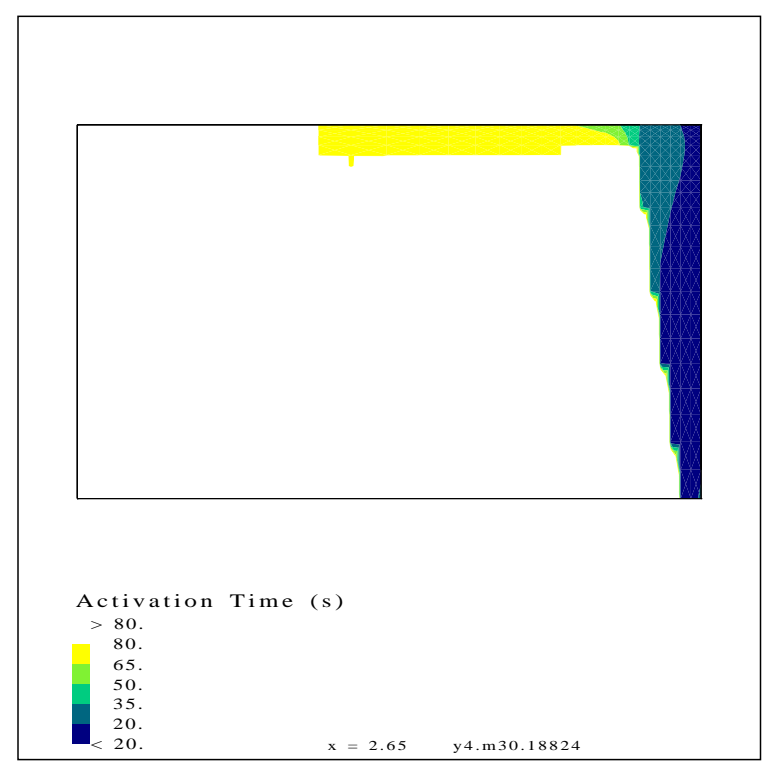

(d) Plane of symmetry

Figure 31: Simulated activation time in the open plan room from run 23.

Note: See figure 6 for the location of the plane of symmetry and the plane at the centerline of the diffuser. 


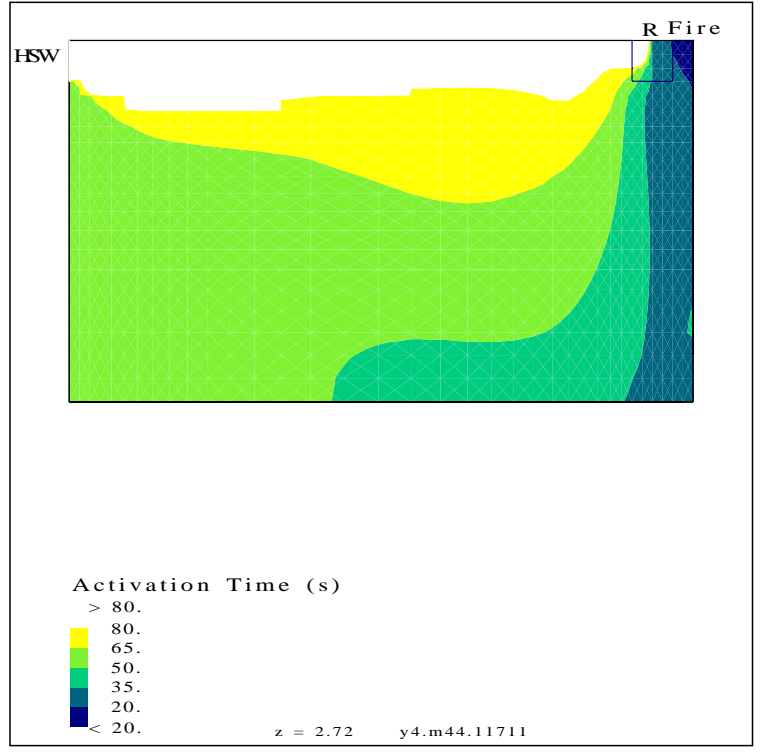

(a) At $0.02 \mathrm{~m}$ (0.79 in) below the ceiling

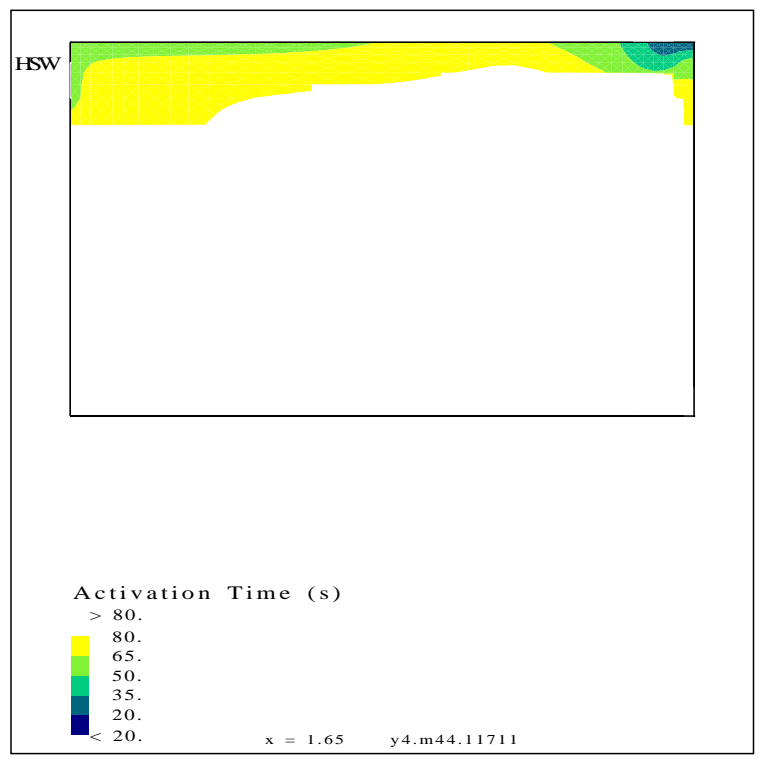

(c) Centerline of the diffuser

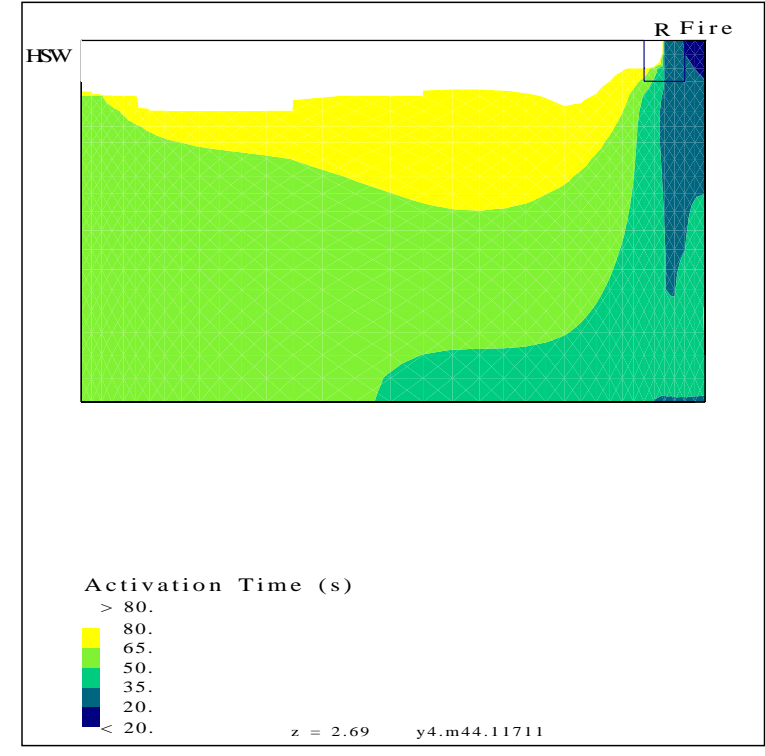

(b) At $0.05 \mathrm{~m}$ (2.0 in) below the ceiling

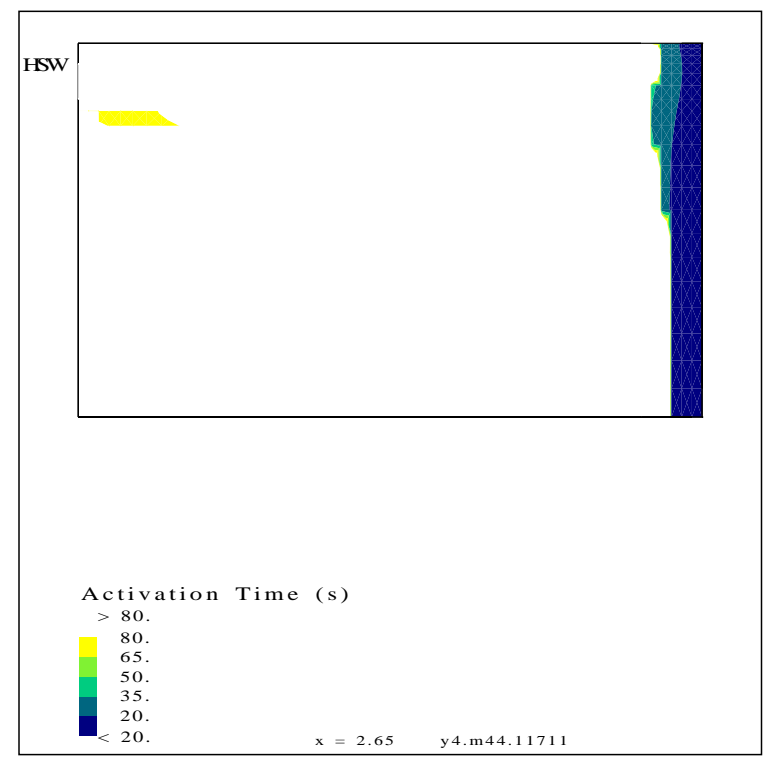

(d) Plane of symmetry

Figure 32: Simulated activation time in the open plan room from run 24.

Note: See figure 6 for the location of the plane of symmetry and the plane at the centerline of the diffuser. 


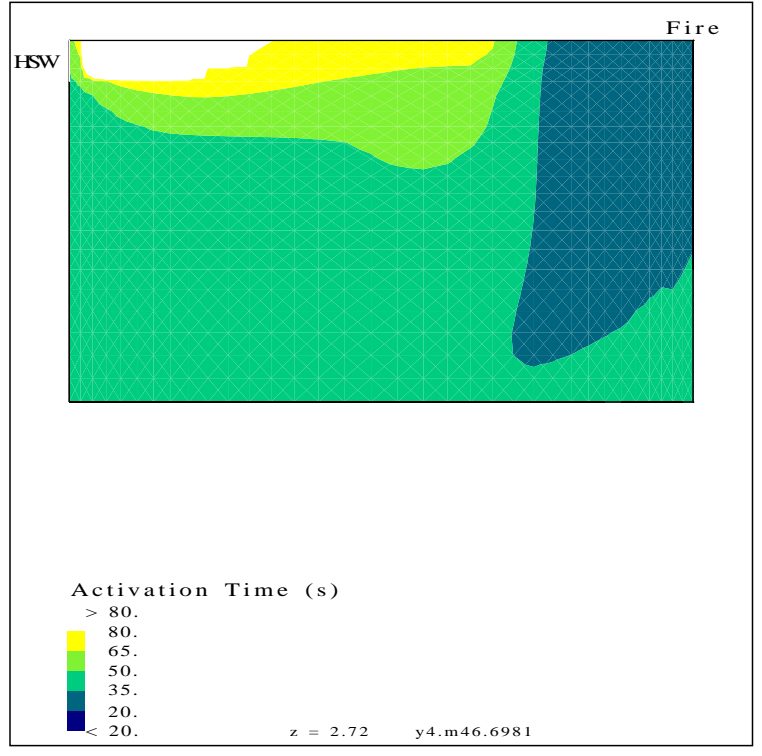

(a) At $0.02 \mathrm{~m}(0.79 \mathrm{in})$ below the ceiling

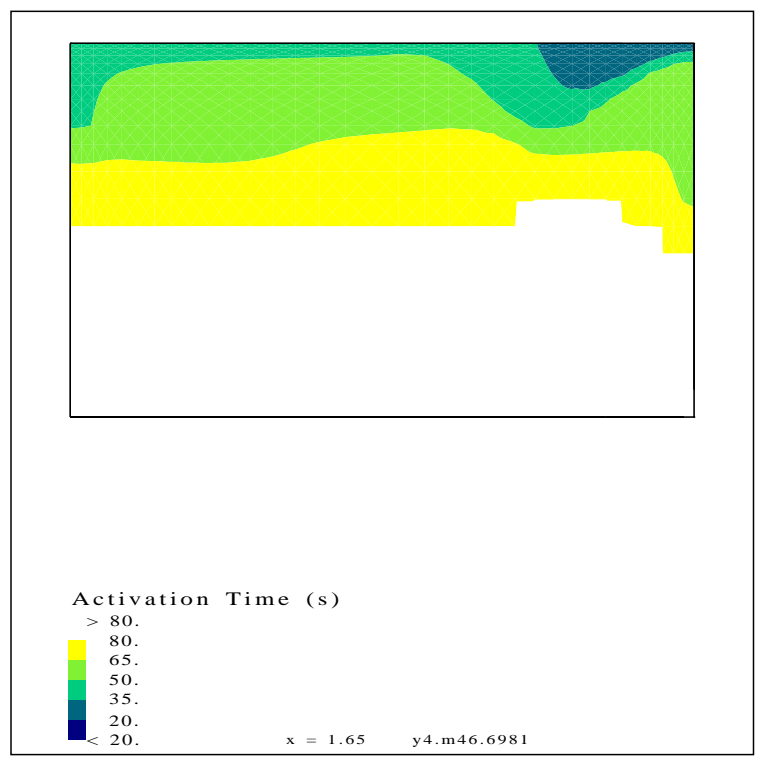

(c) Centerline of the diffuser

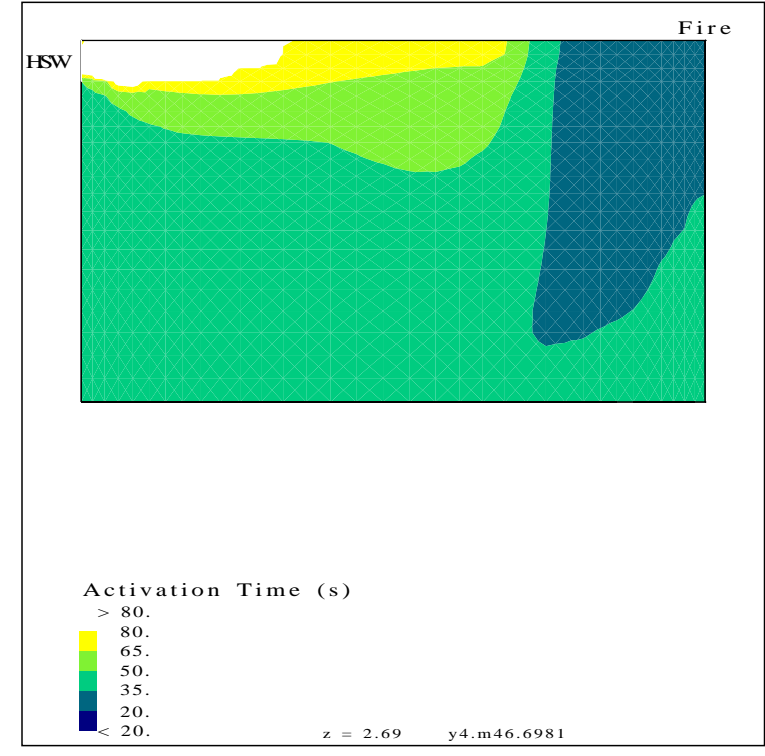

(b) At $0.05 \mathrm{~m}$ (2.0 in) below the ceiling

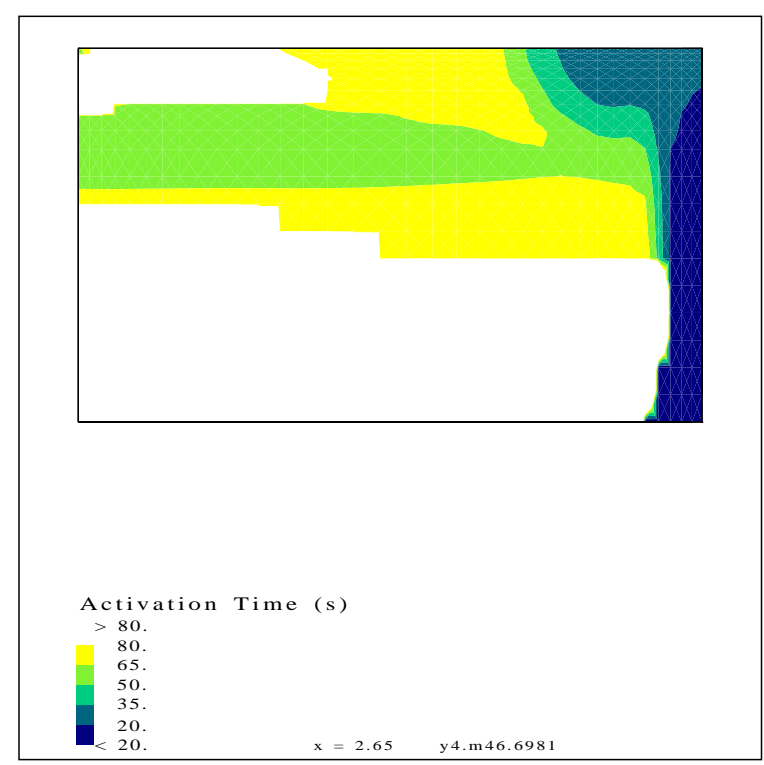

(d) Plane of symmetry

Figure 33: Simulated activation time in the open plan room from run 25.

Note: See figure 6 for the location of the plane of symmetry and the plane at the centerline of the diffuser. 


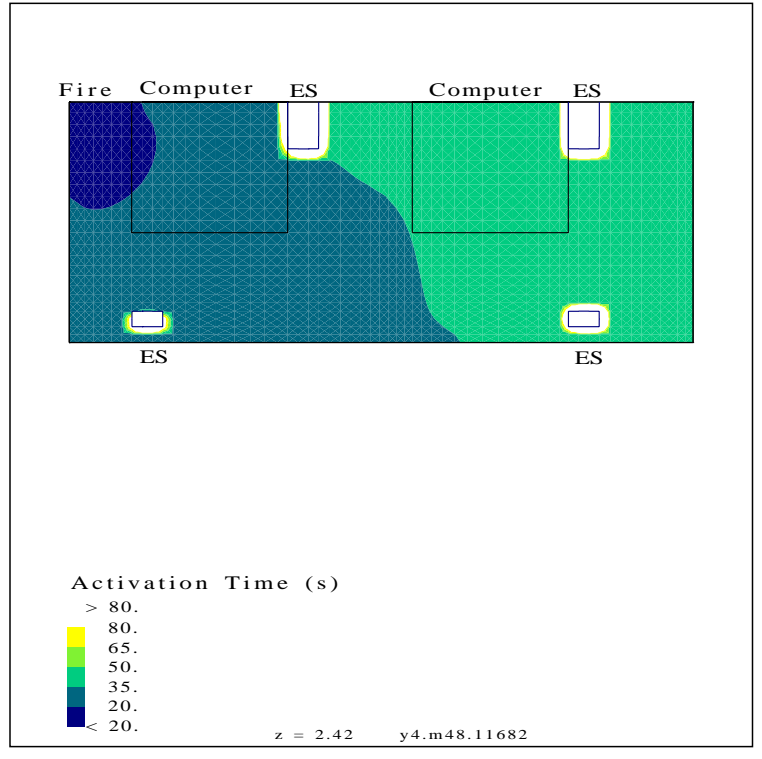

(a) At $0.02 \mathrm{~m}$ (0.79 in) below the ceiling

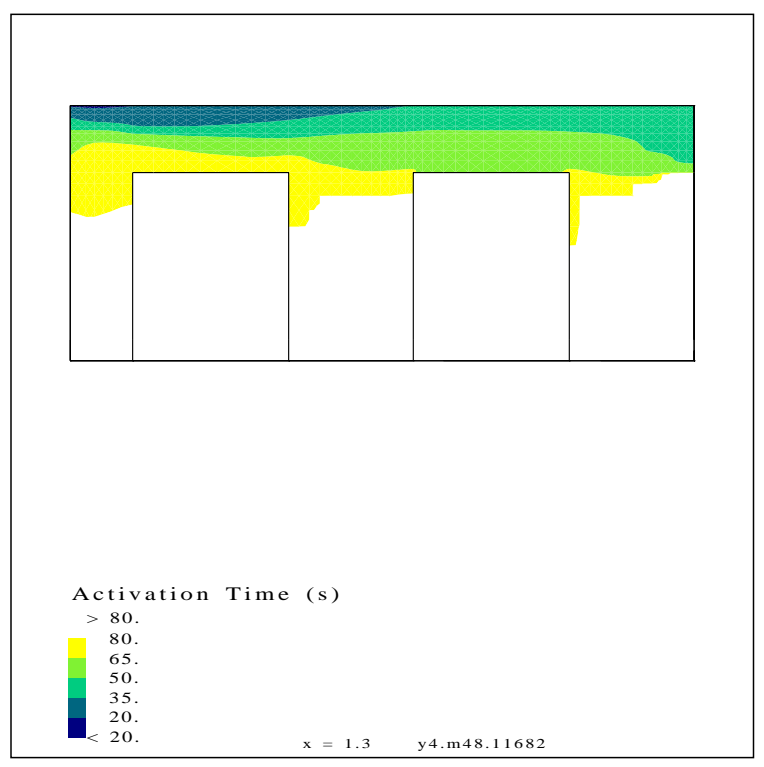

(c) Centerline of the diffuser

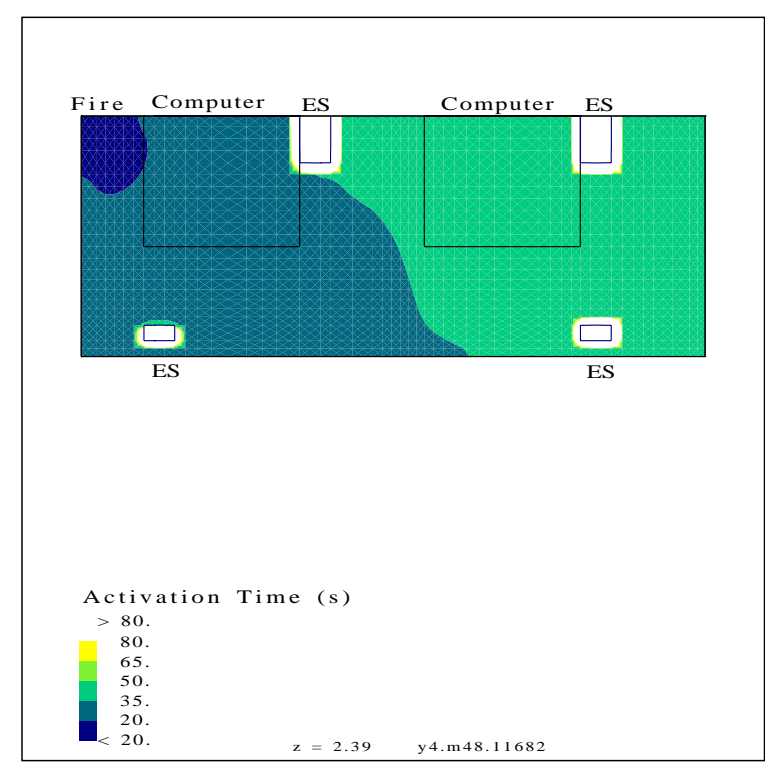

(b) At $0.05 \mathrm{~m}$ (2.0 in) below the ceiling

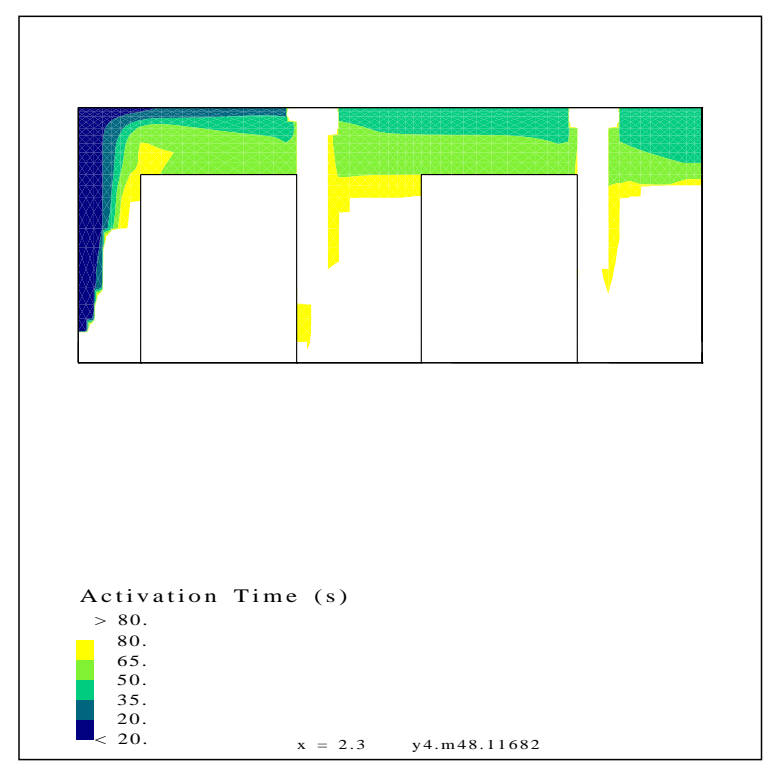

(d) Plane of symmetry

Figure 34: Simulated activation time in the open plan room from run 26.

Note: See figure 6 for the location of the plane of symmetry and the plane at the centerline of the diffuser. 


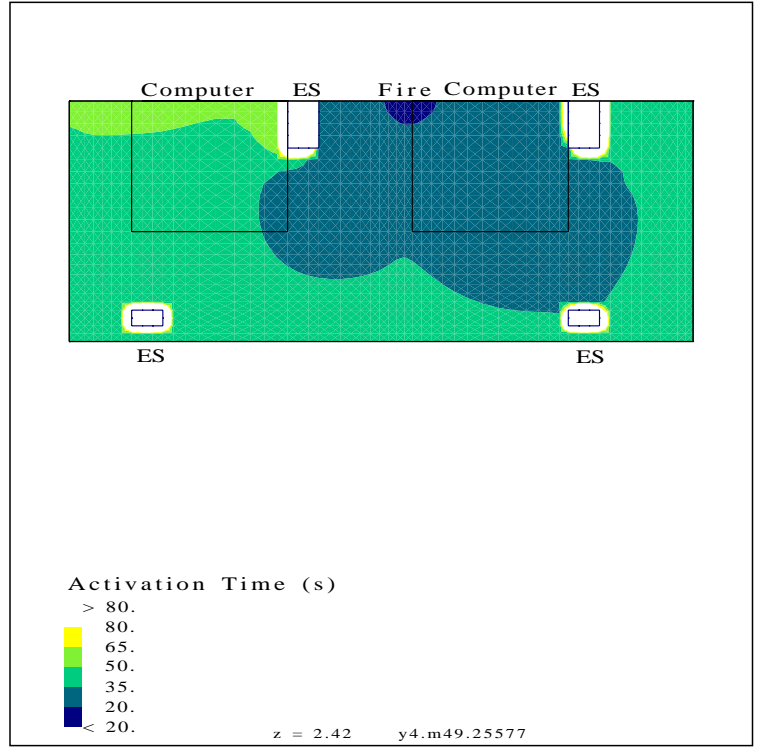

(a) At $0.02 \mathrm{~m}$ (0.79 in) below the ceiling

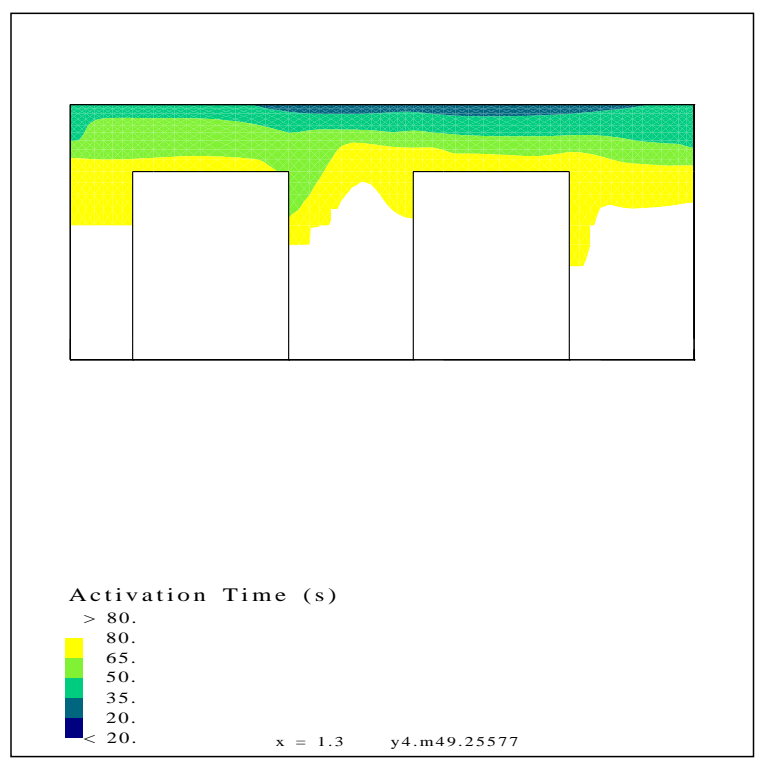

(c) Centerline of the diffuser

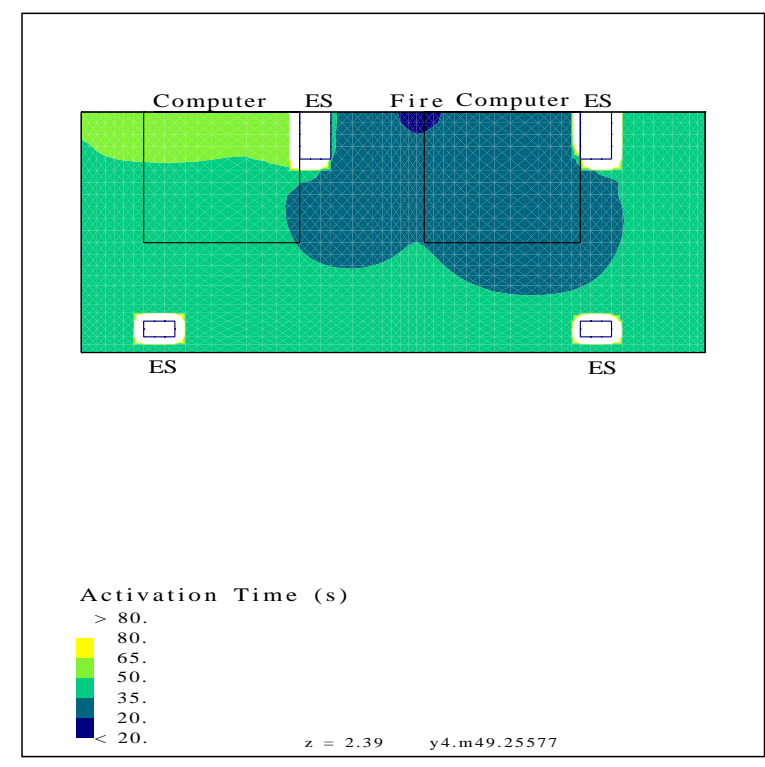

(b) At $0.05 \mathrm{~m}$ (2.0 in) below the ceiling

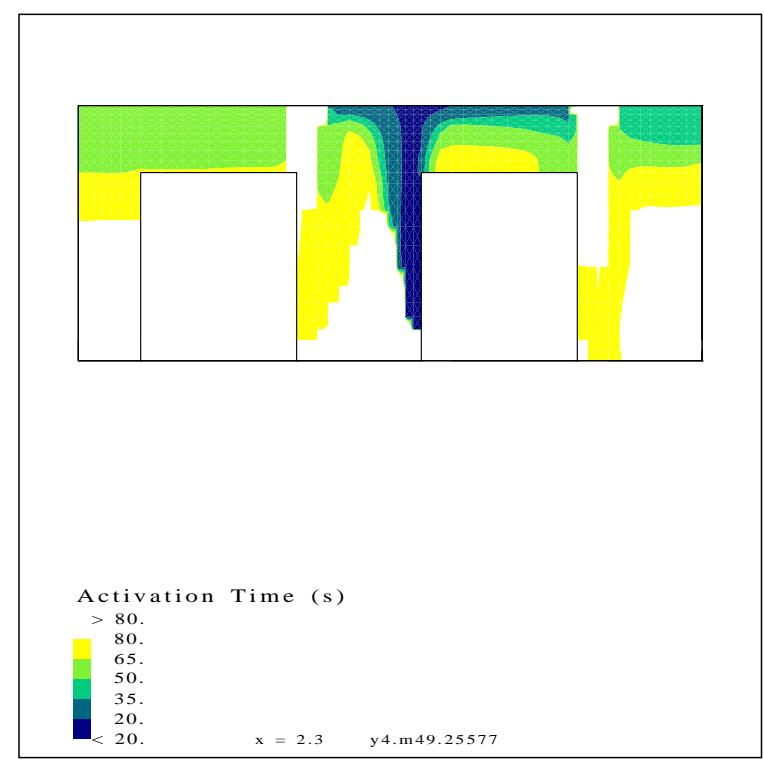

(d) Plane of symmetry

Figure 35: Simulated activation time in the open plan room from run 27.

Note: See figure 6 for the location of the plane of symmetry and the plane at the centerline of the diffuser. 


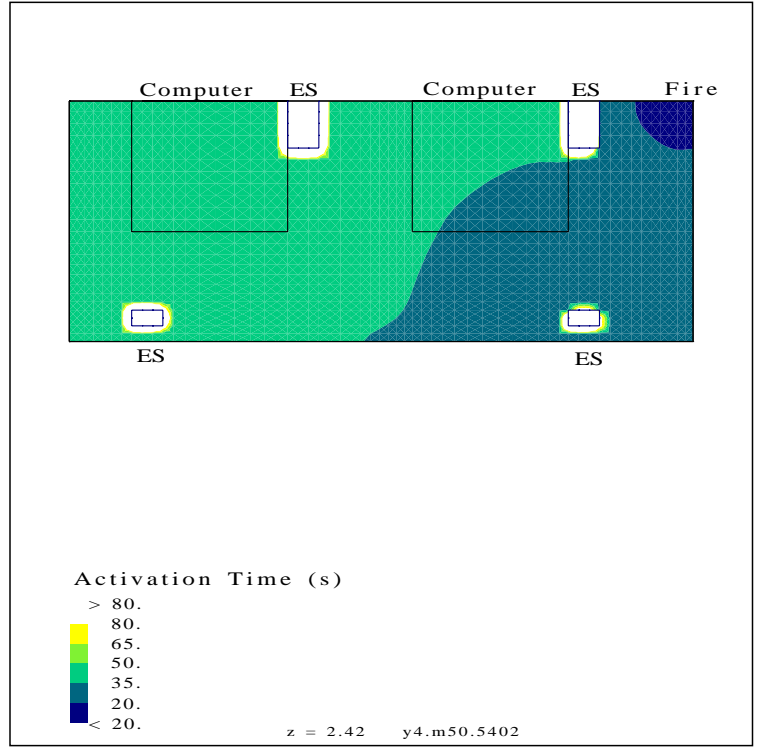

(a) At $0.02 \mathrm{~m}$ (0.79 in) below the ceiling

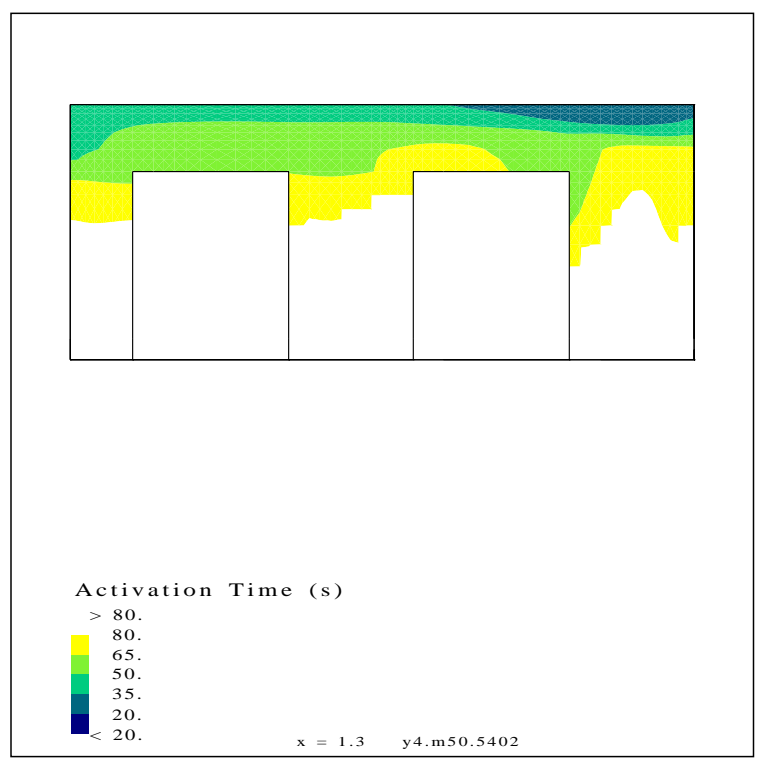

(c) Centerline of the diffuser

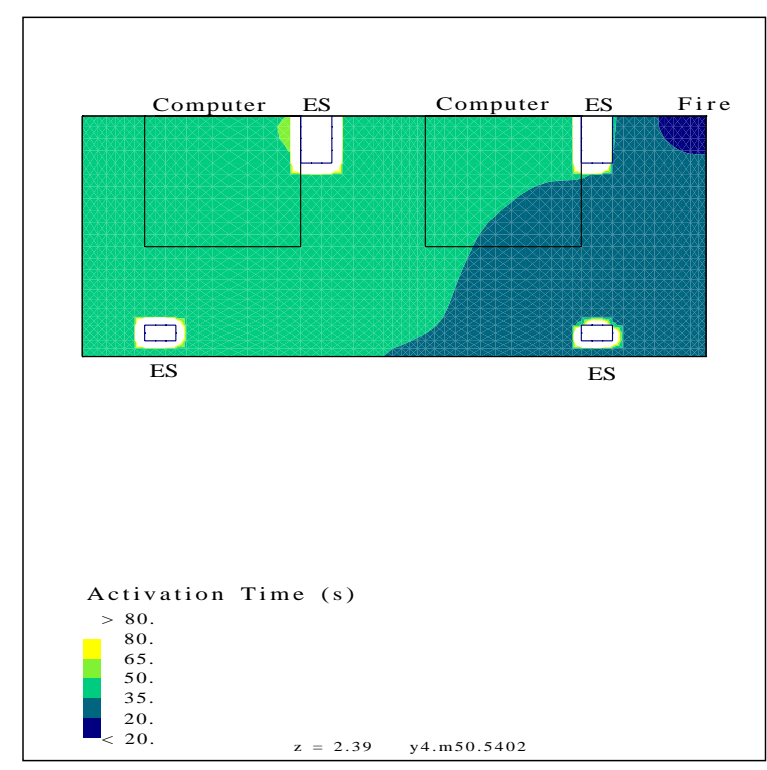

(b) At $0.05 \mathrm{~m}$ (2.0 in) below the ceiling

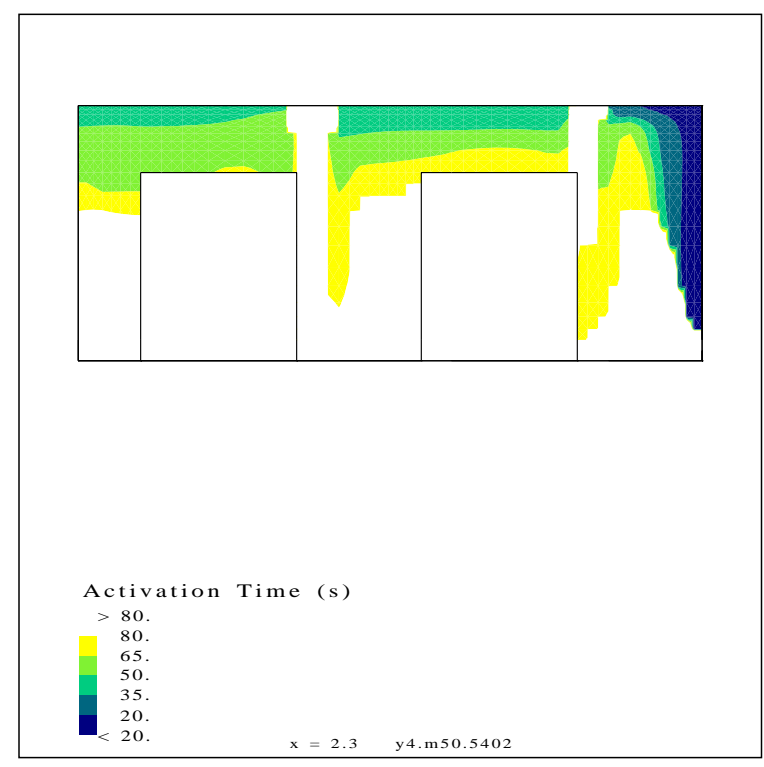

(d) Plane of symmetry

Figure 36: Simulated activation time in the open plan room from run 28.

Note: See figure 6 for the location of the plane of symmetry and the plane at the centerline of the diffuser. 


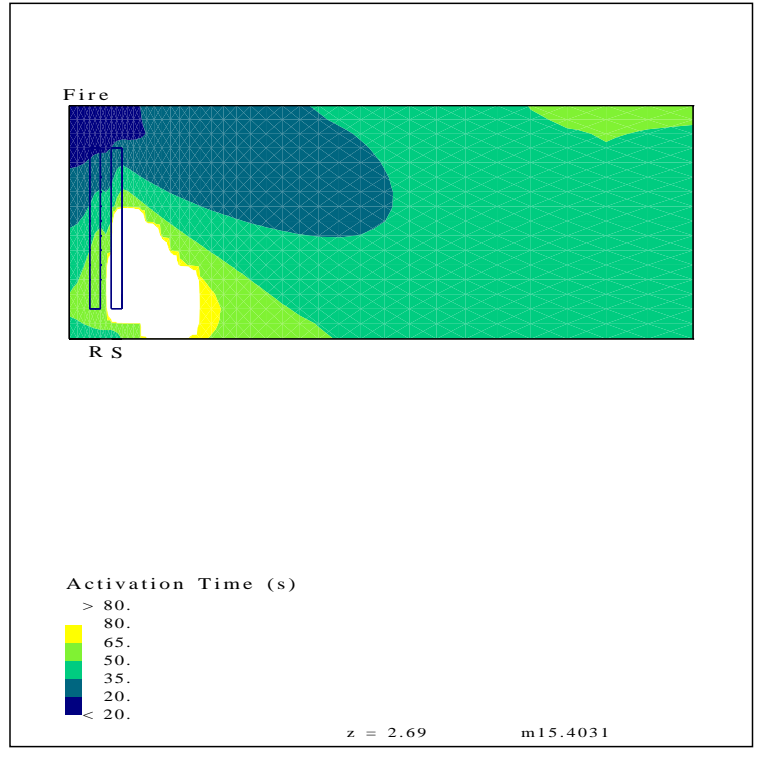

(a) At $0.02 \mathrm{~m}$ ( $0.79 \mathrm{in})$ below the ceiling

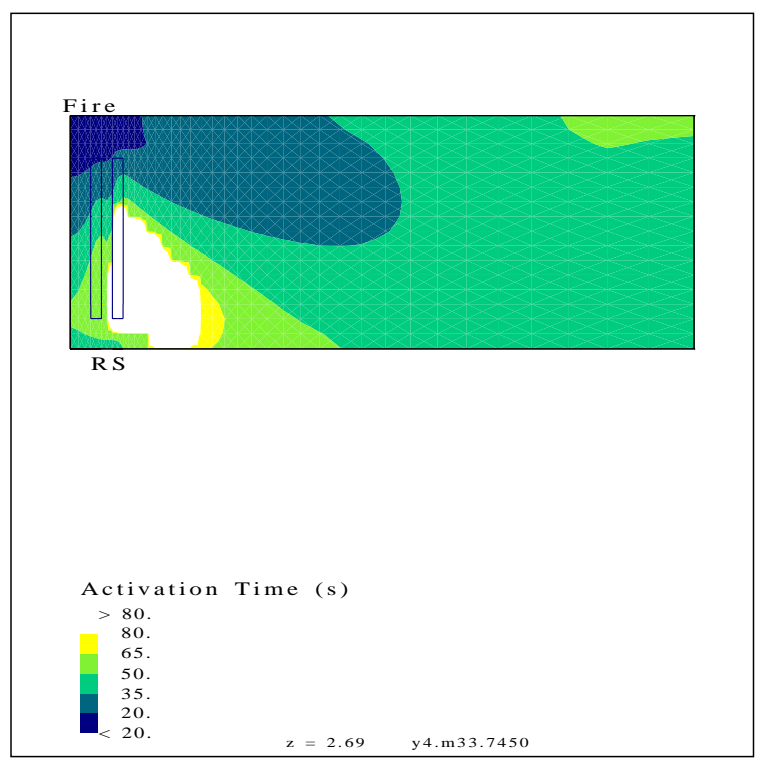

(c) Centerline of the diffuser

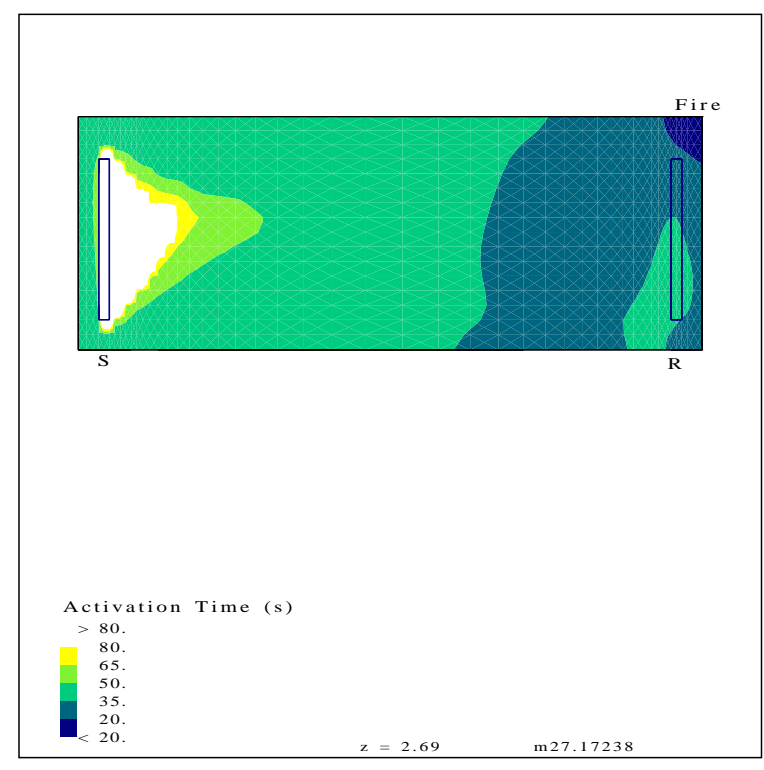

(b) At $0.05 \mathrm{~m}$ ( $2.0 \mathrm{in})$ below the ceiling

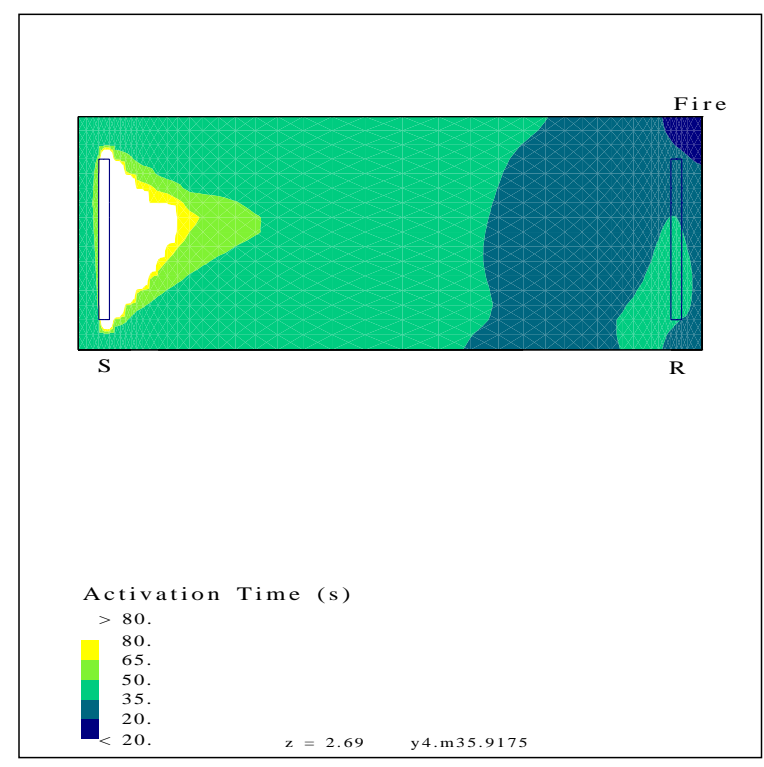

(d) Plane of symmetry

Figure 37: Simulated activation time in the open plan room from run 29.

Note: See figure 6 for the location of the plane of symmetry and the plane at the centerline of the diffuser. 


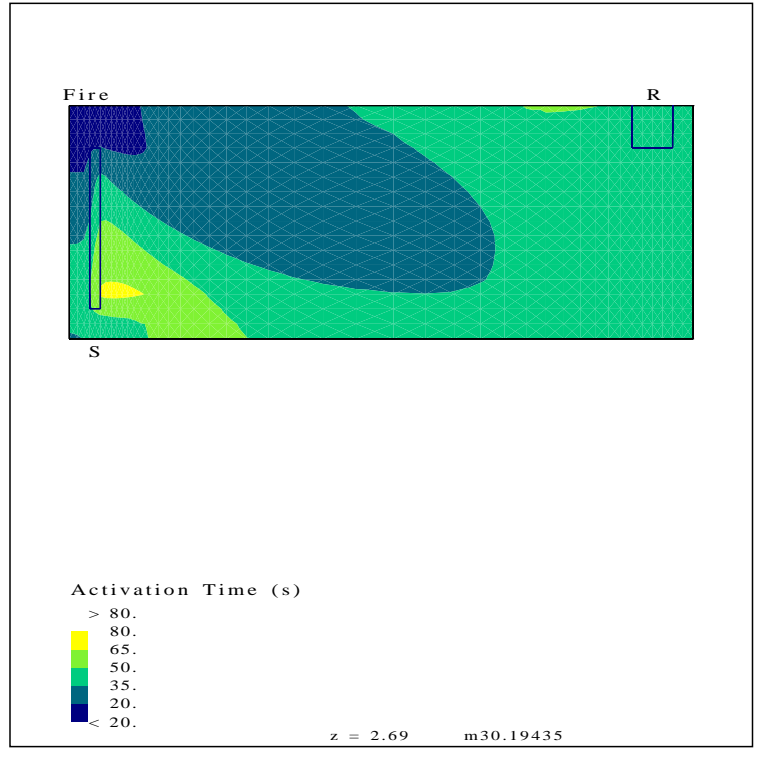

(a) At $0.02 \mathrm{~m}$ (0.79 in) below the ceiling

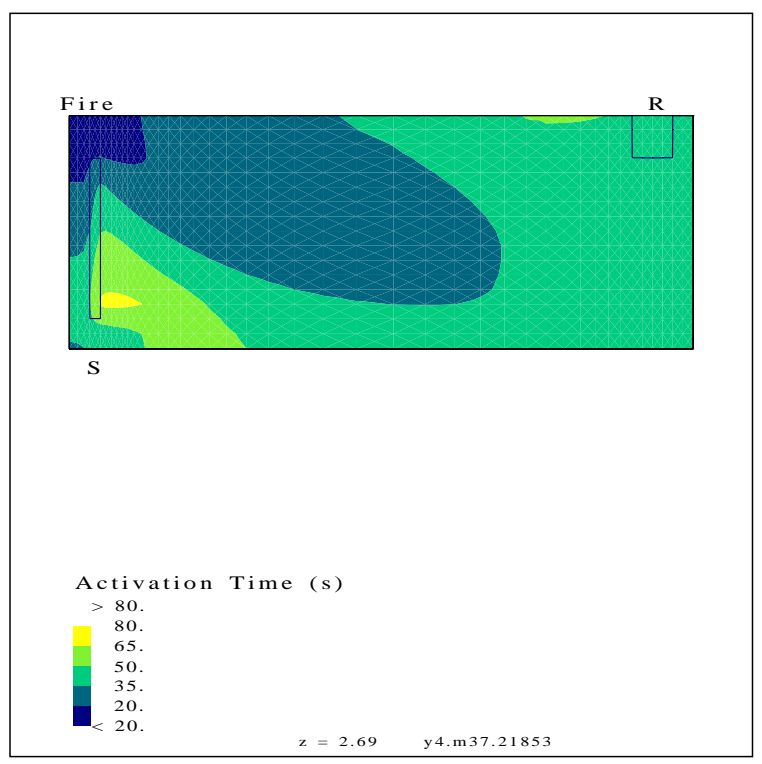

(c) Centerline of the diffuser

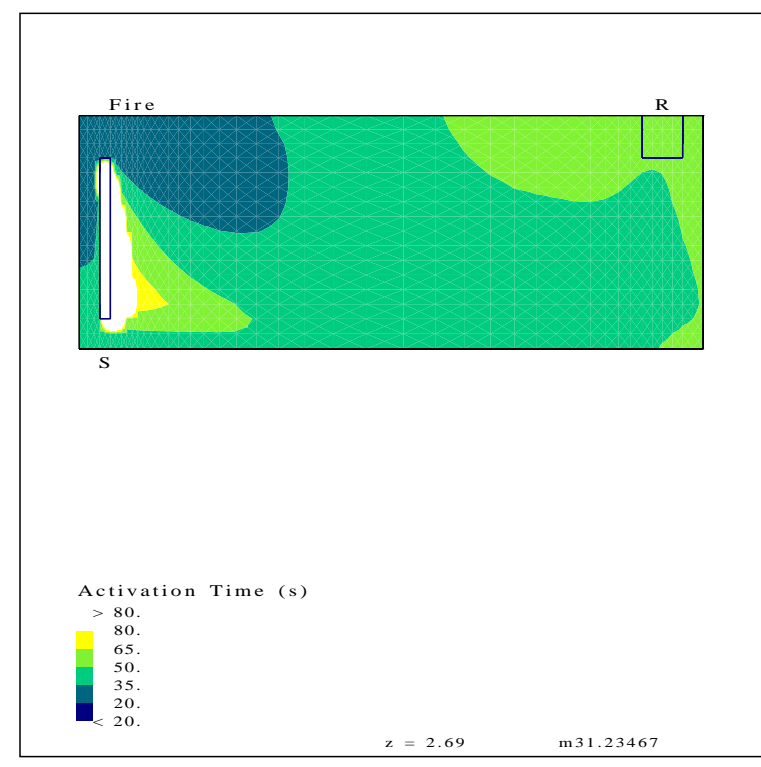

(b) At $0.05 \mathrm{~m}$ (2.0 in) below the ceiling

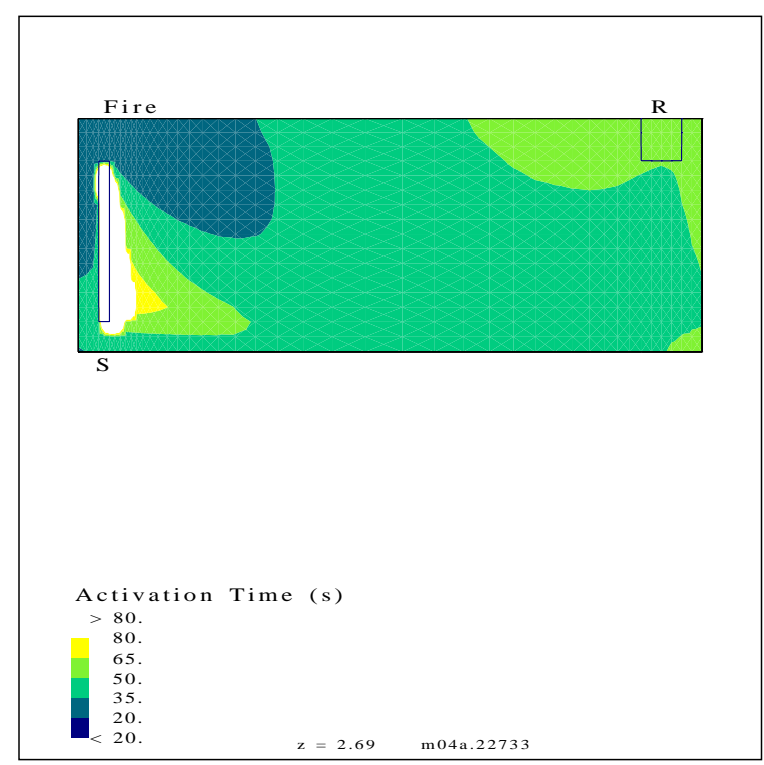

(d) Plane of symmetry

Figure 38: Simulated activation time in the open plan room from run 30.

Note: See figure 6 for the location of the plane of symmetry and the plane at the centerline of the diffuser. 


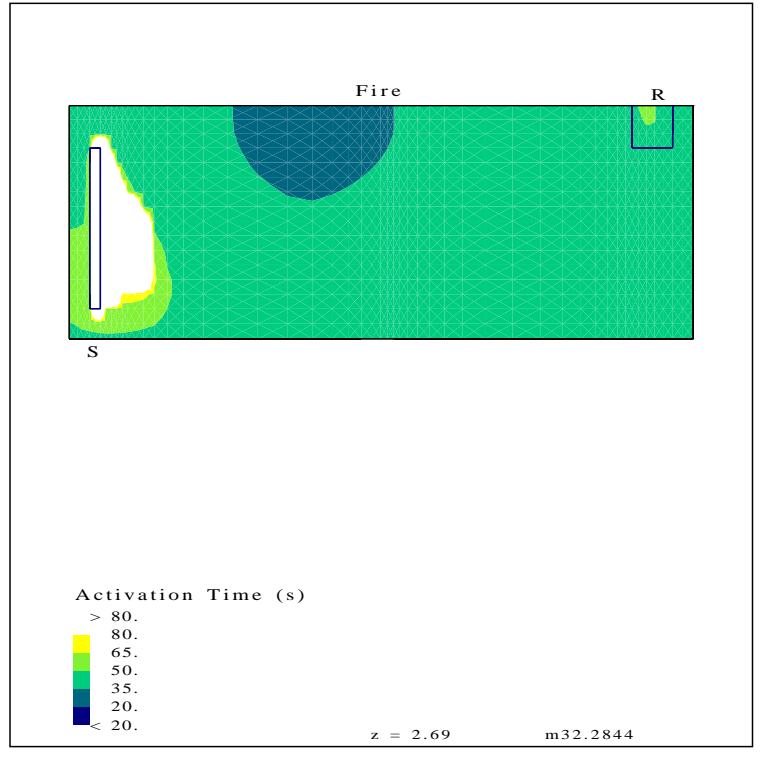

(a) At $0.02 \mathrm{~m}$ (0.79 in) below the ceiling

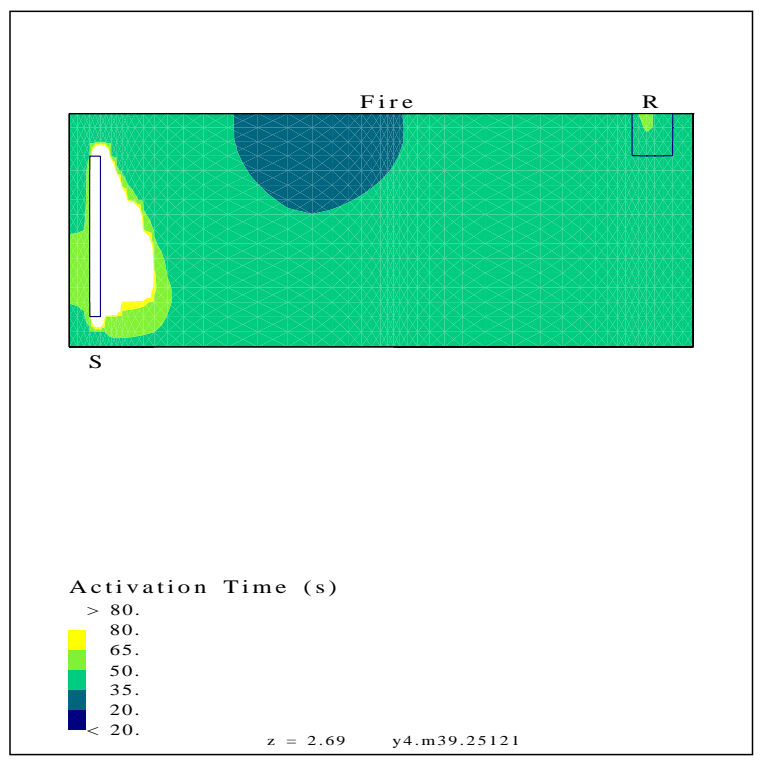

(c) Centerline of the diffuser

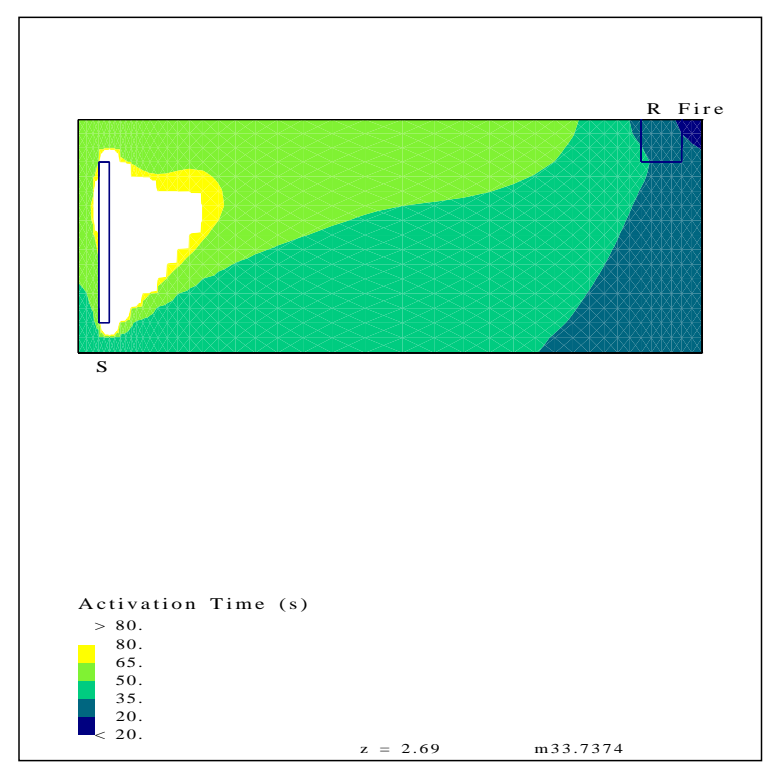

(b) At $0.05 \mathrm{~m}$ (2.0 in) below the ceiling

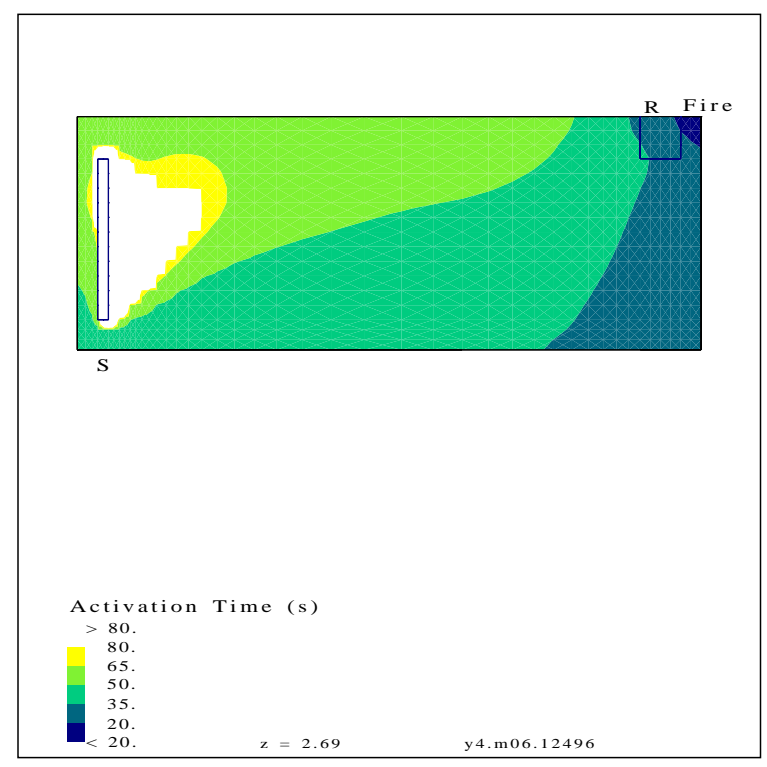

(d) Plane of symmetry

Figure 39: Simulated activation time in the open plan room from run 31.

Note: See figure 6 for the location of the plane of symmetry and the plane at the centerline of the diffuser. 


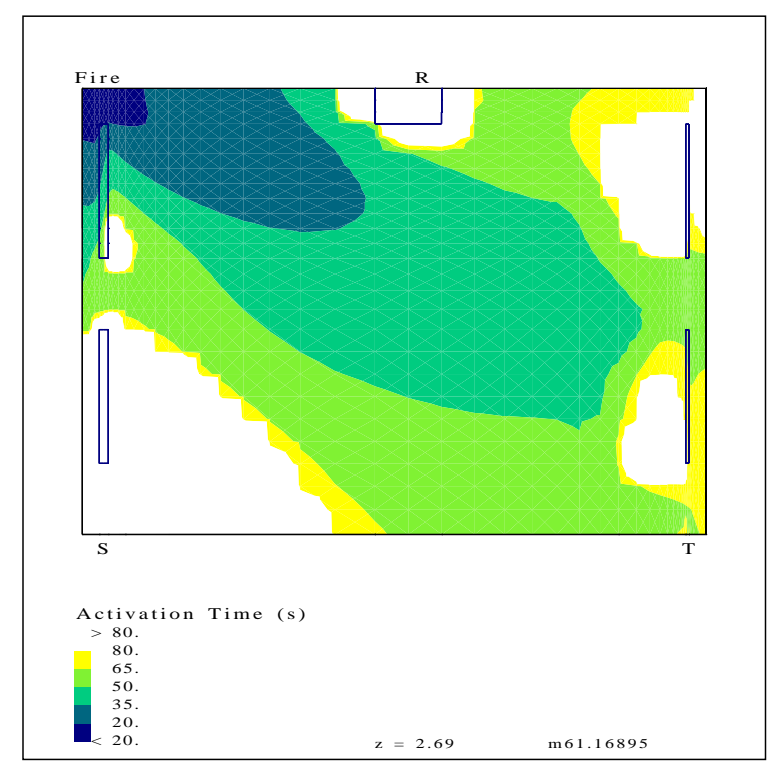

(a) Based on mass density from run 16

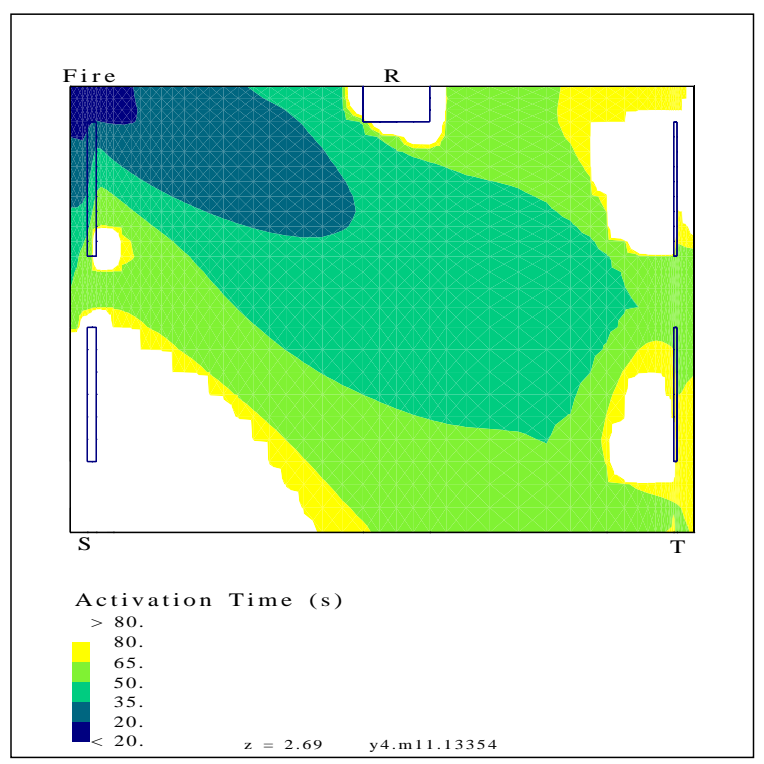

(c) Based on mass density from run 26

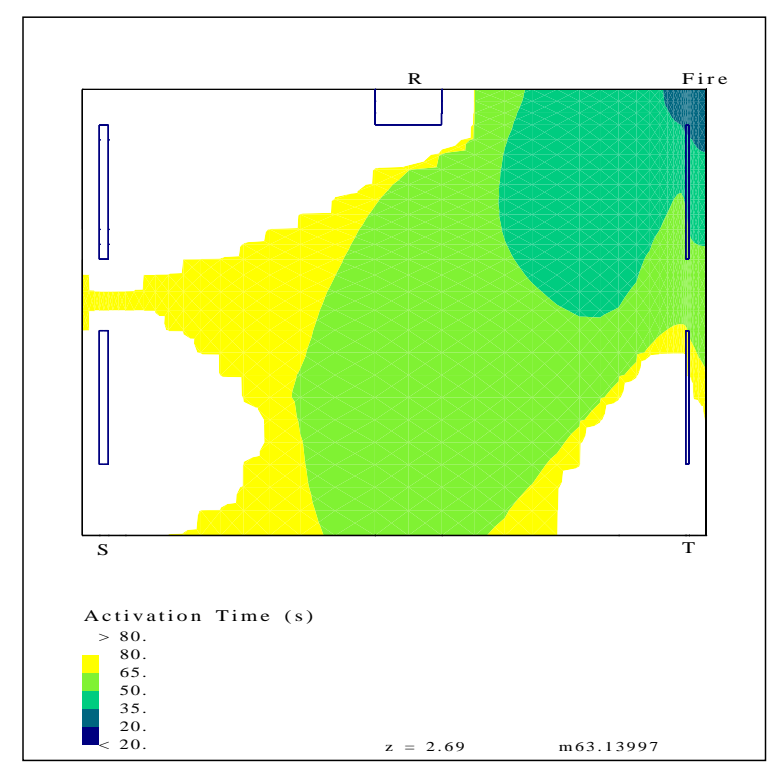

(b) Based on temperature rise from run 16

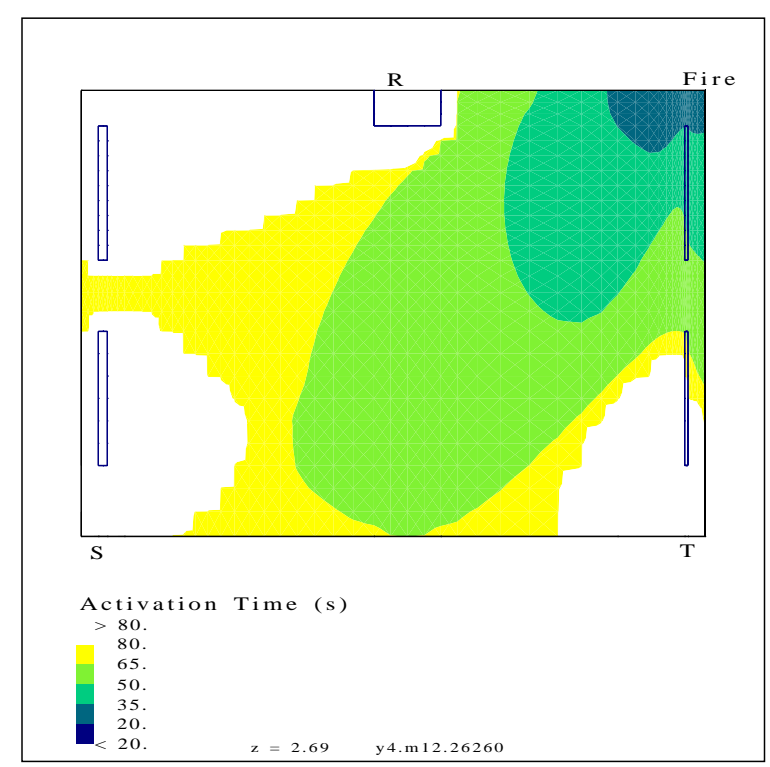

(d) Based on temperature rise from run 26

Figure 40: Comparison of simulated activation times based on temperature rise and on mass density at $0.05 \mathrm{~m}$ ( $2.0 \mathrm{in})$ below the ceiling. Note: See figure 2 for the location of the plane of symmetry, and see figures 5 and 6 for the location of the plane at the centerline of the diffuser. 


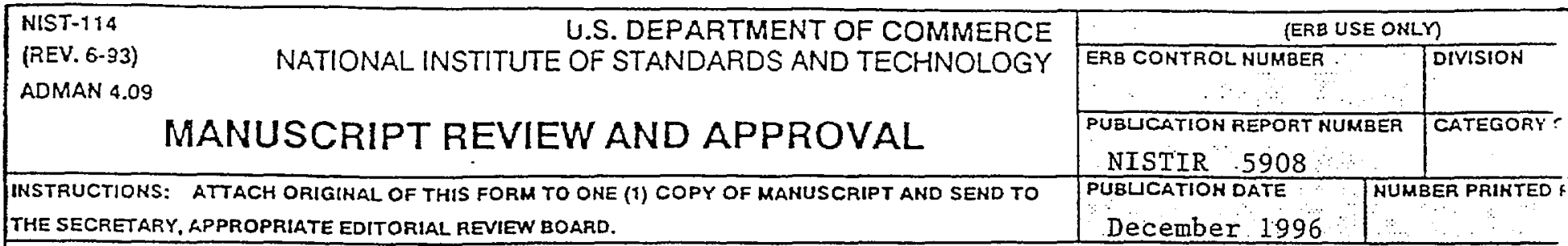
THE SECRETARY, APPROPRIATE EDITORIAL REVIEW BOARD. TITLE AND SUBTITLE (CITE IN FULL)

Simulating the Effects of HVAC Induced Air Flow From Slot Diffusers on Detector Response CONTRACT OR GRANT NUMBER TYPE OF REPORT AND/OR PERIOD COVERED AUTHOR(S) (LAST NAME, FIRST INITIAL, SECOND INITIAL) Klote, John H. Bukowski, Richard W. Forney, Glenn P. Davis, William D. LABORATORY AND DIVISION NAMES (FIRST NIST AUTHOR ONLY) SPONSORING ORGANIZATION NAME AND COMPLETE ADDRESS (STREET, CITY, STATE, ZIP)

National Fire Protection Research Foundation

I Batterymarch Park, Quincy, MA 02269

\title{
PROPOSEO FOR NIST PUBUCATION
}

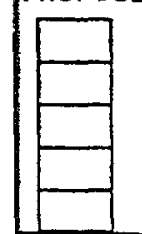
JOURNAL OF RESEARCH (NIST JRES) S. PHYS. \& CHEM. REF. DATA (JPCRD) HANDBOOK (HIST HB) SPECIAL PUBUCATION (NIST SP) TECHMICAL NOTE (NIST TK)

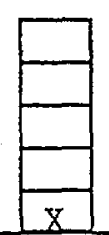

MONOGRAPH (NIST MN) NATL STD. REF. DATA SERIES (NIST NSADS) FEDERAL (NF. PROCESS. STDS. (MIST FIPS) UST OF PUBUCATIONS (NIST LP) MIST INTERAGENCY/INTERNAL REPORT (NISTIR)
PERFORMING ORGANIZATION (CHECK $囚$ ONE:

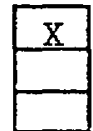

NIST/GAITHERSBURO

HIST/BOULDER

JILA/BOULDER

\begin{abstract}
PROPOSED FOR. NON-NIST PUELCATION (CITE FULLV)
\end{abstract}

$$
\text { s }
$$

SUPPLEMENTARY NOTES

ABSTRACT (A 2000-CHARACTER OR LESS FACTUAL SUMMARY OF MOST SIGNIFICANT INFORMATION. IF DOCUMENT INCLUDES A SIGNIFICANT BIBLIOGRA OR UTERATURE SURVEY, CITE IT HERE. SPELL OUT ACRONYMS OH FIRST REFERENCE.) (CONTINUE ON SEPARATE PAGE, IF NECESSARY,

Rapid activation of fire protection systems in response to a growing fire is one of the important factors required to provide for life safety and property protection. Airflow due to the heating, ventilating and air conditioning (HVAC) system can significantly modify the flow of smoke along the ceiling and must be taken into consideration when a particular system is designed. At present, the standards used to guide the design of systems contain very little quantitative information concerning the impact of airflow produced by HVAC systems. This project is part of a multi year, International Fire Detection Research Project sponsored by the National Fire Protection Research Foundation (NFPRF), and it describes the results of a series of numerical simulations of smoke movement in response to HVAC flows resulting from slot diffusers, slot returns and rectangular returns. The computer model calculated activation times throughout the fire driven flow field.

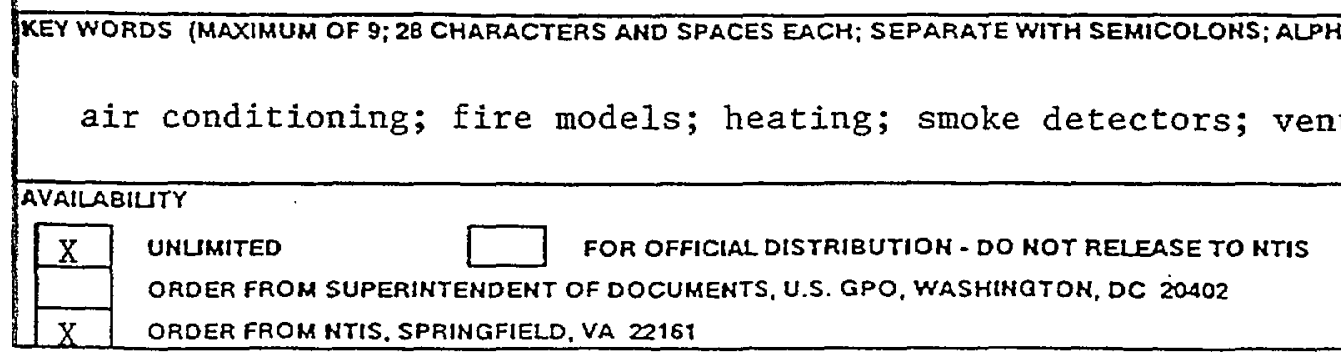

ELECTRONIC FORM 
